\title{
Embleme des Verstummens
}

21 Vertonungen des Gedichts Beiseit

\author{
Ich mache meinen Gang; \\ der führt ein Stückchen weit \\ und heim; dann ohne Klang \\ und Wort bin ich beiseit.
}

Das vierzeilige Gedicht Beiseit (SW 13, 22) ist der meistvertonte Text von Robert Walser. 21 Vertonungen von sechzehn Komponistinnen und Komponisten werden in diesem Kapitel nebeneinandergestellt. Gerade wegen seiner lakonischen Einfachheit ist das Gedicht seit den 1970er-Jahren zu einer WalserChiffre geworden - insbesondere in der Musik. Das vierzeilige Gedicht, 1899 erstmals in der Wiener Rundschau erschienen, erlebte schon zu Lebzeiten Walsers fünf Nachdrucke.

\subsection{Werner Morlangs Beiseit-Interpretation}

In seiner Kargheit wirkt das Gedicht wie in Stein gemeißelt, und es ist kein Zufall, dass es 1987 in Herisau auch in den Stein von Robert Walsers neuem Grab gehauen wurde. Anstelle einer hymnischen Gedächtnisrede formulierte Werner Morlang, der während Jahren die Mikrogramme entzifferte und das Robert Walser-Archiv leitete, bei der Einweihung des Gedenksteins am 15. Mai 1987 eine ebenso kurze wie präzise Analyse dieses Gedichts. Morlangs Betrachtung ist bis heute ein Meilenstein in der Walser-Interpretation und wirkt wie eine Umrahmung der in diesem Kapitel behandelten BeiseitVertonungen. Auch im Sinne einer Hommage an den 2015 verstorbenen Schweizer Germanisten seien hier zwei längere Abschnitte daraus zitiert:

Der Gang, der so lakonisch angesagt wird, führt nur gerade über vier Zeilen und mündet in Laut- und Sprachlosigkeit. Die dabei zurückgelegte Strecke ist unbeträchtlich, und selbst diese Unbeträchtlichkeit minimalisiert Walser, verniedlicht er zu dem für ihn bezeichnenden Diminutiv »ein Stückchen«. Anderseits macht sich derjenige, der sich zu dem bescheidenen Unternehmen anschickt, gleich mit dem ersten Wort als »lyrisches Ich« geltend, und dieses wiederum erklärt durch das Possessivpronomen »meinen« den »Gang« zu einer nur ihm allein zustehenden Besonderheit. 
Noch befremdlicher als die - ohnehin kärglich angegebene - Modalität des Weges nimmt sich die des Zieles aus. Zwar erweist sich der Weg als Heimweg, aber der klassische Topos der Ankunft vermittelt nicht die Traulichkeit des bürgerlichen Heims. Die strenge Endgültigkeit, mit der hier das »Ich« von der Aussenwelt und von jeglicher Lebensäusserung entbunden wird, ähnelt dem Tod. Unversehens scheint der Gang, so kurz er greift, ein ganzes Leben zu umspannen, ein resümiertes Leben sogar, vom unheimlich-heimeligen »Beiseit« aus gesehen. ${ }^{1}$

Ein besonderes Augenmerk lenkt Werner Morlang auf die alternative Fassung des Gedichts:

Auf das Wort »beiseit« gravitiert das Gedicht zu - entsprechend dem gleichlautenden Titel - und findet in ihm, als letztem Wort, seine Ruhe. Entstehungsgeschichtlich handelt es sich dabei lediglich um eine nachträgliche Korrektur, die Walser erst für die Buchausgabe (1909) vornahm und die eine frühere Version ersetzte. Ursprünglich waren die vier Zeilen »Spruch« betitelt, was uns um so eher dazu berechtigen mag, sie nunmehr als Grabtext zu lesen. Viel wichtiger aber: in den ersten beiden Druckfassungen lautete der abschliessende Satzteil noch: »dann ohne Klang / und Wort bin ich befreit«.

Ich wüsste keine Stelle in Walsers Dichtungen, wo uns seine Lebens- und Schaffensbedingungen eindringlicher offenbar würden als im Wechsel der Reimwörter »befreit / »beiseit«, die hier plötzlich wie austauschbare Synonyme auftreten, wobei ein jedes, bezogen auf den biographischen Zusammenhang, polyvalent, mehrsinnig ausgelegt werden kann. ${ }^{2}$

Bisher hat nur die Komponistin Ezko Kikoutchi im Kontext ihrer französischbielerdeutschen Vertonung von Der Teich (vgl. Kap. 8.6.4) auf die >Befreit<Fassung zurückgegriffen. Sie fügt das Gedicht in den ersten Monolog von Fritz ein, in dem er sich über die Anstandsregeln beim Essen und die Bevorzugung seines Bruders Paul beklagt. Nachdem die Komponistin zweimal nur den ersten Vers wie einen inneren Gedanken in den Monolog von Fritz einflicht, führt sie die beiden Texte (bei Ziffer F) im Kurzschluss zusammen. Das >Befreit<-Gedicht wird verzahnt mit der Textstelle »Chum, Fridu, mir wei uf d'Site« (SW 14, 119), allerdings wählt Kikoutchi hier die französische Übersetzung - »Viens, viens Fridu, on va se mettre à l'écart« - was eine auffällige interlinguistische Überkreuzung ergibt: das Gedicht Beiseit wird im

1 Morlang: Robert Walser im »Beiseit«.

2 Ebd. Morlang täuscht sich hier: Nur in der letzten der vier Veröffentlichungen des Gedichts, die vor der Buchausgabe erschienen sind, wird »beiseit« mit »befreit« ersetzt. Vgl. Walser: Gedichte [1899] bzw. ders.: Spruch [1907]. Zu den Varianten vgl. ders.: Gedichte [2021], S. 10of. 
Französischen nämlich mit $\grave{A}$ l'écart ${ }^{3}$ übersetzt. So werden an dieser Stelle mittels der französischen Übersetzung die >Befreit $<$ - und die Beiseit-Variante zusammengeführt. ${ }^{4}$

Das Gedicht und besonders der letzte Vers muss für Walser selbst etwas ganz Besonderes und Exklusives gewesen sein: In seinem Gesamtwerk wird das elidierte Adverb »beiseit« nur dreimal verwendet. ${ }^{5}$ Das zweite Mal verwendet er »beiseit« 1901 im Aschenbrödel, kurze Zeit nach der Erstpublikation in der Wiener Rundschau 1899. Der König spricht zum Prinzen: »Tritt hier mit / ins Schwarz beiseit; im Dunkel so / wird schon ein Wort zu reden sein, / das unsern Hader sanft versöhnt.« (SW 14, 44) Mit diesen Versen wird der Abgang von König und Prinz vorbereitet - mit der alle Gestalt und Figur aufsaugenden Farbe Schwarz sind wir aber auch schon beim 〉Grabtext $<$ von Morlang.

Bei den beiden anderen »beiseit«-Stellen wird das elidierte Adverb mit »sein« als Vollverb verwendet, nämlich im Präsens »bin ich beiseit« im Gedicht und im Imperfekt am Schluss des Prosastücks DerDichter (SW 4, 84f.), das 1914, also nach der Gedichtausgabe, publiziert wurde, aber die gleiche Ambivalenz von trauriger Lustigkeit und fröhlicher Melancholie aufweist: »Ich tat niemand weh, und auch mir tat niemand weh. Ich war so hübsch, so schön beiseit.« $\left(\mathrm{SW}_{4}, 85\right)$

\subsection{Zu den Beiseit-Vertonungen}

Wohl nur wenige Gedichte der Weltliteratur wurden so häufig vertont wie Beiseit. Weil die Vertonungen in diesem Kapitel einzeln betrachtet werden und nur wenige komparatistische Hinweise eingefügt sind - auch auf ein wertendes Gegeneinander-Abwägen wird konsequent verzichtet -, seien ein paar Auffälligkeiten im Sinne von >Diagnosepunkten $<$ zum Voraus benannt. Sie sollen gewisse Redundanzen erklären und auch dazu einladen, selber nach Bezügen zwischen den Vertonungen zu suchen und eigene Entdeckungen zu machen.

In vielen Vertonungen wird Walsers Gedicht nicht von der Musik illustriert, sondern die Musik selbst steht im Zentrum und wird in unterschiedlicher Weise auf ihre Grenzen hin befragt. Das kann geschehen, indem gesungen wie

3 Dies gilt für die mir bekannten Übersetzungen von Marion Graf, Fernand Cambon und Jacques Lasserre, vgl. die drei Angaben zu Walser: À l'écart.

4 Siehe dazu Kap. 8.6.4. Auf ein eigenes Unterkapitel zu dieser nicht isoliert aufführbaren Vertonung wird hier verzichtet.

5 Ich danke Gelgia Caviezel für die Identifikation aller »beiseit«-Stellen. 
gesprochen und vor allem der Schluss, insbesondere das letzte Wort »beiseit«, nur noch geflüstert oder gehaucht wird. Oft wird das anfänglich etablierte musikalische System, sozusagen die Grammatik des Lieds, zum Schluss hin abgebaut, zerstört oder aufgelöst.

Ein spezielles Augenmerk in den Vertonungen verdient die Stelle »ohne Klang und Wort «, bei der im Gedicht in übertragenem Sinn die Musik und die Sprache einander gegenübergestellt und negiert werden. Es gibt Vertonungen, die an dieser Stelle den Sinn hervorheben und von der Frage ausgehen, wie »kein Klang « in Klang gesetzt werden kann, sei es, indem an dieser Stelle die Musik verstummt, sei es, indem selbstreflexiv die musikalische Grammatik verändert wird. In anderen Kompositionen dient die Gegenüberstellung von Musik und Sprache als Anlass, klangvoll den sinnbefreiten »Klang« dem reflektierenden und >trockenen « Wort « gegenüberzustellen.

Ähnlich vielfältig wird »und heim« vertont. So kann das Enjambement zwischen zweitem und drittem Vers in den Hintergrund und die syntaktische Struktur des Gedichts in den Vordergrund gerückt werden. Andere Möglichkeiten beziehen »und heim « motivisch auf das »Ich mache « des Anfangs oder führen »heim « in ein gesummtes $m$ über und nehmen damit das Verstummen des Schlusses vorweg, weil das $m$ als stimmhafter Nasallaut mit geschlossenem Mund gesungen werden muss.

Der von Werner Morlang dargelegte Gegensatz von vergrößertem Gestus im ersten und miniaturisiertem im zweiten Vers sowie die Spannung zwischen den ersten beiden Versen und den beiden letzten ist vielen Vertonungen eingeschrieben. Das zeigen zahlreiche Symmetrien oder Beinahe-Symmetrien. Die 24 Silben des Gedichts - aufgeteilt in viermal sechs Silben bzw. fünf zweisilbige und vierzehn einsilbige Wörter - bringen in der Tradition zeitgenössischer Musik eine große Verführung zu Zahlenspielen mit sich. Erstaunlich ist allerdings, dass keine reine zwölftönige Arbeit vorliegt, obwohl die 24 Silben zu einer klassischen Zwölftonkomposition, zum Beispiel mit Grundstellung und Krebs der Reihe, geradezu einladen. Aber das würde zu einer geschlossenen und allzu stimmigen Komposition führen und die Idee des Gedichts gerade verpassen. Dessen >kompositorische< Qualität besteht ja darin, dass die formale Strenge der Verse eine chiastisch zerrüttete Innenwelt verbirgt. Deshalb wird die Reihentechnik, etwa bei Heinz Holliger, nur als prekäre Utopie ausgewiesen.

Auf die Lakonik des Gedichts wird musikalisch ganz unterschiedlich reagiert: Sie kann ostentativ in den Vordergrund gestellt werden, wobei meist eine untergründige zweite Schicht mitläuft, oder sie kann artifiziell überhöht oder in fast schon szenische Lösungen überführt werden. Wie bei vielen Walser-Vertonungen gibt es auch bei Beiseit eine literarische Rezeption: 
Da wird das Gedicht gerade in jüngeren Vertonungen in unterschiedlichste literarische Kontexte gestellt, in denen sich helvetische mit weltliterarischen Aspekten und die Auseinandersetzung mit der deutschen Literaturgeschichte kritisch überlagern.

Die auffälligste Erscheinung bei den Vertonungen ist die Disposition des musikalischen Raums, in der die Grenzerfahrung des lyrischen Ichs mit der Grenzerfahrung des menschlichen Gehörs bzw. der Instrumente konfrontiert wird. Oft wird das lyrische Ich in die Klangmitte, quasi in den leeren Raum zwischen den Randregistern gestellt, beim Klavier repräsentiert durch die höchste und die tiefste Taste. Diese räumliche Disposition kommt zwar nicht nur bei den Beiseit-Vertonungen vor (vgl. in Kap. 12.2 die Ausführung zur strukturellen Bedeutung des fehlenden Subkontra- $A s$ des Klaviers bei Max Beckschäfers Melodram Schwendimann), aber deren Redundanz ist doch auffällig. Generell spielt die Mittellinie oder Mittelachse eine zentrale Rolle.

Bei den Beiseit-Vertonungen lässt sich die Tendenz beobachten, es >anders< machen zu wollen, einen je eigenen, besonderen Gang zu finden. Das beginnt schon bei Urs Peter Schneider, dessen Beiseit I die einzige streng serielle Komposition in seinem großen Gesamtwerk darstellt und der deshalb gleich ein gänzlich anderes Beiseit II folgen lässt. Vor allem der oft gespielte, bei Schott verlegte und bei ECM als CD publizierte Beiseit-Zyklus von Heinz Holliger hat für viele nachfolgende Komponistinnen und Komponisten Referenzcharakter, weniger im Sinne eines Vorbilds denn als Aufforderung, einen eigenen Weg zu suchen und Gegenmodelle zu entwickeln. Deshalb bieten die zwanzig Vertonungen dieses Kapitels einen so vielfältigen und reichen Überblick verschiedenster Walser-Zugänge und geben zugleich auch einen Abriss zu fast sechzig Jahren Kompositionsgeschichte. ${ }^{6}$

\subsection{Marie-Louise Wolfensberger und Heinz Wehrle: Improvisierte Walser-Lieder (1962)}

Die vier von Marie-Louise Wolfensberger ${ }^{7}$ und Heinz Wehrle improvisierten Walser-Lieder stellen mutmaßlich die erste erhaltene Musikaufnahme mit

6 Zum Beiseit, das Ezko Kikoutchi in Der Teich integriert hat, vgl. Kap. 8.6.4.

7 Leider konnte die Improvisatorin und Sängerin Marie-Louise Wolfensberger bisher nicht sicher identifiziert werden. Im Archiv von SRF taucht sie nur dieses eine Mal auf. Am 19. Mai 2015 erschien in der Neuen Zürcher Zeitung eine Todesanzeige von Marie-Louise BoschettiBluntschli, geborene Wolfensberger (29.05.1932-13.05.2015), die mit dem Motto »Dein Singen bleibt für immer« versehen ist. Es könnte sich dabei um Marie-Louise Wolfensberger gehandelt haben. Allerdings: Die Traueradresse ist Vezia bei Lugano. Eine Todesanzeige vom 
Robert Walser dar und sind auch die erste öffentliche musikalische Auseinandersetzung mit dem Autor nach seinem Tod 1956. Basierend auf der von Carl Seelig edierten Gedicht-Ausgabe bei Schwabe von $1944^{8}$ wagten Wolfensberger und Wehrle das einmalige Experiment, sowohl Gesang als auch Klavierbegleitung frei zu improvisieren; dabei wurde auch mit den Texten improvisiert. Stilistisch könnte man Einflüsse von Hugo Distler oder Jehan Alain ausmachen, die Wehrle, langjähriger Organist der Kirche Meilen, auch kompositorisch prägten. ${ }^{9} 1962$ war Heinz Wehrle allerdings vor allem als Leiter Jazz des damaligen Landessenders Radio Beromünster bekannt. ${ }^{10} »$ Den bleibendsten Eindruck hinterliess [...] die von Wehrle 1964 inszenierte Serie $>$ Jazz liveく, die 111mal über den Sender ging und bis 1982 bestand. «11

Über das Umfeld der Aufnahme und für welche Sendung sie produziert wurde, gibt der Bandbegleitzettel im Archiv von SRF keine Auskunft. Die Erstausstrahlung erfolgte erst knapp zwei Jahre nach der Produktion. Auffällig ist allerdings, dass Wolfensberger und Wehrle die Gedichte Walsers in einen religiösen Kontext stellten, denn neben vier Walser-Gedichten wurde auch eine Vokalise, ein »Halleluja Amen« und das Gespräch zwischen Jesus und Nikodemus (Johannes 3,1-13) in der gleichen improvisierten Weise umgesetzt. Der religiöse Aspekt erklärt auch die Auswahl der Walser-Gedichte, die man als wehmütig-melancholisch verstehen kann - neben Beiseit waren es Bangen (SW 13, 26), Schnee (I) (SW 13, 15) und Gebet (SW 13, 10).

Wolfensberger und Wehrle scheinen auf ihre Leistung ziemlich stolz gewesen zu sein: Auf der Vorderseite des Bandbegleitzettels steht »Völlig frei impr. ohne Noten und Notizen « und recto wird nochmals insistiert: »Sämtliche sieben Studien wurden ohne jegliche Vorbereitung und Abmachung aus dem Stegreif improvisiert«. Tatsächlich verlangt diese Leistung Respekt ab,

26. März 1958 für eine gleichnamige Tante verweist ebenfalls auf Vezia als Wohnort und ist schon mit Marie-Louise Bluntschli-Wolfensberger unterzeichnet. Am 17. September 1966 erscheint eine Todesanzeige für ihren Ehemann Rudolf Bluntschli, einen auf dem Waffenplatz Monte Ceneri tätigen Instruktionsoffizier der Artillerie. Das ist ein geografisches und kulturelles Umfeld, das nicht unbedingt auf eine frei improvisierende Sängerin verweist.

8 Walser: Gedichte [1944]. Auf diese Ausgabe verweist der Bandbegleitzettel zur Aufnahme.

9 Ich habe Heinz Wehrle als sozial und politisch engagierten Kollegen bei Radio SRF noch erlebt. Seine cholerischen Ausbrüche waren legendär, er konnte sich ihnen auch vom Orgelpult aus hingeben, wenn er einer bigotten Predigt ein donnerndes Ausgangsspiel nachschickte.

10 Vgl. Schmid: Heinz Wehrle, S. 12.

11 Staub: Zwei Wegbereiter der Zürcher Jazzszene, S. 54. 
denn ohne Absprache tonal zu begleiten, Melodien gegenseitig zu imitieren und kleine Kontrapunkte zu setzen, also >richtige< Lieder zu gestalten, ist anspruchsvoll und 1962 eine seltene Erscheinung.

In allen Improvisationen wiederholt Marie-Louise Wolfensberger Textteile; aber sie tut es bei keinem Gedicht so ausgiebig wie im Falle von Beiseit, dem kürzesten Text der Improvisationen. Dabei ist spannend zu hören, wie die Logik des Gedichts die Improvisierenden irritiert und zu zunehmender Demut zwingt. Im Folgenden ist der Improvisationsverlauf des Textes protokolliert. Einfach gesetzter Text wurde schlicht, syllabisch vorgetragen, kursiv gesetzt sind Silben mit zwei Tönen pro Silbe, und fett markierter Text zeichnet emphatische Ornamentierungen von drei bis sechs Tönen pro Silbe aus.

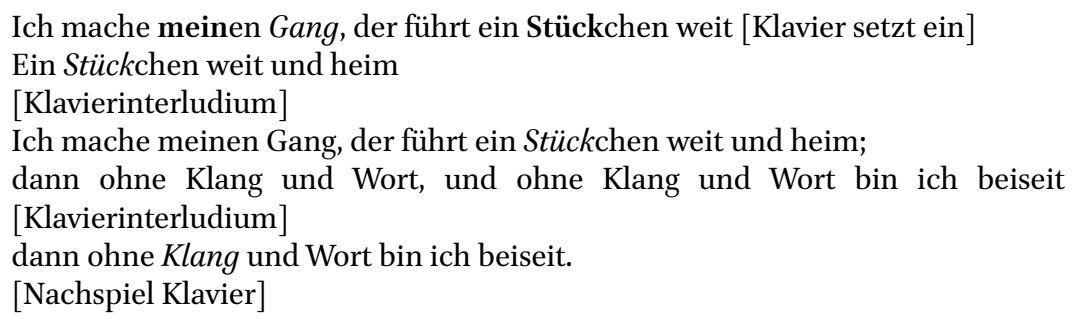

Beiseit beginnt als einzige der vier Walser-Improvisation mit der Stimme allein: Marie-Louise Wolfensberger >schießt $\ll$ mit neckischem AllegrettoTempo und einer weitgreifenden Melodie los. Nach »Stückchen« scheint sie zu realisieren, dass mit diesem Gestus nicht durchzukommen ist. Sie lässt sich aber wenig anmerken und wiederholt das »Stückchen«, diesmal ohne Melismen und somit auf die Aussage und nicht deren Ausschmückung konzentriert; da Wehrle mit seinem Klaviereinsatz sowohl das straffe Tempo als auch den tänzerischen Habitus übernimmt, zieht die Sängerin am Ende des zweiten Verses gleich weiter mit »und heim«. Da kann das Klavier die melodische Anfangslinie der Sängerin weiterspinnen. Danach singt die Sängerin in einfachem Ton den Rest des Gedichts durch, >verhaspelt sich aber beim Versuch, »dann ohne Klang und Wort « emphatisch auszugestalten, und es kommt zu einem Durcheinander der Wörter »Klang«, »ohne«, »und« und »Wort«. Nach dem Klavierinterludium sammelt sich Wolfensberger, fügt »Klang und Wort« in einer Umspielungsfigur zusammen, und Wehrle lässt das Lied nach harmonischen Kreuzgängen ruhig ausklingen.

Diese erste Beiseit-Vertonung ist noch nicht affiziert von Todessymbolen und erscheint als die unbefangenste; sie ist getragen von einem Gottvertrauen, bei dem man zum Schluss nicht »beiseit«, sondern »bereit« zu hören vermeint. 
Die ersten notierten Vertonungen von Beiseit stammen von Urs Peter Schneider. Er hat das Gedicht gleich zweimal vertont und als Beiseit I und Beiseit II in sein Liederbuch (vgl. Kap. 4.4) integriert. Beiseit II hat er im gleichen Jahr zusätzlich mit einem Sprecher und einer Trommel versehen und als eigenständige Komposition mit dem Titel Motto für vier Musiker publiziert. Mehrere Kompositionen zum gleichen Text sind bei Schneider nichts Außergewöhnliches. Bedeutsamer ist die Beschränkung auf exakt zwei Vertonungen, was auf das Doppelgesichtige von Walser verweist: So schildere »Nr. I das Herausgehen in die Welt; Nr. II den Rückzug «. ${ }^{12}$ Skizzen zu Beiseit I gehen ins Jahr 1958 zurück, die eigentliche Komposition ist aber ins Jahr 1973 zu datieren. ${ }^{13}$

$195^{8}$ war es eine noch einfache Reihenkonstruktion; jetzt aber geht das so, dass auf jeder Tonhöhe des Soprans »etwas« passiert, nicht tonhöhenbedingt, aber im Sinne einer musikalischen Vielfalt (in anderen Parametern). ${ }^{14}$

Die beiden Vertonungen - es sind die einzigen Vertonungen im konventionellen Sinne, die Schneider zu Walser komponiert hat - erscheinen zunächst als Gegensätze (vgl. Abb. 45 und Abb. 46): Beiseit II ist einfach und schlicht konzipiert. Der »Gang« wird mit dem ruhigen Schreiten der Melodie ausgedrückt. Mit Atempausen wird das Enjambement der Verszeilen hervorgehoben. Beiseit I dagegen ist ausschweifend, zieht alle Register, ist in einem virtuosen seriellen Stil gefasst, der garantiert, dass sich alles spiegelt und umdreht, aber doch kein Klang und keine Konstellation genau wiederholt wird. Das Gemeinsame der beiden Vertonungen liegt in der ostentativ lapidaren Klavierbegleitung, die alles Illustrierende verweigert.

Beiseit I ist bis heute die kompositorisch am stärksten kontrollierte und auf den ersten Blick >unwalserischste< Komposition. Alle Parameter mit Ausnahme der Klangfarbe sind determiniert; das radikale serielle Modell verhindert jede Möglichkeit zur Wortausdeutung, die in Schneiders kompositorischem Kosmos ohnehin keinen Platz hat.

12 Brief von Urs Peter Schneider an Roman Brotbeck vom o8.o7.2016.

13 »Von meinem ersten Walser-Lied weiss ich noch, dass ich $195^{8}$ die Textsilben unter eine Elftonreihe (asymmetrisch, aber in etwa hierarchisch) geschrieben hatte. [...] Bei meinen Datierungen vermerke ich oft die erste Skizze, nicht nur den Abschluss; hier schienen 15 Jahre zu passen.« Ebd.

Brief von Urs Peter Schneider an Roman Brotbeck vom 15.12.2020. 


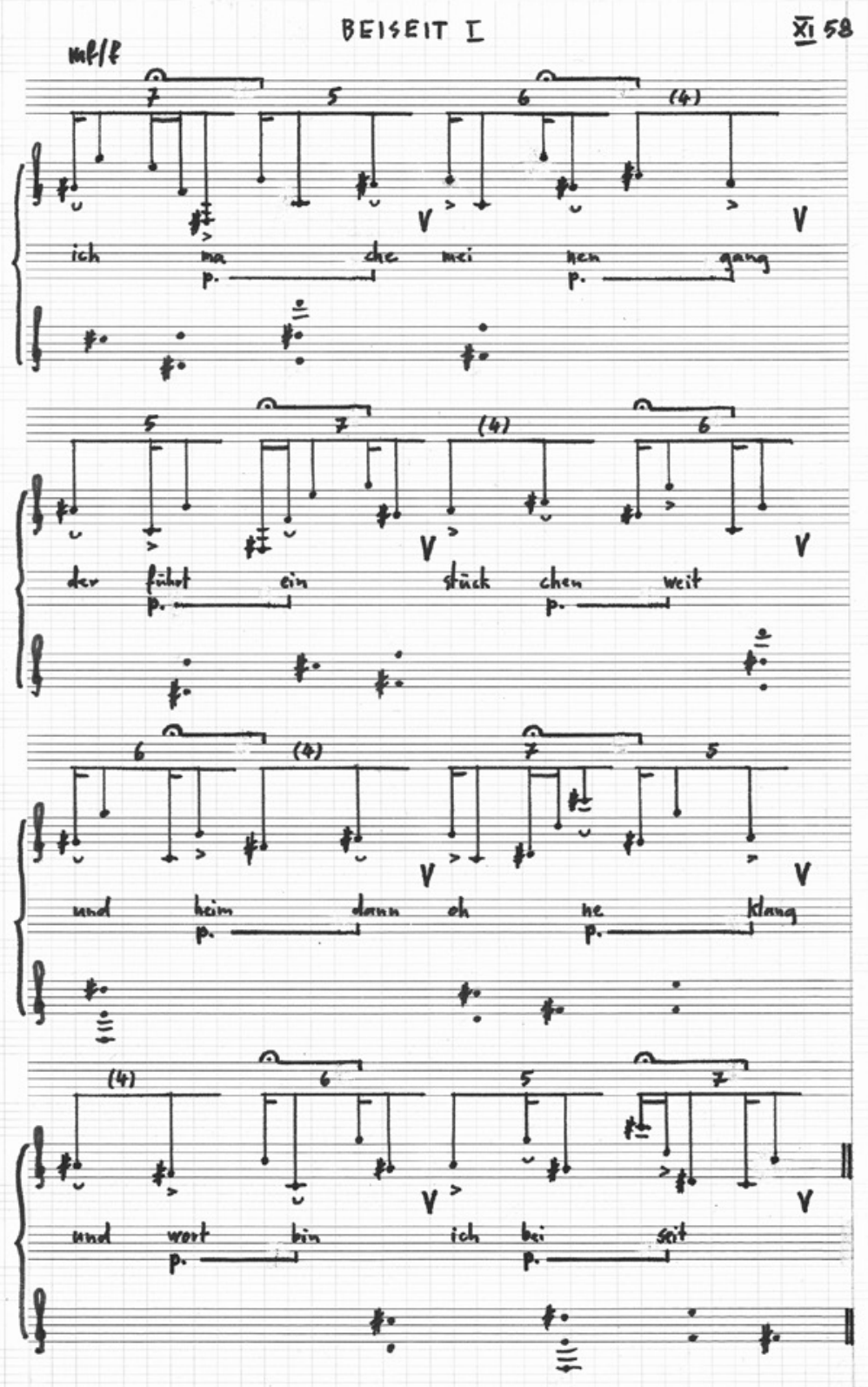

Abb. $45 \quad$ Urs Peter Schneider: Beiseit I aus Liederbuch 

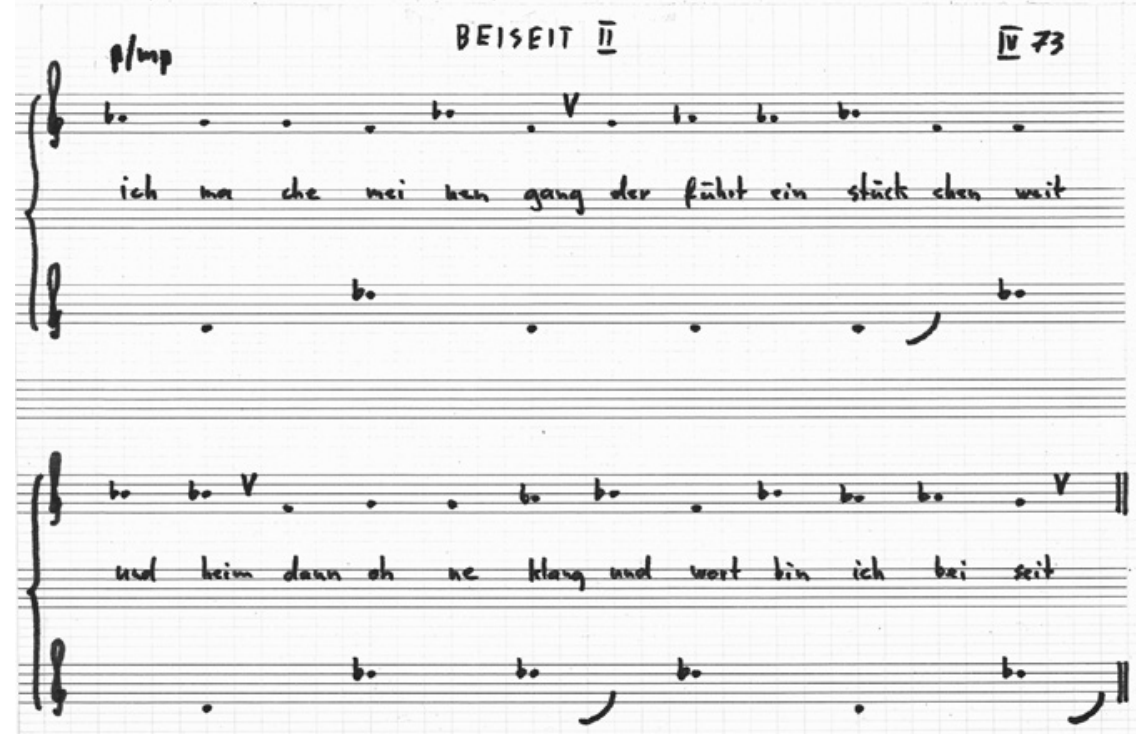

Abb. $46 \quad$ Urs Peter Schneider: Beiseit II aus Liederbuch

Bei serieller Musik denkt man zuallererst an eine Tonhöhenreihe, von der alle anderen Parameter abgeleitet sind. In Beiseit I sucht man eine solche Reihe vergeblich, stattdessen komponiert Schneider in Tonhöhen- und Intervallkonstellationen. Abbildung 47 zeigt die Tonhöhenstruktur der Gesangsstimme: Für die beiden Doppelverse benutzt Schneider zwei Zehnton-Konstellationen im Umfang von 25 Halbtönen (entspricht 2 Oktaven plus 1 Halbton), die symmetrisch überlagert sind. Der Gesamtumfang der Singstimme beträgt anspruchsvolle zweieinhalb Oktaven und verlangt die Tessitura zugleich einer tiefen Alt- und einer hohen Sopranstimme. Die Zehntonkonstellation der Schlussverse liegt eine Quinte höher als zu Beginn, was bei den zwei hohen cis $^{3}$ (bei »[oh]ne« und »bei[seit]«), die beide Male aus der mittleren Lage heraus >angeschossen $<$ werden müssen, wie es im Jargon von Koloratursopranistinnen heißt, eine durchaus aggressive und grelle Wirkung hat.

Innerhalb dieser beiden Zehnton-Raster gibt es je zwölf Intervallkonstellationen, die aus sieben Intervalltypen bestehen und sich ebenfalls symmetrisch zueinander verhalten. Sie sind in Abbildung 47 über bzw. unter der zentralen Achse aufgelistet. Zusammenfassend ergibt das: acht Duodezimen in drei Varianten, 24 große Septimen in sechs Varianten, vier kleine Septimen in zwei Varianten, je vier große und kleine Terzen bzw. eine Quarte in zwei Varianten und vier kleine Sekunden in zwei Varianten. Damit aber noch nicht genug der Ordnung, denn auch die Diastematie - ob die Intervalle nach oben 


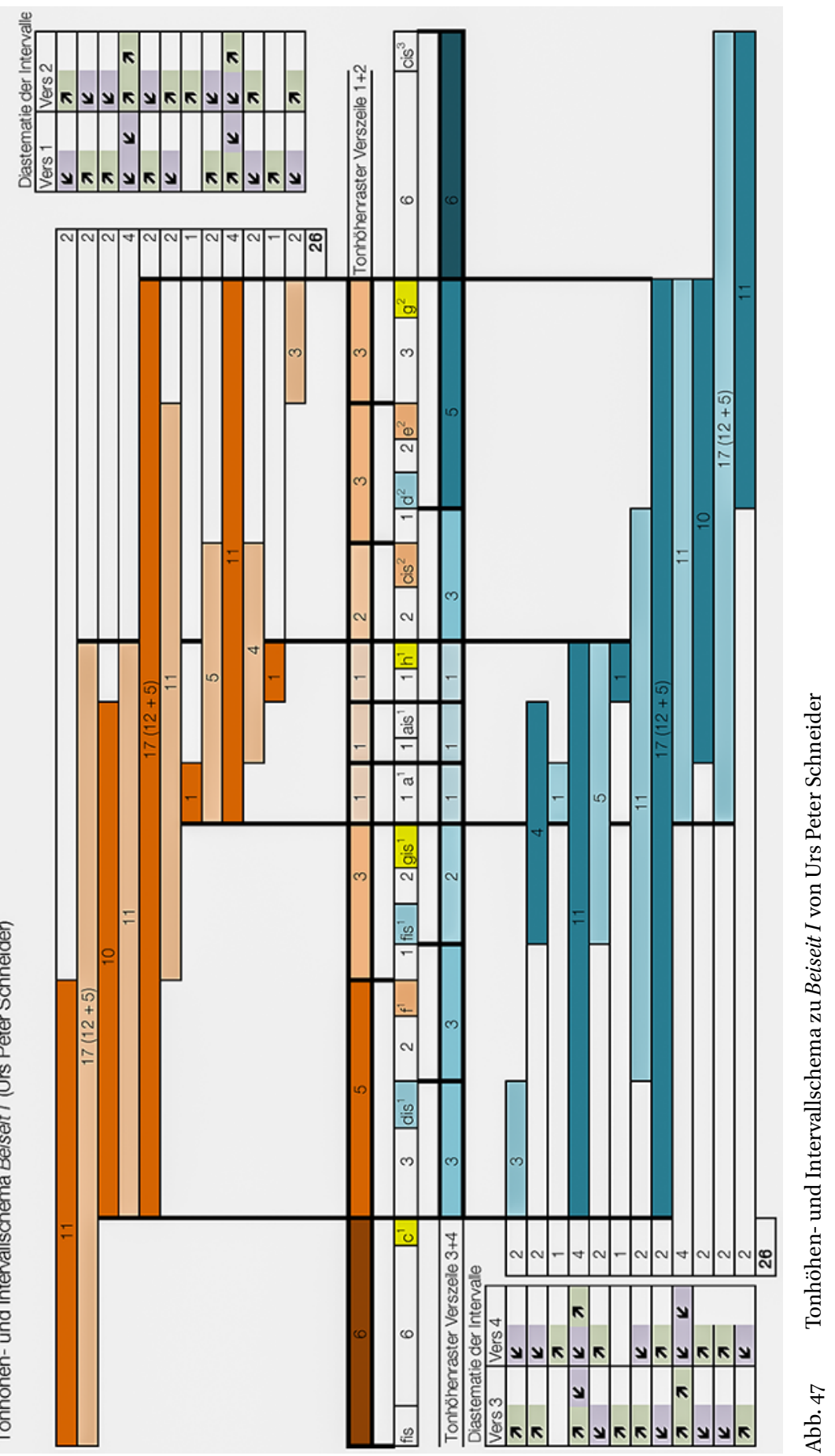


oder unten weisen - ist von Schneider symmetrisch exakt verteilt. Einzig die vier kleinen Sekunden in der Mitte der Systeme sind >leittönigく auf jede vierte Verssilbe hin immer nach oben gerichtet.

In jeder Zehntonkonstellation fehlen zwei Töne, $d$ und es in der ersten respektive $e$ und $f$ in der zweiten. Aus diesen Tönen - ergänzt durch cis und fis besteht die Klavierbegleitung, die komplementär zur Gesangsstimme angelegt ist. Die Tonhöhen, die in beiden Zehntonkonstellationen vorkommen und die in Abbildung 47 mit fetten Verbindungsstrichen gekennzeichnet sind, fehlen also in der Klavierbegleitung bei allen vier Versen. Allerdings wechselt in jeder Verszeile die Abfolge von Einklang, Zweiklang und Dreiklang, und der zweite Teil stellt auch in der Klavierbegleitung eine Spiegelung des ersten Teils dar.

In der Begrifflichkeit der mittelalterlichen Isorhythmie ausgedrückt, besteht das Stück somit aus einer Talea mit vier Gliedern (4, 5, 6 und 7 Sechzehntel). Jedes der Glieder mit Ausnahme desjenigen mit vier Sechzehnteln erscheint in zwei rhythmischen Formen, die unterschiedlich akzentuiert sind. Die Abfolge der Glieder ändert in jedem Vers, und auch diese Abfolge ist im zweiten Teil symmetrisch gespiegelt. Die einzelnen Glieder der Talea werden aber nicht gespiegelt, was die von Schneider geliebte Fast-Symmetrie ergibt und jene Wiederholungen verhindert, die sich bei einer konsequenten Symmetrie zwangsläufig ergeben würden. Die Fast-Symmetrie sschüttelt‘ alle Strukturen nochmals durch - und doch entstehen typische isorhythmische Effekte, bei denen minimales Variieren die Musik belebt. Zum Beispiel erklingen die gut erkennbaren großen Terzen alle auf das Talea-Glied mit der Länge von vier Sechzehnteln und erscheinen damit in den Versen an wechselnden Orten.

Trotz seiner radikalen Serialität darf man Beiseit I - aus Sicht der klassischen Serialität - als >beiseitig` bezeichnen: Mit den Zehntonreihen, der unterschiedlichen Verteilung der Intervalle und dem gegensätzlichen Duktus des Klaviers fehlt dem Lied jene serielle Utopie, die Claude Lévy-Strauss als »'utopie du siècle, qui est de construire un système de signes sur un seul

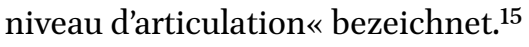

Beiseit II wirkt daneben zunächst wie ein Schock. Taucht man allerdings genauer in die Struktur der beiden Vertonungen ein, ergeben sich erstaunliche Konvergenzen, denn auch Beiseit II ist von einem Symmetrismus dominiert. Das geht bereits aus der Tonhöhenstatistik hervor (vgl. Abb. 48).

Es wird nur auf vier Tonhöhen im Umfang einer Quarte gesungen (ein symmetrisches Tetrachord). In jedem Vers werden zwei Tonhöhen wiederholt, jeweils an unterschiedlicher Stelle. 


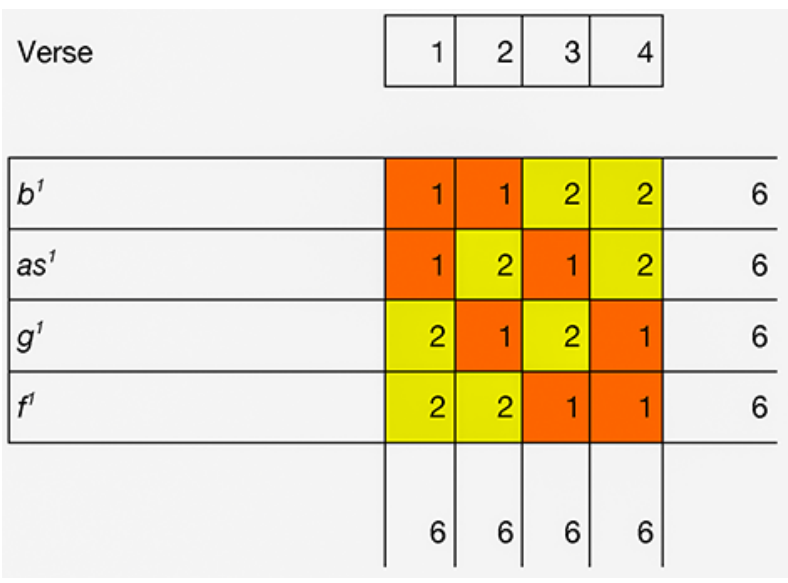

Abb. 48 Tonhöhenstatistik zu Beiseit II von Urs Peter Schneider

Die Klavierbegleitung beschränkt sich diesmal nur auf zwei Töne, die - ohne Basstöne - in der gleichen Oktavlage liegen wie die Singstimme. Sie bilden die verminderte Oktave $d^{1}-d e s^{2}$ und umspannen die gesungenen Töne symmetrisch, bilden aber zur diatonischen Singstimme eine dissonante Spannung; die Zahlen kennzeichnen die Anzahl Halbtöne zwischen den Tönen:

$$
d^{1}-3-f^{1}-2-g^{1}-1-a s^{1}-2-b^{1}-3-d e s^{2}
$$

Die einfache Klavierstimme ist komplexer, als es scheint: Die zweite Zeile ist der Spiegelkrebs der ersten; zudem ist der Anschlag der zwölf Klaviertöne so auf den Gesang abgestimmt, dass von den acht möglichen Intervallen, die zwischen den beiden Tönen des Klaviers und den vier Tönen der Singstimme möglich sind - nämlich je zwei kleine Terzen, Quarten, Tritoni und kleine Sexten - sieben erklingen; einzig die kleine Terz $b^{1}-d e s^{2}$ wird bloß im Ausklang des Klaviers hörbar. Und kein Zufall ist sicher auch, dass zwei der vier Tritoni, die einzigen dissonanten Intervalle in diesem Stück, zum Schluss auftreten und damit ein subtiles >Beiseit< in Bezug zum konsonanten Anfang darstellen. Erst bei »führt« erklingt der erste Tritonus. So bringt die Klavierbegleitung wie in Beiseit I mit dessen Isoperiodik eine kaum wahrnehmbare Asymmetrie ins einfache Lied.

Mit der Zufügung von zwei Stimmen schuf Schneider aus Beiseit II die Komposition Motto für vier Musiker. Die prägende Strukturzahl 6 wird übernommen, ebenso die Homophonie: Singstimme $(4 \times 6)$ und Klavier $(2 \times 6)$ werden identisch beibehalten; sechs Töne werden in einer Fast-Symmetrie von weichen Schlägen auf das »Trommelfell einer total entspannten, nur als 
Geräusch wahrnehmbaren grossen Trommel« begleitet; der Sprecher verdoppelt (hier fett hervorgehoben) in strenger Symmetrie zweimal sechs Silben der Singstimme, was zu einer neuen Sinnkonstellation führt:

[ich] $m a$ [che mei]nen gang, der führt [ein stückchen] weit und [heim dann oh] ne klang und wort [bin ich] bei[seit]

Bei den kursiv markierten Silben kommt es zu einem Zusammenklang aller vier Ausführenden, was eine asymmetrische Anlage gibt - drei Zusammenklänge im ersten Verspaar, einer im zweiten. Möglich wird dies, weil sich die unterschiedlichen symmetrischen Systeme der vier Stimmen gerade nicht zu einem »système de signes sur un seul niveau d'articulation «16 zusammenfügen, was durchaus Schneiders Motto entspricht.

\subsection{Daniel Glaus: Beiseit (1980)}

Mit 23 Jahren komponierte Daniel Glaus ( $\left.{ }^{*} 1957\right)$ noch während seiner Ausbildung am Konservatorium Bern (Orgel bei Heinrich Gurtner, Musiktheorie bei Theo Hirsbrunner und - gegen dessen ausdrücklichen Rat ${ }^{17}$ - auch Komposition bei Sándor Veress) Beiseit für mittlere Stimme und Klavier. Für Glaus ist diese bisher nicht zur Aufführung gelangte Komposition, die hier erstmals veröffentlicht wird (vgl. Abb. 49), »stilistisch eine Studienarbeit in meiner damaligen Auseinandersetzung mit dem frühen Webern «.18 Das Lied ist nur mit sechs Tonhöhen komponiert, zwei chromatischen Dreitongruppen, die im Tritonus-Verhältnis zueinander stehen: $b, h, c-e, f$, ges. Die Auswahl möglicher Intervalle ist wegen dieser Disposition stark eingeschränkt. Es sind - mit Ausnahme der Großterzen $c-e$ und ges $-b$ - vor allem Quarten, Quinten und große Septimen sowie kleine Nonen möglich. Diese dominieren denn auch die Komposition, zumal Glaus unter dem Einfluss Weberns Sprünge bevorzugt und Sekundgänge vermeidet.

Mit diesem eingeschränkten Material realisiert Glaus einiges, was auch spätere Beiseit-Vertoner beschäftigen wird, zum Beispiel die Mittelachse, die den musikalischen Raum teilt: hier mit den Tönen $f^{1}$ und $g e s^{1}$, auf die zwölf

16 Lévy-Strauss: Le cru et le cuit, S. 32.

17 Auch sechs Jahre nach dessen Tod blieb Veress für den unversöhnlichen Hirsbrunner »ein greiser ungarischer Emigrant«, der »alles Neue mit den Worten kommentierte: Das läuft sich tot.« Vgl. Hirsbrunner: Tendenziell, nicht starr, S. 4. 
Beiseit (Robert Walser) für mittlere Stimme und Klavier
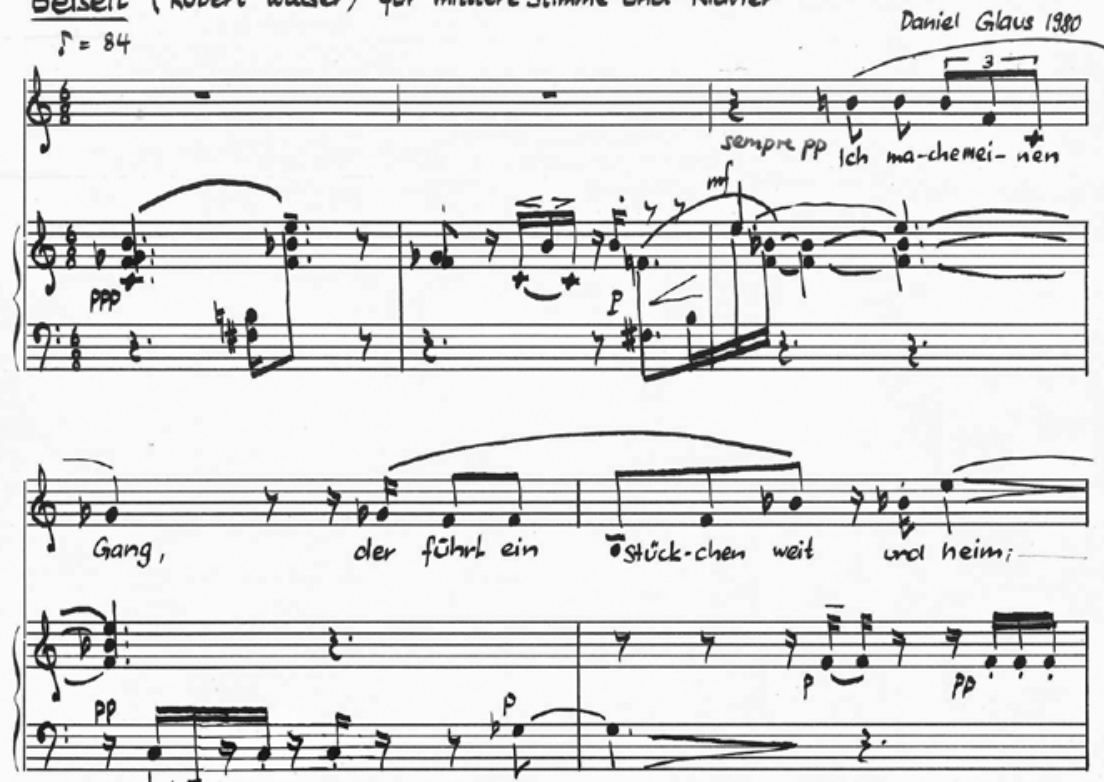

$6 ?$
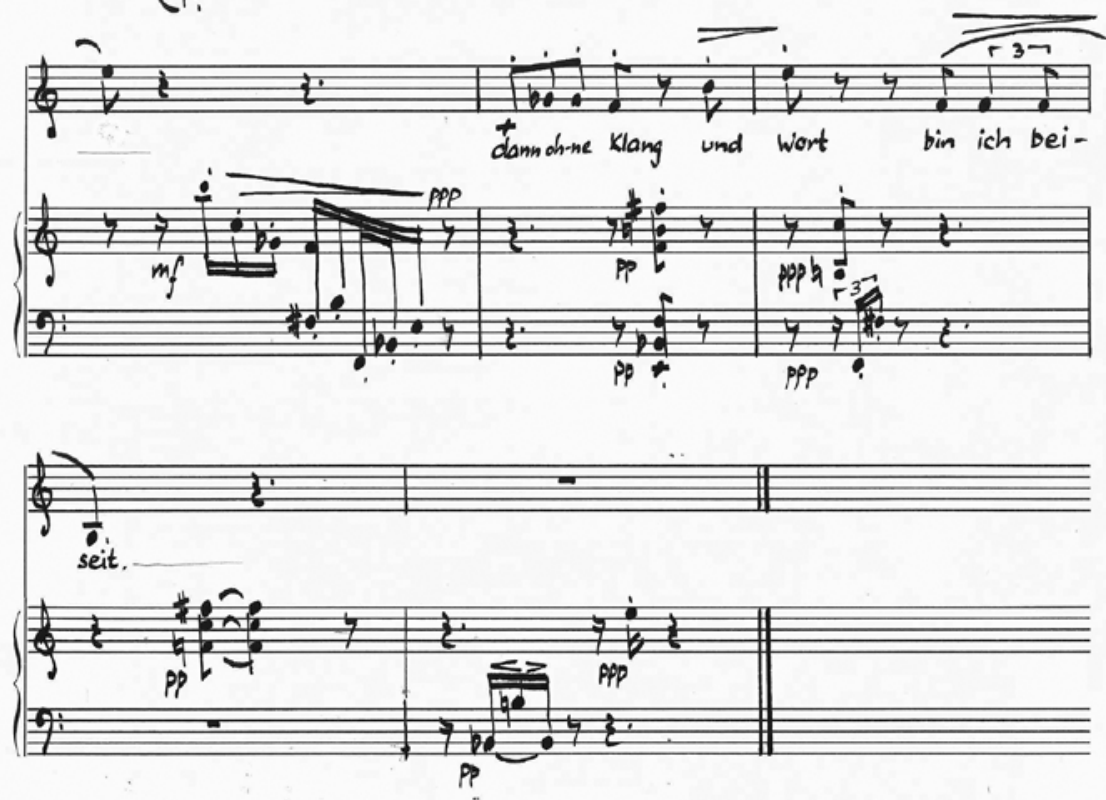

Abb. 49 Daniel Glaus: Beiseit 
der 24 Töne der Singstimme fallen - auch Heinz Holliger wird bei seinem Beiseit dieselbe Mittelachse als Zentrum wählen. Mit den vier Randtönen der Singstimme, die den Umfang einer Undezime aufweist, werden zentrale Wörter des Gedichts hervorgehoben: $h$ und $e^{2}$ für »Stückchen « und für »heim « sowie gespiegelt $e^{2}$ und $h$ auf »Wort« und »beiseit«. Die Klavierbegleitung ist geprägt vom Wechsel horizontal verlaufender, weit ausgreifender Melodien und vertikaler Akkordstrukturen: Der erste Akkord (mit den ineinander verschränkten Tritoni $c^{1}-g e s^{1}$ und $f^{1}-h^{1}$ ) hat für die Singstimme thematische Bedeutung, denn mit diesen Tönen sind »Ich mache meinen Gang« und »dann ohne Klang und « gestaltet. Der erste Teil des Liedes ist im Klaviersatz von großen Septimen, der zweite von kleinen Nonen bestimmt. Den auffälligsten Akkord setzt Glaus auf das Wort »Klang«; er enthält die einzige Oktave des ganzen Liedes - im >Webern-Stil< ein klarer >Fehler<. Aber Glaus will hier nicht nur mehr Klang, sondern auch wirkungsvoll drei von insgesamt vier kleinen Nonen zusammenführen, die in seinem Sechstonsystem möglich sind: $E-f$, $B-h^{1}$ und $f^{1}-f i s^{1}$. Die vierte mögliche None $h-c^{1}$ erklingt nach $»$ Wort «. Dieses System der Nonen ist ihm wichtiger als das Oktavenverbot.

\subsection{Günter Buhles: Walser-Lieder (1987)}

1987 komponierte Günter Buhles ( $\left.{ }^{*} 1943\right)$ vier Walser-Lieder für Sopran und ein Holzblasinstrument; für die Uraufführung 1994 beim BadenWürttembergischen Tonkünstlerfest war es eine Altflöte. Als letztes Lied wählte Buhles das Gedicht Beiseit.

Buhles ist ein vielseitig tätiger Musiker, der als Komponist, Interpret und Improvisator einer stilistischen Offenheit verpflichtet ist. Als Flötist und Saxophonist spielt und unterrichtet er Improvisation in Jazz und Klassik. Seit Ende der 199oer-Jahre hat Buhles sowohl Kammer- als auch Orchestermusik geschrieben, zum Beispiel Konzert für Orchester (1995), das Saxophonkonzert Prisma (1998/99) und den Essay für Orchester (2005/o6). Viele seiner Werke, darunter auch fünf Streichquartette, können der Verbindung von Jazz und zeitgenössischer Musik, dem sogenannten Crossover, zugeordnet werden. LiedKompositionen nehmen im Schaffen von Buhles einen breiten Raum ein. In seiner Oper Die Judenbuche $(2001 / 02)^{19}$ nach eigenem Libretto hat Buhles die Arien durch Orchesterlieder auf Gedichte von Annette von Droste-Hülshoff ersetzt.

19 UA am 18.01.2003 Theater Ulm. 
In den frühen 198oer-Jahren stieß Buhles dank eines Fernsehfilms erstmals auf Robert Walser und begann sich für ihn und auch seinen Bruder Karl Walser zu interessieren. ${ }^{20}$

Der Dichter faszinierte mich ungemein als Person. Ich wollte unbedingt mehr von seinen Texten kennenlernen. Damals kaufte ich mir dann »Fritz Kochers Aufsätze«, »Seeland « und »Über Robert Walser«, Dritter Band (herausgegeben von Katharina Kerr) und das Insel-Taschenbuch mit Gedichten, von denen ich dann die vier von mir danach vertonten aussuchte. ${ }^{21}$

Die Walser-Lieder sind sparsam gehaltene Bicinien; Walsers Verse werden mit einfacher Melodik und oft periodisierter Rhythmik deklamiert.

Mit der Knappheit wollte ich vor allem der sparsamen und schlichten Sprache der Gedichte von Robert Walser nahekommen. Ich sehe in dem Duo von zwei ansonsten unbegleiteten Melodielinien auch die Andeutung von bipolaren Gemütszuständen oder aber gleichsam eine innere neben einer hörbaren äußeren Stimme. ${ }^{22}$

Das Holzblasinstrument übernimmt in den vier Liedern eine unterschiedliche Funktion: Im ersten Lied Wie immer (SW 13, 14) legt das Blasinstrument in Pfundnoten nur einen kontinuierlichen Grund, der für das »Wie immer« steht. Im zweiten Lied Angst (I) (SW 13, 15f.) gestaltet sich ein Wechselgesang zwischen Instrument und Gesang, in der ruhigen Schäferstunde (SW 13, 16f.) greifen die beiden Stimmen gleichwertig ineinander und im abschließenden Beiseit (vgl. Abb. 50) evoziert das Instrument eine dem ruhigen Gang der Sängerin entgegensetzte, ornamentierende und verspielte Welt. Diese bricht aber sinnigerweise bei »ohne Klang « ab, während die Singstimme noch bis $\mathrm{zu} »$ und Wort« allein weitersingt; der Schluss wird nur noch gesprochen. Die zwanzig gesungenen Silben des Gedichts sind mit acht Tönen gestaltet, die zweite und die letzte Silbe der Verse sind mit punktierten Halben deutlich hervorgehoben. Der Reim »Gang « - »Klang « wird mit demselben Ton $e s^{2}$ betont. Nur je einmal braucht Buhles die Tonhöhen $h^{1}$ und $d^{2}$, und zwar für die in der Struktur des Gedichts auffälligen Wendungen »[und] heim « sowie »[und] Wort«, die beide mittels Enjambement wie falsche Kadenzen an den Versanfang gesetzt sind, wobei die beiden »und « noch einen Anfangsreim bilden.

$20 \quad$ Es handelte sich um den Film von Percy Adlon, Der Vormund und sein Dichter.

21 E-Mail Günter Buhles an Roman Brotbeck vom 13.10.2016. Für die genannten Bände vgl. Kerr: Über Robert Walser III; Walser: Gedichte [1984].

22 E-Mail Günter Buhles an Roman Brotbeck vom 13.10.2016. 


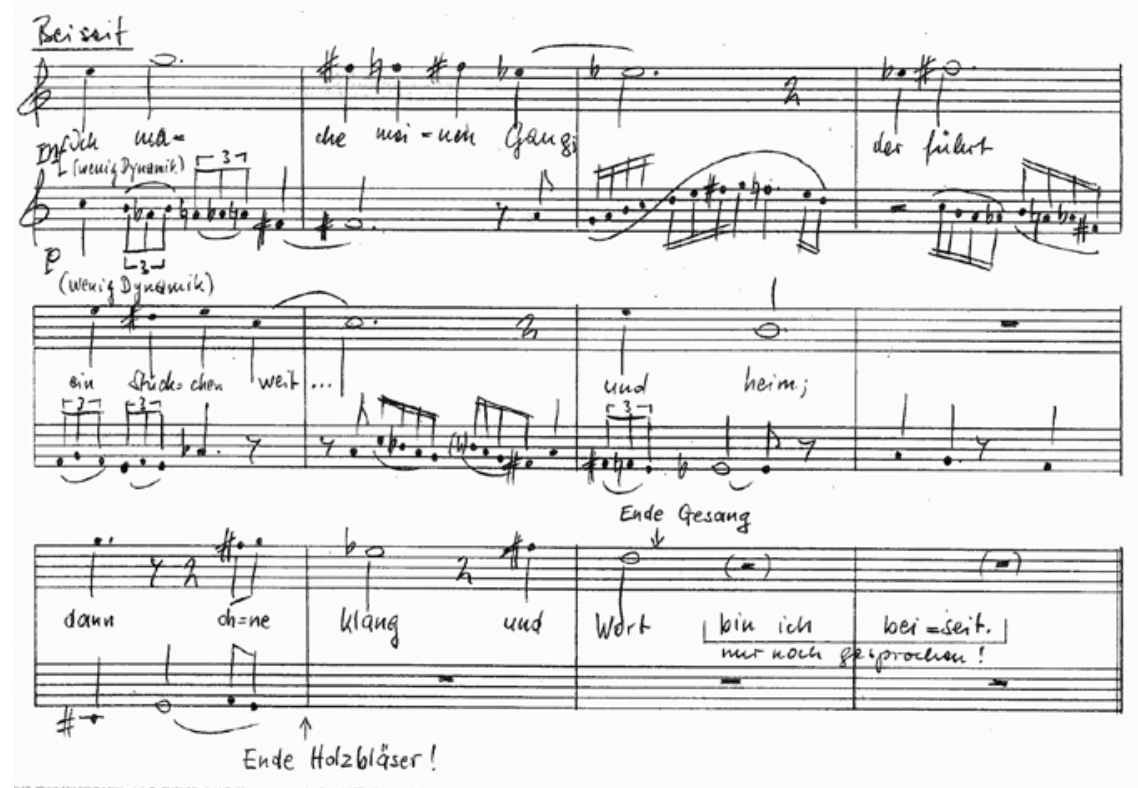

Abb. 5o Günter Buhles: Beiseit

Mit Buhles beginnt bei den Beiseit-Vertonungen die Tradition des gesprochenen und ohne Musik gestalteten Schlusses. Als ließe sich das Wort »beiseit« nicht vertonen - und schon gar nicht illustrierend ausdeuten -, wird es in vielen Vertonungen nur noch gesprochen und damit im >musiklosen< Modus seines Erfinders Robert Walser belassen. Bei Buhles, der mit dem Verstummen des Instruments indirekt auch den fehlenden Klang vertont, wird der gesprochene Schluss durch den Kontrast zum ansonsten emphatischen Gesang noch akzentuiert.

\subsection{Heinz Holliger: Beiseit (199o/91)}

Das Polizeifoto des im Schnee liegenden toten Schriftstellers mit klaren Trittspuren im Schnee war der Impuls zu Heinz Holligers Beiseit-Vertonung, die den gleichnamigen Lieder-Zyklus eröffnet (vgl. Kap. 6.4). Dieses Foto ist in der Walser-Rezeption zu einer Ikone für den letzten Spaziergang des Schriftstellers geworden. Wie Lucas Marco Gisi jüngst überzeugend nachwies, handelte es sich wahrscheinlich nicht um die Spuren von Walsers letzten Schritten (vgl. Vorwort, Anm. 16). Holliger hat diese Trittspuren in den Schritten der Singstimme quasi grafisch umgesetzt, zuerst in einfachen Wechseln, dann in Doppelschritten (vgl. Abb. 51). 


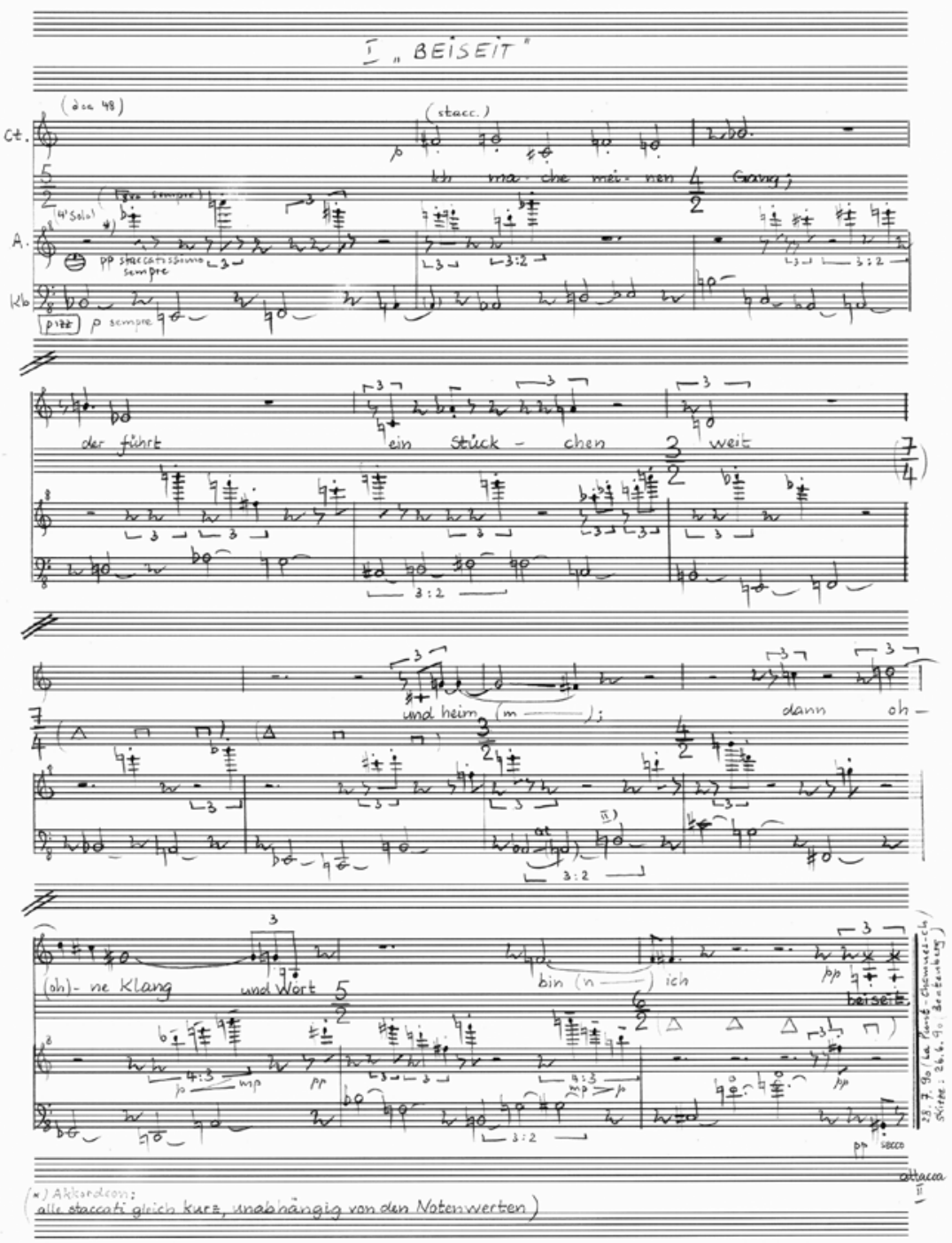

Abb. $5^{1} \quad$ Heinz Holliger: Beiseit

Das Motiv des Spaziergangs wird auch in der Form des Liedes aufgenommen: Holliger wählt eine Passacaglia, die ursprünglich vom spanischen Volkstanz Pasacalle stammt. Ihr Name enthält ebenfalls das Motiv des Spaziergangs: "pasar la calle « (»die Straße queren«) und »pasear la calle« (»der Straße entlang gehen«). Holliger verwendet kein festes Bassthema - wie dies bei der Passacaglia üblich ist -, sondern komponiert eine frei fortschreitende Form. 
Die Melodie des Kontrabasses wird vom in höchster Lage spielenden Akkordeon gespiegelt, allerdings rhythmisch so verschoben, dass es nie zu einem gemeinsamen Einsatz von Singstimme, Akkordeon und Kontrabass kommt. So entstehen drei distinkte >Gänge<: am obersten Klangrand das Akkordeon, am untersten der Kontrabass und exakt in der Mitte der Kontratenor. Die Spiegelachse von Akkordeon und Kontrabass $\left(B_{2}\right.$ und $\left.e s^{4}\right)$ befindet sich zwischen den ersten Tönen der Singstimme und entspricht dem um einen Viertelton erhöhten $f i s^{1}$. Es ist eine >unhörbare<, quasi gedachte Spiegelachse, weil dieser Viertelton im halbtönigen Stück nie erklingen kann.

$$
B_{2}-3^{2} \text { Halbtöne }-f i s^{1}-g^{1}-3^{2} \text { Halbtöne }-e s^{4}
$$

In diesem musikalischen Raum bewegt sich die Singstimme meist in der Mitte zwischen den Polen des Hörbaren. Für die ersten beiden Verse des Gedichts wählt Holliger für die Singstimme eine Zwölftonreihe, die sich um diese Spiegelachse herum symmetrisch entfaltet, wobei die ersten drei Töne gespiegelt werden: zuerst mit aufsteigendem Halbton und Tritonus nach unten, dann mit absteigendem Halbton und Tritonus nach oben.

Die für den zweiten Vers noch verbleibenden sechs Töne der Reihe werden ebenfalls symmetrisch aufgeteilt: »der führt « (absteigende kleine Sexte) »ein Stück-« (aufsteigende kleine Sexte) »-chen weit« (absteigende Quinte).

Holliger erliegt nicht der Versuchung, die 24 Silben von Walsers Gedicht mit zwei Zwölftonreihen >vollkommen< erscheinen zu lassen: Die Zwölftonreihe, die durchaus unorthodox mit einer reinen Quinte endet, wird nicht weiterverwendet, so als wollte Holliger ausdrücken, dass die Zwölftontechnik eben nur »ein Stückchen « weit führt und mit ihrer strukturellen Logik Walsers Texten nicht beikommt. Er bringt allerdings zu Beginn des dritten Verses noch ein Fragment der Reihe, mit klarem Textbezug: »und heim $(\mathrm{m})$ « wird mit dem Krebs der drei ersten Töne der Singstimme gestaltet. Das Enjambement, mit dem Walser in gewissem Sinne den Schluss des Gedichts bereits vorwegnimmt, wird von Holliger hervorgehoben: Es ist die einzige Stelle im Lied, wo der strenge syllabische Vortrag kurz unterbrochen wird. Das gesummte Phonem »m« wird zum Zeichen für Verschließung, Verstummen und Trauer, verstärkt durch den Gegensatz zum staccato vorgetragenen »Ich ma[che] « auf $f i s-g$, das den Krebs zum gesummten Seufzermotiv $g$ - fis darstellt. Dass dieses $» \mathrm{~m}$ « auf fis gesummt wird, zeigt die Identifikation dieser Tonhöhe mit dem lyrischen Ich, ist das fis doch erster und letzter gesungener Ton des Liedes. Holliger hebt mit der musikalischen Inversion auch die Spannung zwischen Vers 1 und Vers 4 hervor, zwischen »ich mache« und »bin ich«. Das Adverb »dann« erzwingt diese Umstellung von Subjekt und Prädikat; der Kontrabass 
intoniert auf dieses Wort Fis, und wohl auch nicht zufällig spielt das Akkordeon als letzten Ton $f i^{3}$.

Dieses »dann « ist in der Komposition ein Drehpunkt: Die Melodie weitet sich über den bisherigen Rahmen der Oktave hinaus, die Begleitinstrumente nähern sich der Mitte, und beim letzten Vers wird ihre strenge Spiegelsymmetrie teilweise durchbrochen. Der Grund ist ein Krebs der Singstimme im Kontrabass, der zusätzlich als Krebsumkehrung vom Akkordeon gespiegelt wird - mit den Tönen, welche die Singstimme bei »ohne Klang und Wort bin« singt. Diese Stelle wird bei Holliger zum klangintensivsten Moment der Vertonung. Holliger unterlegt Instrumentalstimmen oft mit Texten, die nur für die Ausführenden bestimmt sind (vgl. das Zwiegesängelchen, Kap. 6.11) und den Gestus und Vortrag mitprägen sollten. Im Folgenden sei das Umgekehrte versucht: Um die polyphonen Überlagerungen zu zeigen, sind an dieser polyphon verdichteten Stelle den Instrumentalstimmen die impliziten Texte schematisch unterlegt (vgl. Abb. 52).

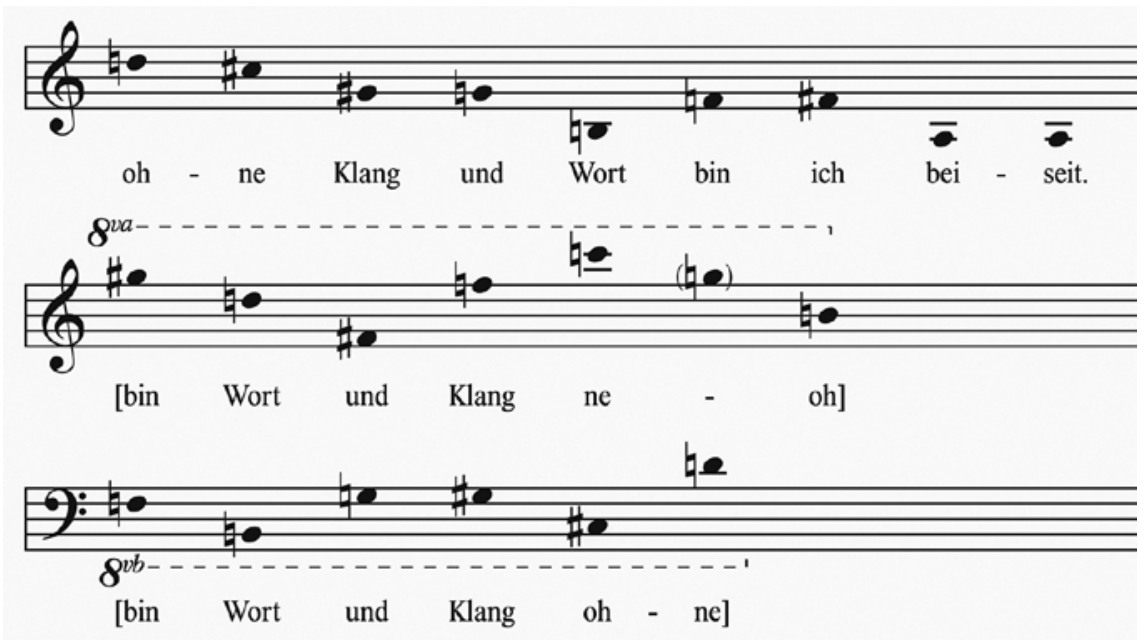

Abb. $5^{2}$ Polyphonie in Holligers Beiseit-Vertonung: Begleitung des Kontratenors durch die Krebsumkehrung im Akkordeon und den Krebs im Kontrabass

Holligers Beiseit-Vertonung reflektiert die musikalischen Mittel, die er verwendet. Er tut es, indem er das anfänglich exponierte Zwölftonsystem nicht zu Ende führt, sondern scheitern lässt, aber auch, indem er `klanglose ‘ Stellen wie »ohne Klang und Wort« besonders klangdicht vertont. Das letzte Wort »beiseit« schließlich wirkt wie von einer anderen Stimme gesprochen, weil der Kontratenor in seine tiefe Normalstimme fällt. 
Spätestens nach der vielbeachteten CD-Einspielung von Beiseit bei ECM Records 1995 darf man annehmen, dass bei den folgenden Vertonungen dieses Gedichts Holligers Beiseit bekannt war.

\subsection{Johannes Harneit: Walser-Lieder (1991)}

Johannes Harneits Beiseit-Vertonung ist integriert in einen Walser-Liederzyklus mit den Ausmaßen eines Schubert-Zyklus. 23 Gedichte aus dem gesamten lyrischen Schaffen Walsers hat Harneit zu einem Zyklus für Sopran und Bariton gefügt (sechs Duette sowie neun Sololieder für Sopran und acht für Bariton). Das Werk kann mit Klavier allein oder mit Instrumenten ad libitum begleitet werden. Für jedes Lied entwickelt Harneit einen eigenen Vertonungsansatz, oft äußerst reduziert; bei Nein, zu spät wird es nie (AdB 2, 307) ${ }^{23}$ zum Beispiel beschränken sich Sopran und Klavier auf drei Töne, nämlich die Oktaven $c^{1}-c^{2}-c^{3}$. Der Klavierpart entspricht dem Komplexitätsniveau einer ersten Klavierstunde, aber die Sängerin muss vierzehn lange Töne auf dem hohen C bei »wie sagt es das Gewissen« durchhalten. Einfaches kann auch schwierig sein.

Für Beiseit - im Zyklus das zwanzigste Lied - wählt Harneit, ähnlich wie Schneider und Holliger, eine symmetrische musikräumliche Anlage (vgl. Abb. 53). Sie wird zu Beginn mit zwei Terzclustern exponiert, die die Begrenzungen des Klaviers markieren. Exakt in die Mitte dieser Klanggrenzen sind die ersten vier Töne des Soprans gelegt, die Harneit in Quinten (7 Halbtöne) anordnet.

$$
A_{2}-C_{1}-33-f i s-7-c i s^{1}-7-g i s^{1}-7-d i s^{2}-33-a^{4}-c^{5}
$$

Diese Grunddisposition erklärt auch, weshalb Harneit hier zwingend die Sopranstimme wählen musste: Weil nur sie diesen Klangraum in der Mitte abdecken kann. Das ganze Lied ist aus diesem Anfangskern heraus entwickelt.

23 Harneit gibt dem Lied den Titel Nein und verändert den Text zu »Nein, zu spät ist es nie«. Harneit: Robert Walser-Lieder, S. 19-22. 
In jede der drei Quinten des Beginns werden zwei weitere Töne eingefügt. Auch diese Melodietöne sind symmetrisch um die Achse $e^{1}-f^{1}$ angeordnet, sodass eine neuntönige Struktur entsteht (as/gis wird wiederholt).

$$
f i s-3-a s-2-b-3-c i s^{1}-3-e^{1}-1-f^{1}-3-g i s^{1}-3-h^{1}-2-c^{2}-3-d i s^{2}
$$

Aus den viertönigen Kleinterzclustern des Beginns ist die Klavierbegleitung gebildet. Dabei gibt es drei Clustertypen, die den gesamten Zwölftonraum abdecken:

$\begin{array}{ll}\text { Typ X: } & a-c \\ \text { Typ Y: } & c i s-e \\ \text { Typ Z: } & f-a s\end{array}$

Drei der vier Töne jedes Clustertyps sind auch im Tonhöhenmaterial der Singstimme enthalten (fett hervorgehoben):

$\begin{array}{lll}\mathrm{X}: & \mathrm{Y}: & \mathrm{Z}: \\ \boldsymbol{c} & \boldsymbol{e} & \text { gis } \\ \boldsymbol{h} & \text { es } & g \\ \boldsymbol{b} & d & \text { fis } \\ \boldsymbol{a} & \text { cis } & f\end{array}$

Diese Cluster-Typen sind ausgeglichen verteilt (8 Typ X, je 7 für Typ Y und Z). Interessant ist, dass der Typ X am Anfang und in der Mitte dominiert, nach »und heim; dann, ohne « aber verschwindet. Eine Erklärung für diese komplementäre Tonhöhenorganisation könnte sein, dass im Typ X jene Quinttöne ( $f i s-c_{i s}{ }^{1}-$ $g i s^{1}-$ dis $\left.^{2}\right)$ fehlen, um die herum die Melodie der Singstimme konstruiert ist. Wenn mit Typ X am Beginn die beiden Klangränder markiert sind, schafft die Singstimme ein komplementäres Tonhöhenfeld. In diesem Konzept ist das »bin ich beiseit«, das oft klanglich und strukturell abgesetzt wird, bei Harneit deutlicher in die Struktur der Komposition integriert, weil die Cluster der Typen Y und Z, die die Komposition abschließen, die Singstimme besser in die Klavierbegleitung einbinden.

In Abbildung 54, einer Visualisierung der Textverteilung auf die Tonhöhen, ist gut sichtbar, wie Harneit in der Vertonung am Schluss nicht ins strukturelle Aus, sondern in die Anfangsdisposition zurückführt. Auch die implizite Symmetrie in der Stimmführung wird erkennbar. 

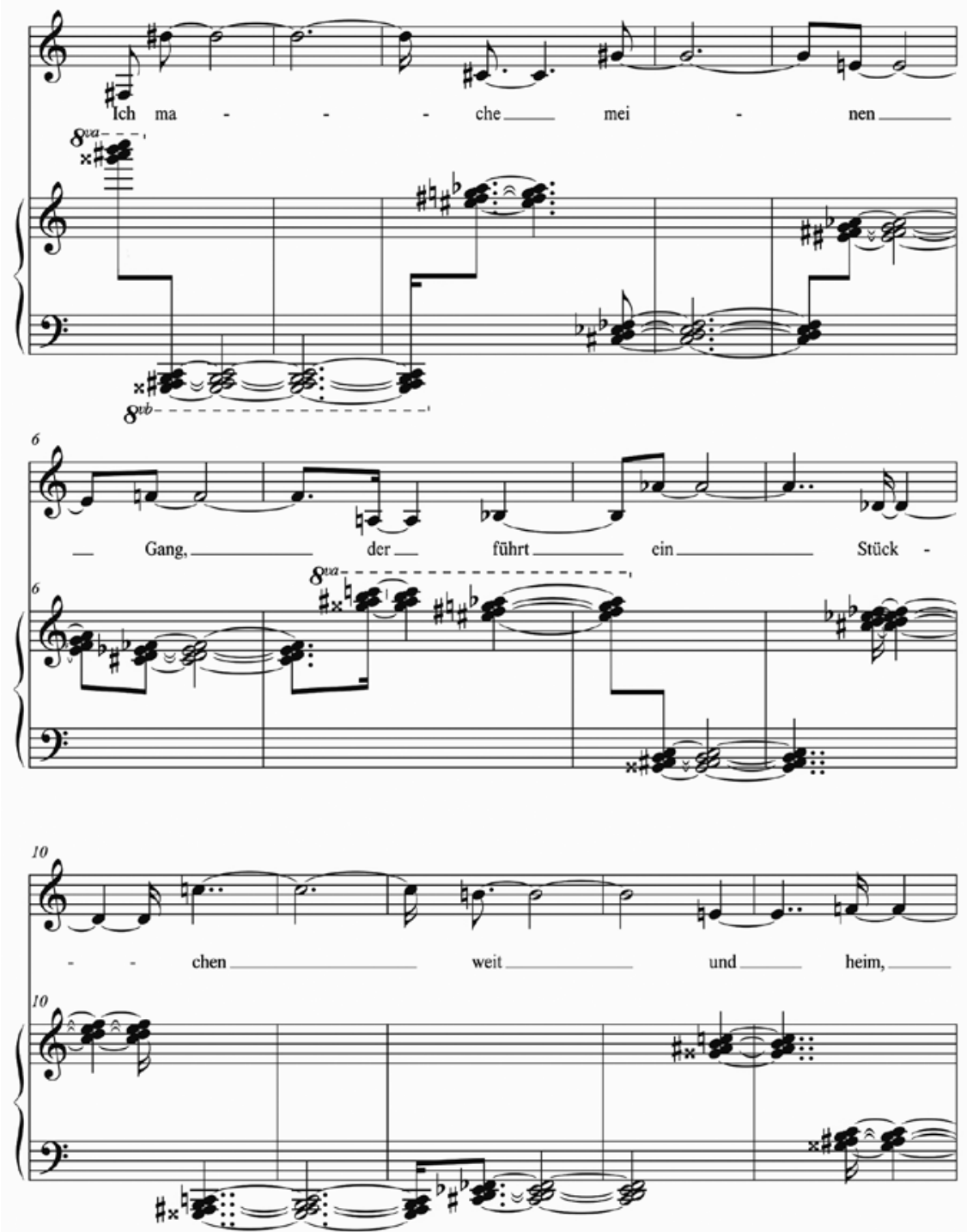

Abb. 53 Johannes Harneit: Beiseit 

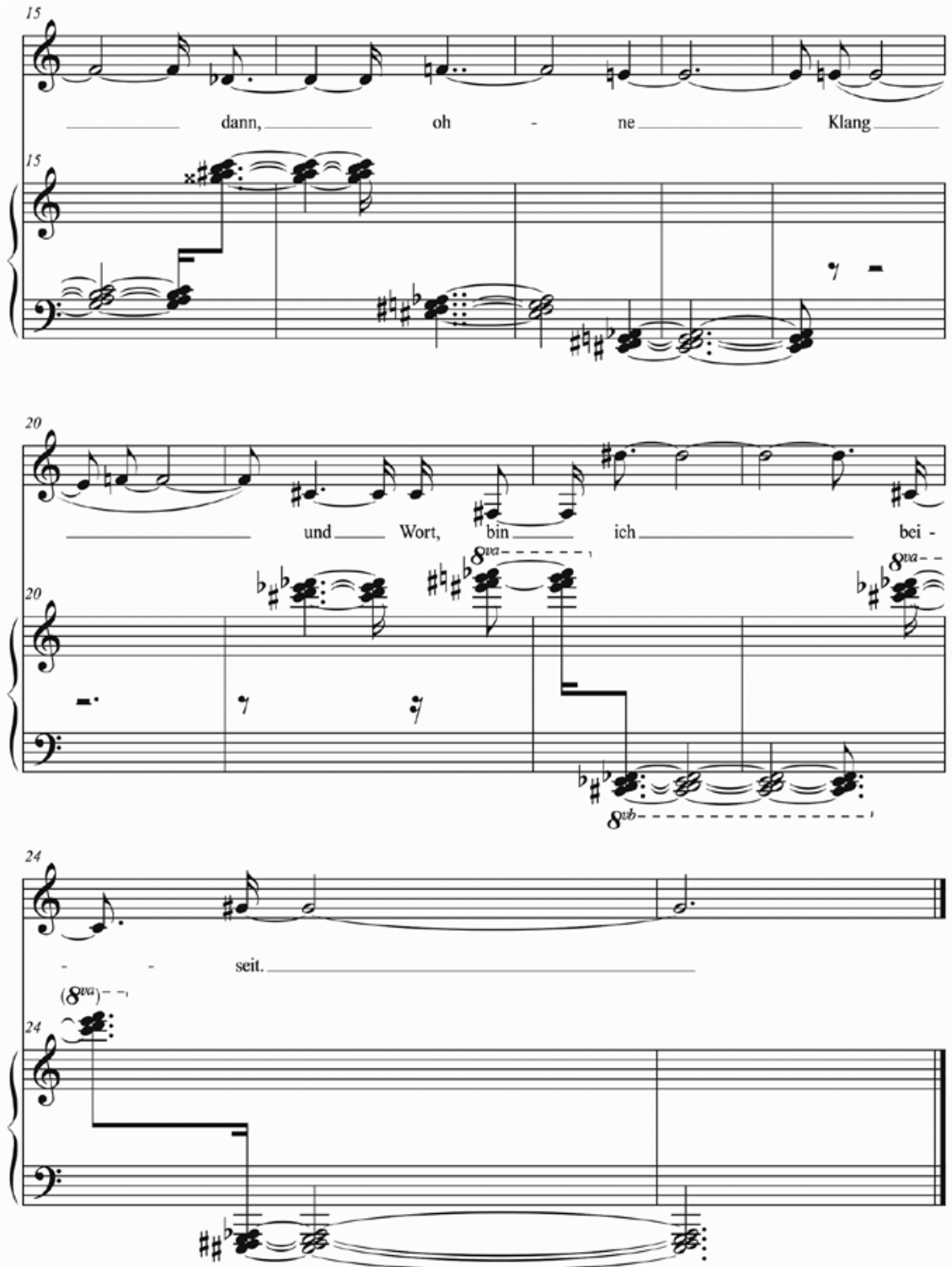


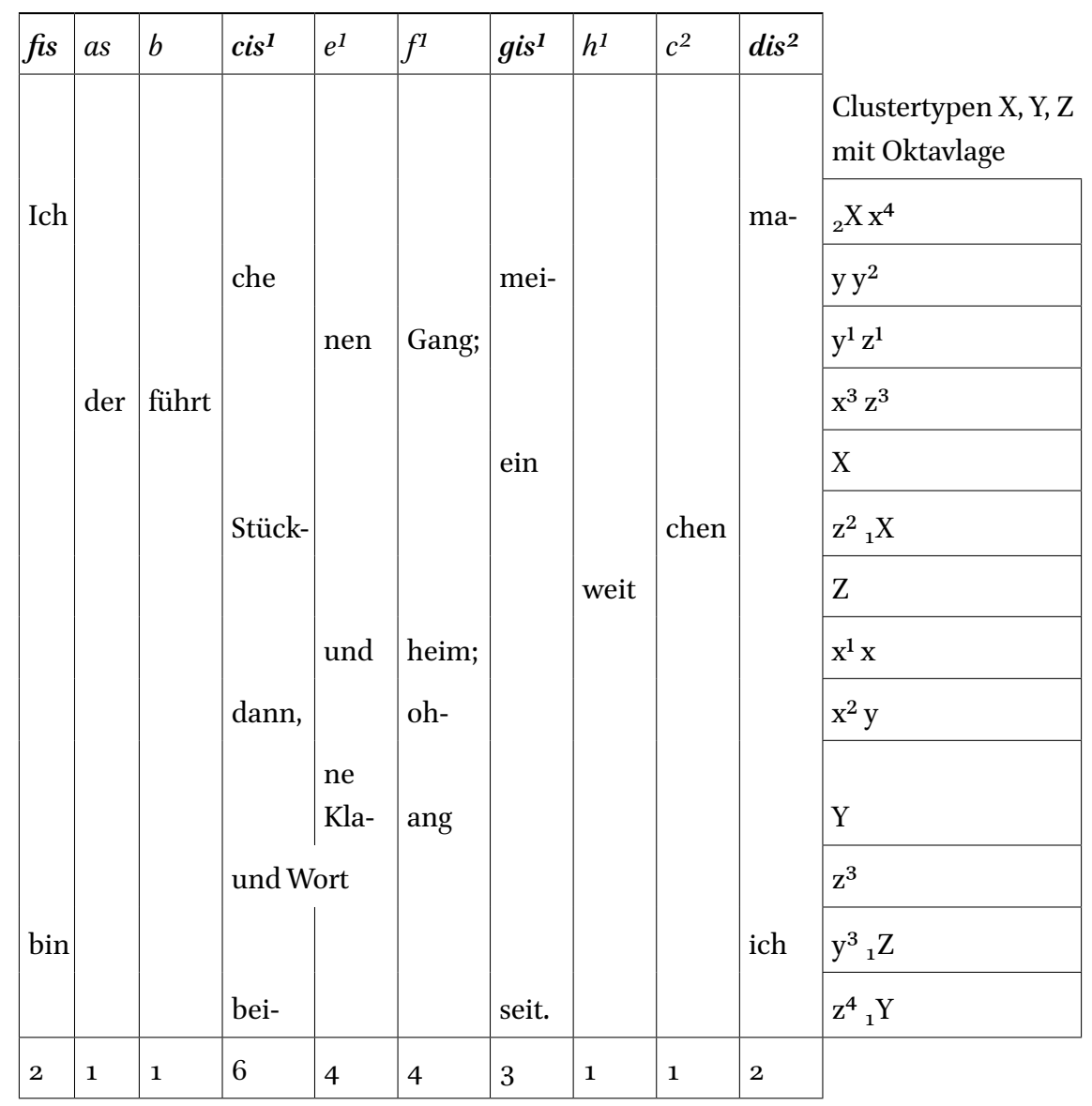

Abb. 54 Verteilung des Textes auf Tonhöhen in Harneit: Beiseit 
In der rechten Spalte sind die Clustertypen $\mathrm{X}, \mathrm{Y}$ und $\mathrm{Z}$ in der entsprechenden Oktavlage notiert; mit $\mathrm{x}-\mathrm{z}$ sind die Oktavlagen ab der kleinen Oktave bezeichnet. Obwohl die Cluster in den Oktavlagen statistisch ausgeglichen verteilt sind, fällt auf, dass der Cluster-X-Typ dem ersten Teil vorbehalten bleibt.

Auch die Anzahl Töne der Gesangsstimme sind symmetrisch verteilt. Einzig die Töne cis $^{1} /$ des $^{1}$ und gis $^{1} / a s^{1}$ sind in diese Symmetrie nicht eingebunden. Die Verwendung der Tonhöhen ist ebenfalls symmetrisch: Am Anfang und am Schluss dominieren die Strukturtöne mit den Quinten, in der Mitte jene Ergänzungstöne, mit denen die Quinten differenziert werden.

Die Wirkung dieser Vertonung ist zerrissen und aggressiv. Zwar macht Harneit keinerlei dynamische und artikulatorische Angaben, aber die engen Viertoncluster - die Harneit alle Note für Note ausschreibt, auch wenn er auf Doppelkreuze zurückgreifen muss - wirken in der Höhe als äußerst scharfe Dissonanzen und in der Tiefe als Klangkleckse, die vor allem im Verklingen diffuse Obertonklänge hörbar machen.

\subsection{Gloria Isabel Ramos Triano: 21 Gedichte von Robert Walser (1996)}

Die in Maracay (Venezuela) geborene Gloria Isabel Ramos Triano verbrachte ihre Jugend in Santa Cruz de Tenerife. Nach einem Klavier- und Kompositionsstudium in Barcelona absolvierte sie 1991 bis 1995 als Bundesstipendiatin der Eidgenossenschaft am Konservatorium Bern (heute Hochschule der Künste Bern) bei Ewald Körner und Manfred Honeck die Ausbildung zur Kapellmeisterin. Nach dem Abschluss gewann sie zahlreiche Preise als Dirigentin und leitete von 2001 bis 2004 als erste Frau ein spanisches Staatsorchester, die Orquesta de Córdoba. Gloria Isabel Ramos Triano bewegt sich als Dirigentin und Komponistin zwischen dem spanischen und deutschen Sprachraum.

Von der Sängerin und Komponistin Kathrin Frauchiger wurde Ramos Triano 1996 auf den Kompositionskurs während der Holliger-Walser-Woche in Biel (vgl. Kap. 11.9) aufmerksam gemacht. Daraufhin komponierte sie einen 21 Lieder umfassenden Zyklus - und damit einen der längsten Walser-LiederZyklen überhaupt. Es war keine Liebe auf den ersten Blick. Nach tagelanger Lektüre, während der es Ramos Triano vorkam, als würde sie »in ein Stück Karton beissen«, änderte sich ihre erste Einschätzung:

Zwischen den Zeilen begann eine faszinierende Kraft zu fliessen, fesselnd, wie ein Mysterium. Ich wollte diese Herausforderung annehmen, auch wenn ich mich mit der Sprache nicht wirklich identifizieren konnte. Es faszinierte mich doch, sie in Klänge zu fassen: die Rauheit seiner lyrischen Welt, die Leere, die 
er hervorzaubert ohne erdrückend zu wirken. Ich erkannte in seinen Texten eine matte, aber nuancenreiche Farbpalette, die vor sich hinfliesst - ohne Entwicklung, geprägt von Langeweile bis zur Erschöpfung, von Wehrlosigkeit und Resignation, Fantasiemangel und Weigerung, sich aus seinen achromatischen Schatten heraus zu bewegen. Und doch - hie und da - stiessen fluoreszierende Blitze heraus, die eher hysterisch anmuteten, oder es wälzten sich ironische und groteske Wellen, wie in einem Kabarett ... Meine Auswahl erlaubte mir, diese Nuancen in Klänge zu formen. Dabei war mir wichtig, möglichst minimalistisch zu bleiben, eine Musik wie im Hintergrund zu komponieren, die wie das »Geräusch « der Gedanken wirkt. Nur an wenigen Stellen gibt es grelle und aufdringliche Ausbrüche oder Rhythmen, die quasi den »tanzenden Zynismus« darstellen. ${ }^{24}$

Ramos Triano gab dem Werk treffenderweise den Titel Gedichte, denn in dieser Komposition stehen Walsers Texte klar im Vordergrund; als Vorbilder könnten Hugo Wolf, Hans Werner Henze oder Aribert Reimann genannt werden, die sich in ähnlicher Weise um die präzise Deklamation des Textes bemühen und die Klavierbegleitung eher als klangliche Stütze und kommentierenden Widerpart denn als Mittel zur Bebilderung und Emotionalisierung benutzen. Auch bei Gloria Isabel Ramos Triano beschränkt sich die Klavierbegleitung oft auf wenige Töne. Häufig sucht sie nach einem Tonzeichen oder einem Motiv, das wie eine Formel das ganze Lied prägt.

21 Gedichte von Robert Walser ist ein vielfältiger Liederzyklus, der vor musikalischen Ideen sprüht, auf starke Kontraste angelegt ist und durchaus drastische Vertonungen enthält, wie das Fortissimo-Lied Nicht? (SW 13, 13f.), in dem die Frage »Scheint denn die Sonne heut nicht? « förmlich herausgeschrien wird.

Beiseit ist das siebzehnte Lied des Zyklus' und eines der rätselhaftesten (vgl. Abb. 55). Es besteht aus vier Schichten, die melodisch und rhythmisch getrennt sind und sich nie kreuzen. Alle vier Schichten symbolisieren unterschiedliche Gänge. Die Randschichten sind statisch: Zuunterst der Orgelpunkt auf Ais und ab Takt 6 Fis, zuoberst die Singstimme, die auf $d^{1}>$ psalmodiert<. Die mittleren Stimmen sind zwei Ostinati in Form von Wechselbewegungen, das obere in Ganztönen, das untere in Kleinterzen.

Bei Takt 6 findet ungefähr nach zwei Dritteln des Gedichts ein harmonischer Wechsel statt: die oberste Schicht bleibt gleich, die zweite sinkt um einen Halbton, die dritte um einen Ganzton und die unterste um eine Großterz. 
Beiseit
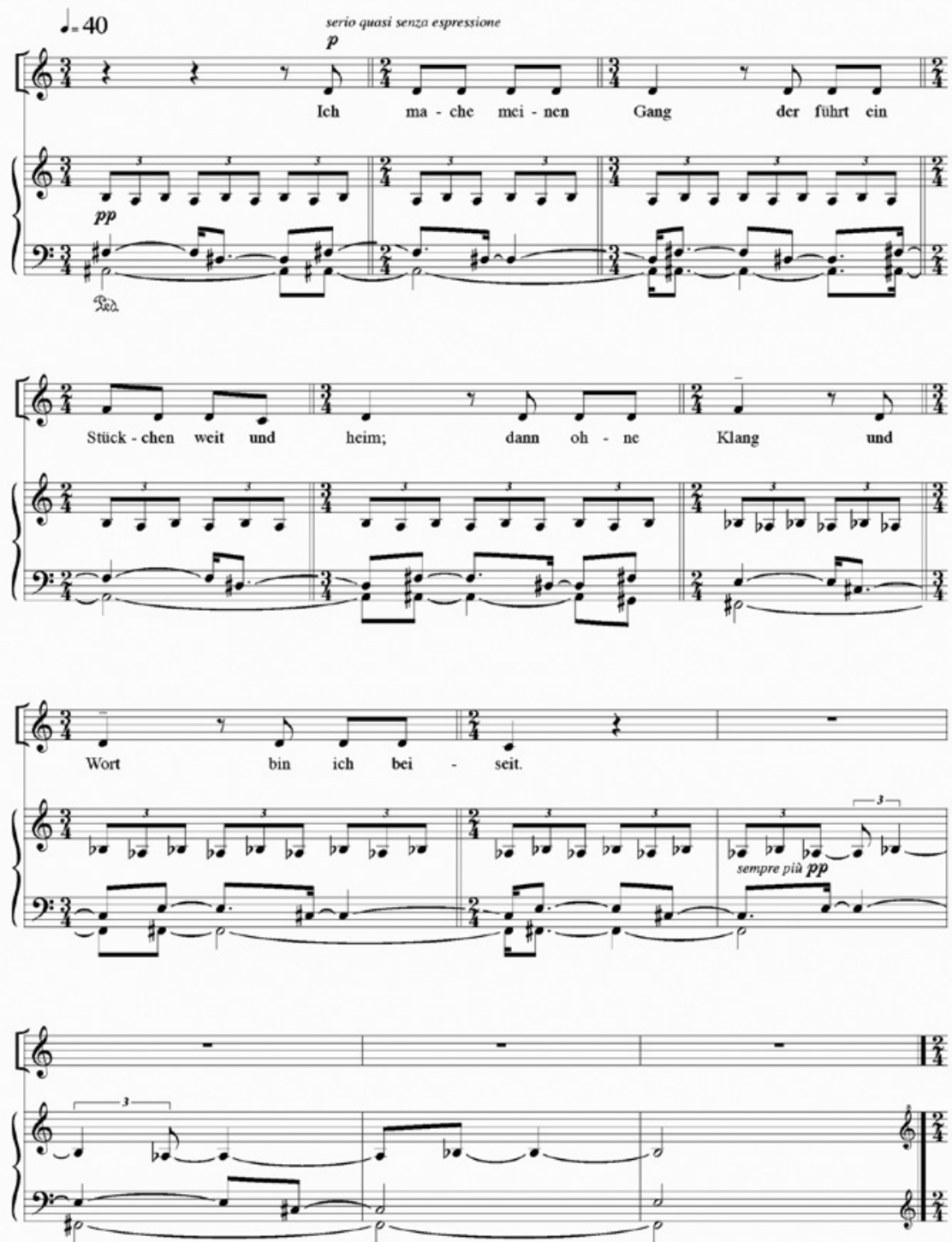

Abb. 55 Gloria Isabel Ramos Triano: Beiseit 
Harmonisch und rhythmisch sind die Mittelstimmen an die Randschichten gebunden. Die ostinate Wechselbewegung in der rechten Klavierhand verläuft konsequent im 9/8- respektive 6/8-Takt zur Singstimme, sodass nur 12 von 24 Tönen der Singstimme zusammen mit einer der Wechselnoten erklingen. Nach $3+2+3+2+3(=13)$ Vierteln beginnt der zweite Teil rhythmisch in analogerWeise, das Absinken um einen Ganzton verändert aber den harmonischen Bezug zur Singstimme. Im ersten Teil konsoniert die Singstimme zur Wechselbewegung mit Quarte $\left(a-d^{I}\right)$ und Kleinterz $\left(h-d^{I}\right)$, im zweiten Teil dissoniert sie mit einer der Wechselnoten im Tritonus $\left(a s-d^{I}\right)$.

Die untere Wechselbewegung ist an den Orgelpunkt angebunden und konsoniert im ersten Teil mit kleiner Sexte und Quarte; auch hier dissoniert ab Takt 6 eine der Wechselnoten zum Orgelpunkt - mit der kleinen Septime (Fis -e).

Die beiden unteren Stimmen sind polymetrisch zu den oberen angelegt: Zwar sind auch sie in fünf >Takte< gegliedert, aber in solche zu $10+11+10+$ $11+10$ Sechzehntel $\left(=5^{2}\right.$ Sechzehntel $=13$ Viertel $)$. Die Technik erinnert an die Talea-Technik der isorhythmischen Motette des Mittelalters, in der teilweise sich überlagernde rhythmische Modelle (= Talea) die Form der Motette prägen und organisieren. Diese Technik erlaubt die Unabhängigkeit der Stimmen untereinander, aber auch die Unabhängigkeit von rhythmischer und melodischer Struktur. Beides trifft auch auf Beiseit von Gloria Isabel Ramos Triano zu. Abgesehen vom allerersten Ton treffen die oberen und die unteren Schichten kein einziges Mal zusammen. Bei Takt 6, nach zwei Dritteln - wo auch in der isorhythmischen Motette oft ein Einschnitt erfolgt - wechseln zwar die drei unteren Schichten die Tonhöhen, aber das rhythmische Schema bleibt sich gleich, und es folgt eine zweite Talea, die allerdings ab Takt 9 satztechnisch und nicht etwa tempomäßig abgebremst wird, so als hätten die isorhythmischen >Räder< die Zähne verloren und würden leerlaufen.

Harmonisch haben die oberen und unteren Schichten im ersten Teil einen polytonalen Aspekt, weil sie in sich konsonieren, aber gegeneinander scharf dissonieren, etwa der Orgelpunkt Ais mit beiden Wechseltönen des Ostinatos der rechten Hand: Ais - $a$ (große Septime) und Ais - $h$ (kleine None), zudem auch die Wechselnote dis zur Singstimme mit einer großen Septime $\left(\right.$ dis $\left.-d^{I}\right)$.

Im zweiten Teil des Liedes bei »Klang« verändert sich die Harmonik zu einem ganztönigen Aggregat, in das sogar der letzte Ton der Singstimme integriert ist $(d-e-f i s-a s-b-c)$. Einzig die Wechselnote cis in der linken Hand passt nicht dazu; sie bildet zum Orgelpunkt Fis eine konsonante Quinte und zum $d$ der Singstimme eine dissonante kleine None.

Ramos Triano interpretiert Beiseit auf eigenständige und originelle Weise: Das lyrische Ich ist nicht in einer räumlichen Mitte, wie bei vielen anderen Vertonungen, sondern schwebt gewissermaßen über allem, eingefroren 
auf einem Ton; die zwei zusätzlichen Tonhöhen in der Singstimme (je zweimal $c^{1}$ und $f^{1}$ ) dienen als Markierungen, mit denen vor allem die Wörter »Stückchen«, »Klang « und »beiseit« betont werden. Kein Wort wird illustriert, alle Bewegung ist zum lectio-ähnlichen Vortrag des Gedichts erstarrt; keine dynamischen Veränderungen, keine Akzente; einzig mit den Pausen wird die Deklamation etwas gestaltet. Darunter laufen komplexe Uhrwerke, die den einfachen Gang in ein Zeitnetzwerk einbinden, Symbol für viele andere Gänge und zugleich für die Einsamkeit des zum Einzelton reduzierten Gangs des lyrischen Ichs, dessen drei Töne $d, c$ und $f$ in keiner der anderen Schichten auftauchen.

\subsection{Klaus Oldemeyer: In meinen Ohren ... (2001)}

Vierzig Jahre lang war Klaus Oldemeyer ( $\left.{ }^{*} 1941\right)$ Klavierprofessor an der Hochschule für Musik Köln, von 1993 bis zu seiner Emeritierung 2007 außerdem Dekan des Fachbereichs 1, wozu neben den Tasteninstrumenten auch Dirigieren, Musiktheorie und Komposition gehörten. Den komponierenden Pianisten zeichnet aus, dass er die »unselige Trennung von Produktion und Reproduktion [...] immer aktiv aufzuheben versucht « hat. ${ }^{25}$

Es gehört mit zum Schicksal großer Pädagogen, dass sie über ihre langjährige Wirkungsstätte hinaus wenig bekannt sind und ihr Ansehen vor allem durch ihre Studentinnen und Studenten weiterlebt. So wurde ich auch von einem seiner ehemaligen Studenten, dem Sänger und Komponisten Martin Wistinghausen, auf Oldemeyers Walser-Vertonungen aufmerksam gemacht. Klaus Oldemeyer beschäftigte sich zweimal mit Walser: 2001 komponierte er einen Zyklus von vier Liedern, den er In meinen Ohren ... nannte und der mit einer Beiseit-Vertonung endet. 2006 setzte er Wiegen (SW 13, 12) ans Ende seines Drei-Lieder-Zyklus; es ist ein extremes Stück, weil Oldemeyer es in reiner Diatonik vertont, nur die weißen Klaviertasten verwendet und sich intervallisch weitgehend auf Quinten beschränkt. Die Singstimme singt immer dieselbe dorische Tonleiter (das Hexachord von $h$ bis $d$ ), fünfmal abwärts und zum Schluss bei »wohl in den Traum hinein« einmal aufwärts - es ist eine Musik, die mit minimaler und zunehmend erlöschender harmonischer Energie eine zauberhafte Wirkung entfaltet.

Für Beiseit findet Oldemeyer einen wunderlichen Weg, indem er ein Minidrama aus dem Gedicht macht. »Gemächlich schlendernd « ist die Tempobezeichnung des Liedes; schon in der Klaviereinleitung wird kein schwerer Gang angekündigt. So wird »meinen Gang« mit übermütig großen Intervallen 
und einem Nonsprung in die Tiefe vertont und dreimal mit abnehmender Dynamik wiederholt; es entsteht ein »quasi Echo«(Abb. 56, S. 15, 1. System), so als wäre der »Gang « nur der Widerhall seiner Anfangsenergie. Diesen EchoEffekt bringt Oldemeyer bei »ein Stückchen weit« nochmals, hier allerdings schon mit weniger dynamischer Energie (vgl. Abb. $5^{6}$ ).

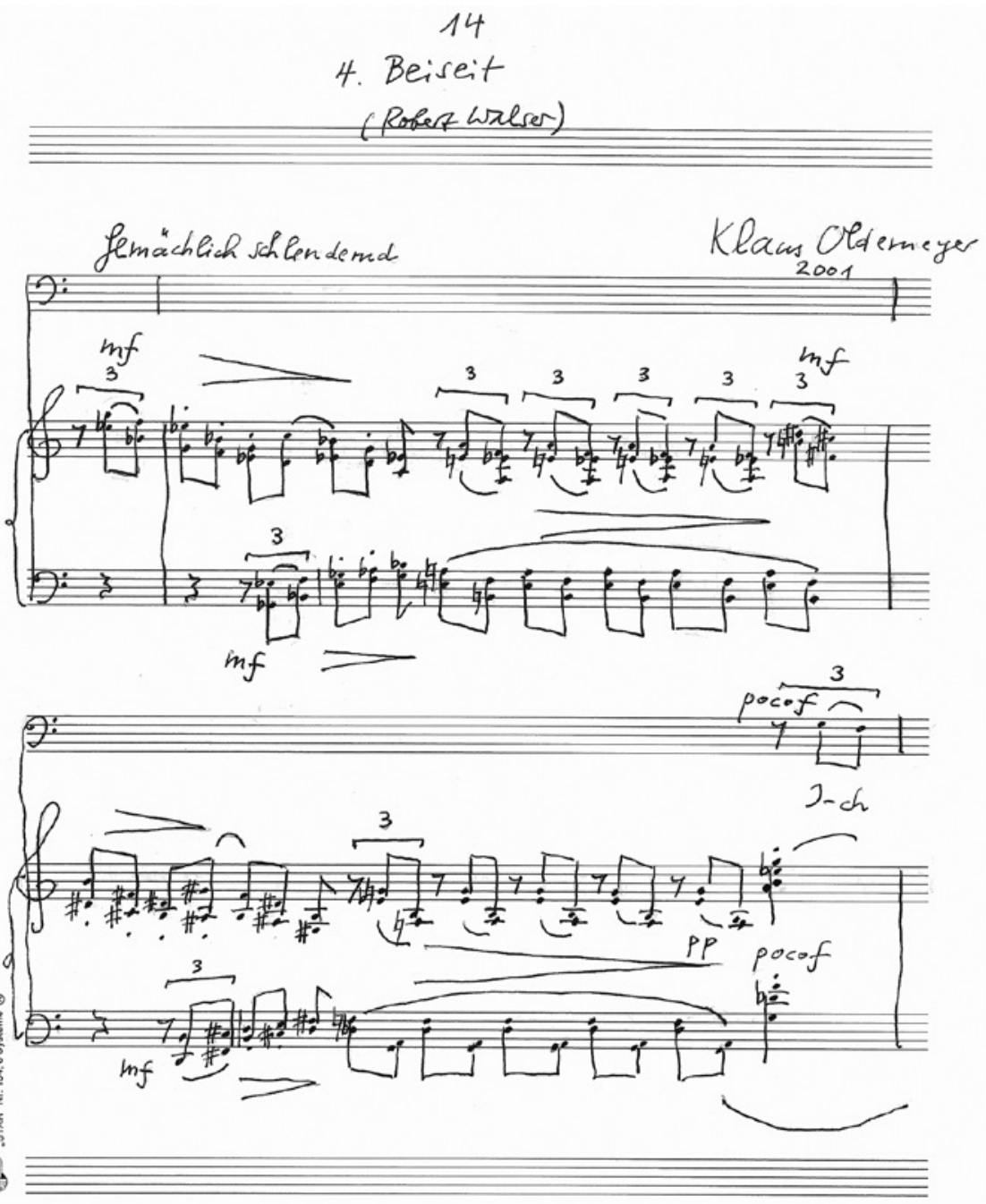

Abb. $56 \quad$ Klaus Oldemeyer: Beiseit 


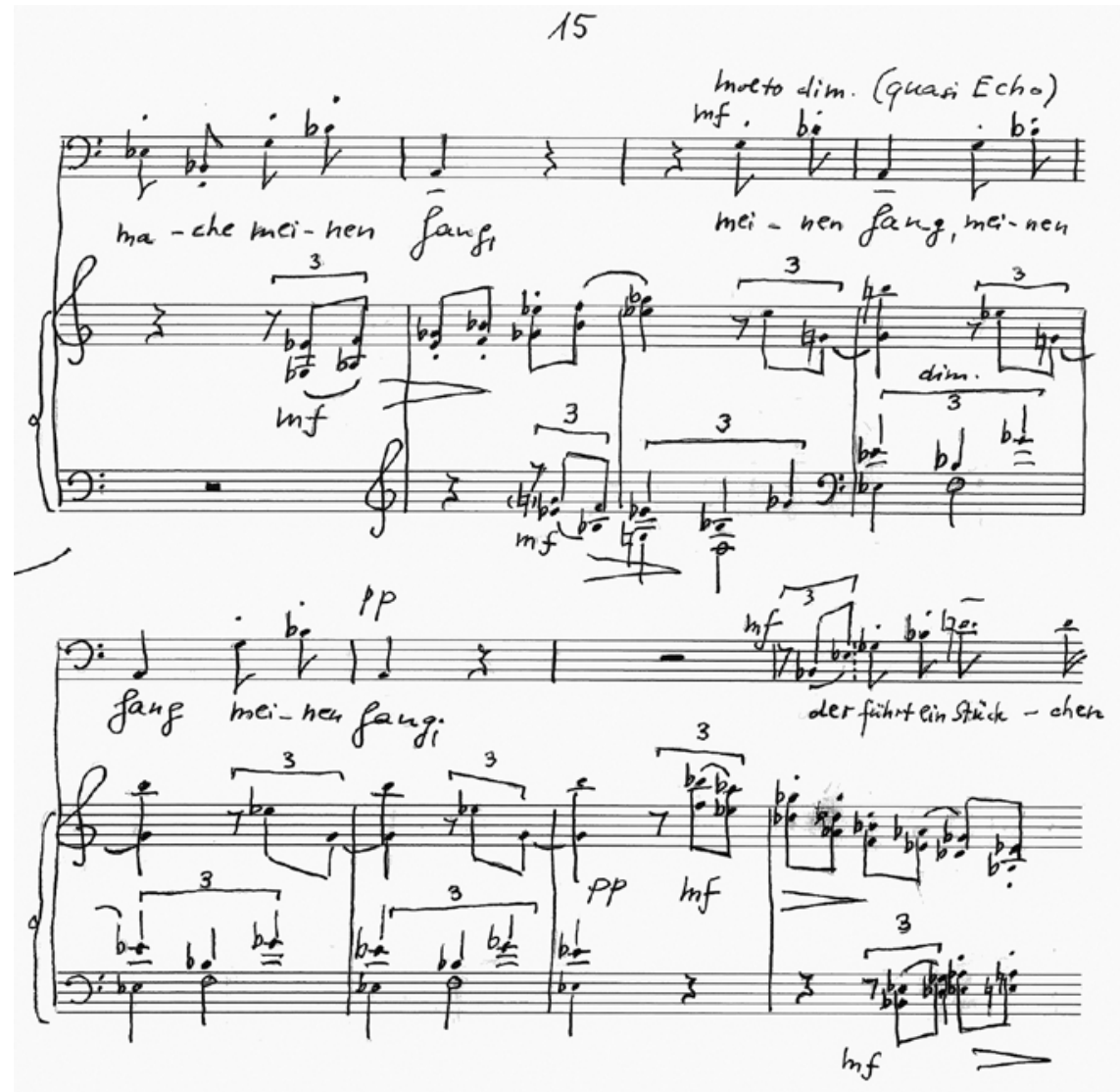




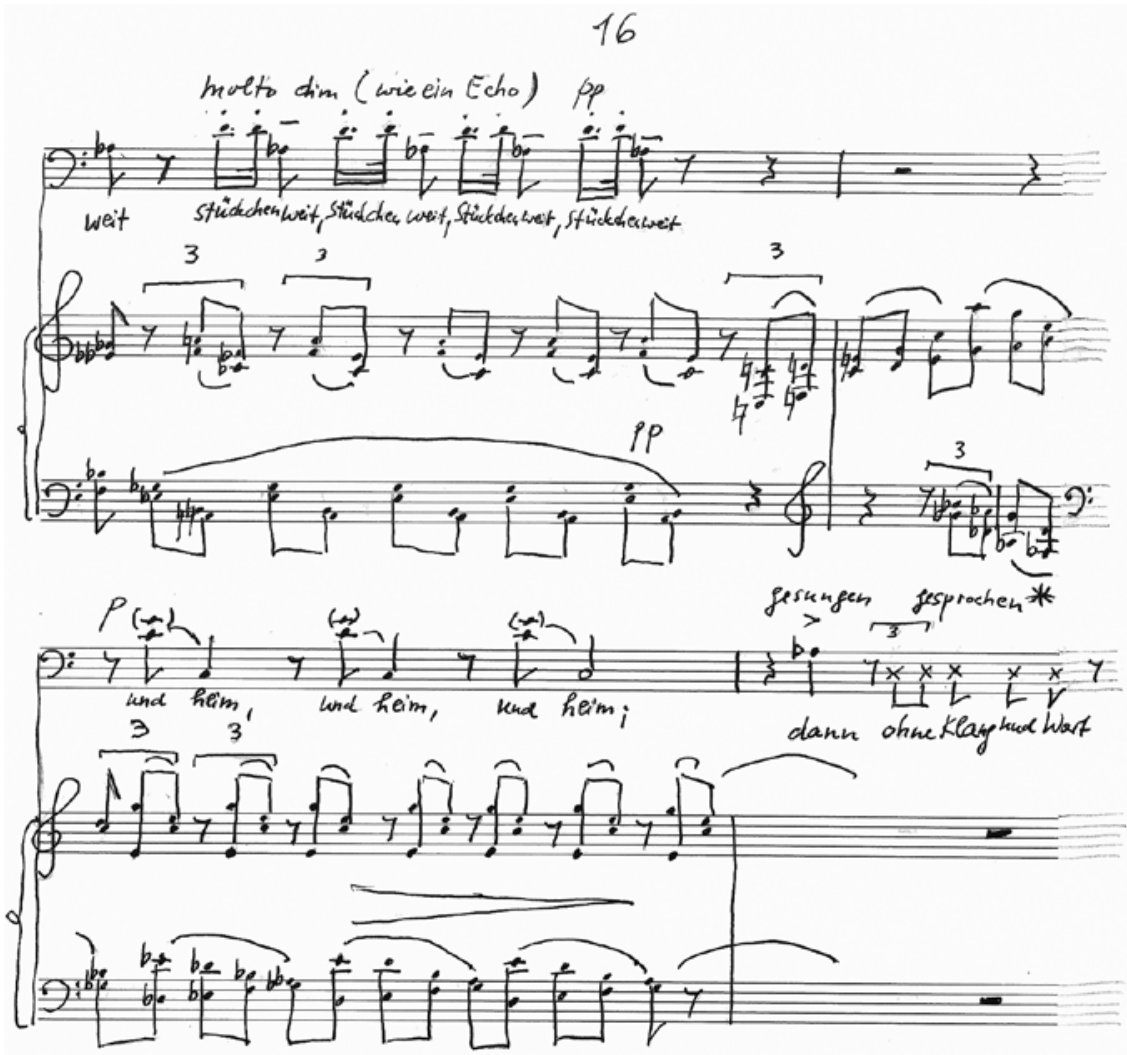

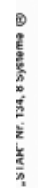

* hormales sprechton

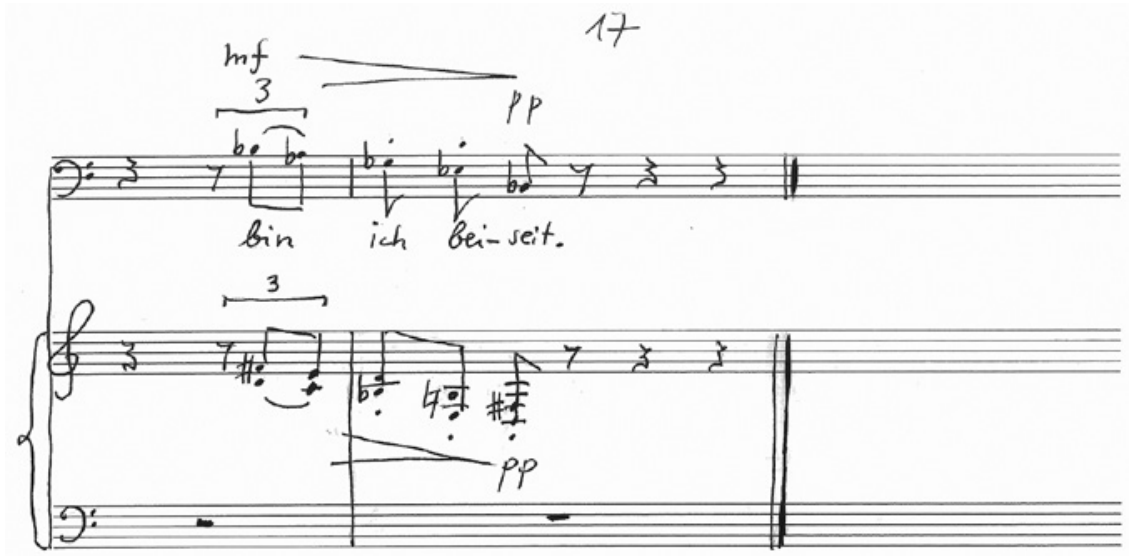


Überraschend ist die Lösung bei »und heim«: Dieses wird zwar auch wiederholt, aber nur zweimal und ohne Echo-Effekt, sei es, weil der Gesang auf der tiefen dynamischen Pianostufe gar keinen Widerhall mehr bewirken kann, sei es, weil das lyrische Ich mit den Oktavsprüngen nun >bei sich< angekommen ist. Die rechte Hand des Klaviers affirmiert diese Oktaven mit reinem C-Dur. Es wäre eine reichlich naive Lösung, wenn dazu nicht die linke Hand dissonierend den chromatischen Komplementärraum ausschreiten und das >C-Dur-Heim als bescheidene Illusion ausweisen würde. ${ }^{26}$

Wie schon Günther Buhles lässt auch Oldemeyer »ohne Klang und Wort« nur noch sprechen. »Bin ich beiseit« wird mit einer absteigenden Linie von übermäßigen Dreiklängen dargestellt. Mit den vier übermäßigen Dreiklängen des Halbtonsystems ${ }^{27}$ könnte der ganze chromatische Tonraum ausgeschritten werden, aber Oldemeyer vermeidet diese >Totalität<, denn der Dreiklang $a$-cis- $f$ fehlt. Dafür dreht sich die Bewegung um den Dreiklang $b$-d-ges/fis, der »bin, ich« und »[bei]seit« verbindet und das Beiseit-Ende wie in einer eigenen Welt verschließt.

\subsection{Bruno Karrer: Walser I-III (2006)}

Der Sankt Galler Komponist und Musiktheoretiker Bruno Karrer wurde an Robert Walsers Todestag, am 25. Dezember 1956, geboren. Zu seinem eigenen 5o. Geburtstag wagte er es, sich erstmals mit Robert Walser auseinanderzusetzen. Es entstand ein umfangreiches Projekt aus drei Zyklen mit Walser IDas alles für Sopran oder Tenor und Akkordeon, Walser II - Abendschnee für Sopran und/oder Tenor, Violine und Akkordeon sowie Walser III - So durch die Bäume fällt für Tenor oder Sopran und Violine.

Bruno Karrer, der ursprünglich Gitarre studierte, misstraute als Komponist schon früh der virtuos-komplexen Avantgarde und versuchte, mit ostentativ einfachen und doch streng konstruktiven Mitteln musikalische Verdichtungen $\mathrm{zu}$ erreichen. Auch die Walser-Zyklen sind dieser arte povera-Ästhetik verpflichtet.

Die Singstimme deklamiert über weite Strecken in einfachen Vierteln und kleinen Intervallschritten; es entsteht der Gesamteindruck eines monotonen

26 Seit Alban Berg in der Oper Wozzeck den C-Dur-Dreiklang mit dem >Lohn< identifiziert, den Wozzeck für die medizinischen Versuche bekommt, die der Doktor an ihm verübt, ist C-Dur zur negativen Chiffre geworden. Eine naive Verwendung von C-Dur, die diesen Hintergrund ausschließt, ist fast nicht mehr möglich.

27 Es sind die Akkorde $c$-e-gis, cis-f-a, $d$-fis-ais, es- $g$ - $h$. 
syllabischen Psalmodierens, bei dem >heiliger Text vorgetragen wird. Jede Form von Illustration wird gemieden, keine Exklamationen werden gesetzt, nichts wird gesprochen und nichts mit dramatischer Gestik hervorgehoben, die Dynamik ist statisch und auch die Versrhythmik und die Reime von Walsers Texten werden nicht sonderlich beachtet. Wenn man sich allerdings auf diese unspektakuläre Musik einlässt, wird die kleinste Abweichung von dieser Psalmodie bedeutungsvoll, zum Beispiel eine einzelne Punktierungsfigur, eine kurze vierteltönige Skala, einfache Achteltriolen. Zwei auf einer Silbe gesungene Töne sind schon fast eine Sensation. Der Komponist, Musikkritiker und Musikpädagoge Charles Uzor beschreibt es folgendermaßen:

Die Musik ist schlicht aber dringlich, sie nimmt den Worten nichts, unterstreicht nicht, bleibt fern aller Allüren und gibt einen persönlichen Zugang zu den Gedichten. [...] Karrer geht minutiös und behutsam vor. Jede Miniatur wird aus einer Formidee gestaltet, mit einer Klanglogik, die auch konventionelles Hören verführt. ${ }^{28}$

Belebt wird der Gesang durch die Instrumentalbegleitungen, die vor allem im mittleren Teil stark ausgebaut sind, allerdings verzichtet Karrer auch hier auf Illustration oder Textausdeutung, vielmehr legen die Instrumente einen Grundton, mit dem in jedem Lied die >Aussagen< der Singstimme grundiert werden. Für diese >Aussagen $<$ hat sich Karrer die Mittel selbst stark beschränkt: Er kann mit der Melodie, den Abschnittsbildungen, der metrischen Struktur, der Agogik und der Tonauswahl - quasi dem Tonalphabet - kompositorisch arbeiten. Bei dieser Tonauswahl haben die Zahlen 7 und 8 eine konstitutive Bedeutung. Sie lassen sich schon in der Großform nachweisen: Walser I und Walser II enthalten acht Lieder, Walser III sieben, insgesamt also 23 Miniaturen.

Walser I enthält noch eine weitere Kombination von Sieben und Acht, denn dieser erste Zyklus besteht aus acht Miniaturen, aber nur sieben Texten, weil der Beiseit-Text zweimal vertont wird. Im Unterschied zu Urs Peter Schneiders Doppelvertonung dieses Gedichts ist hier nicht die Unterschiedlichkeit, sondern die Übereinstimmung bemerkenswert, denn die beiden Vertonungen gleichen sich aufs Haar; auch wegen der statischen Begleitung des Akkordeons nimmt man die zweite Beiseit-Vertonung als Wiederholung wahr. Und bei Beiseit I liegt der Verdacht nahe, die Sängerin habe gepatzt (vgl. Abb. 57) und irrtümlich »ich mach'« statt »ich mache« gesungen. 

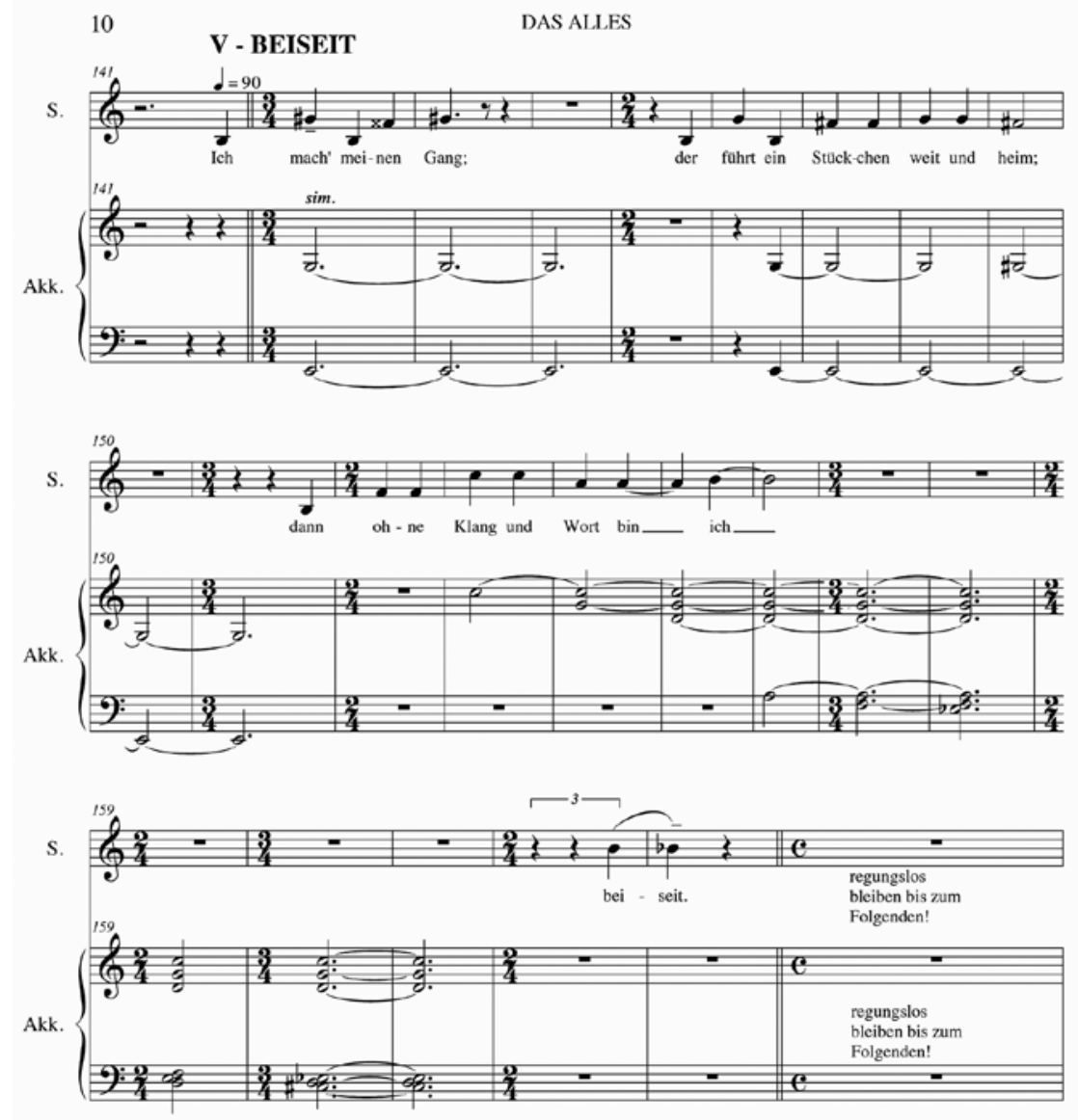

Abb. 57 Bruno Karrer: Beiseit I

Tatsächlich ist es aber Bruno Karrer selbst, der es gewagt hat, in Robert Walsers Vers einzugreifen und das Wort »mache « in »mach' « zu elidieren. Poetologische Gründe kann diese Elision nicht haben, denn sie zerstört gerade Walsers strenge Form von vier sechssilbigen Versen. Neben dem Bestreben, mit dem >aufmunternden< Dreivierteltakt eine metrische Irritation zu kreieren, liegt der Grund dieser provokativen Elision vermutlich im erwähnten hintergründig wirksamen Zahlenkonzept. Durch die Elision enthält das Lied genauso viele Silben wie der dreiteilige Zyklus insgesamt Lieder aufweist, nämlich 23. Auch in der Struktur von Beiseit I mit vier klar getrennten Abschnitten tauchen die Zahlen Acht und Sieben $(5+2)$ erneut auf: 
Ich mach' meinen Gang;

der führt ein Stückchen weit / und heim;

dann ohne Wort / und Klang bin ich

beiseit.
5 Silben 4 Tonhöhen

8 Silben 3 Tonhöhen (1 Tonhöhe neu)

8 Silben 5 Tonhöhen (4Tonhöhen neu)

2 Silben 2 Tonhöhen (1 Tonhöhe neu)

In den Abschnittsbildungen setzt sich Karrer über die Versstruktur von Walsers Gedicht hinweg und etabliert ein achtsilbiges System, das in den Binnenstrukturen die Fibonacci-Folge (1-1-2-3-5-8...) aufscheinen lässt. Diese Fibonacci-Folge bestimmte schon die Platzierung der Beiseit-Lieder innerhalb von Walser I auf der fünften und achten Position.

Insgesamt verwendet Karrer in Beiseit acht Tonhöhen ( $c$, f, fis, g, gis, $a, b$, $h)$, die sich auf den Rahmen einer kleinen None $\left(h-c^{2}\right)$ beschränken. Das enharmonisch verwechselte fisis zu Beginn des Liedes ist als $g$ mitgezählt. Mit der auffälligen Schreibweise fisis statt $g$ will Karrer zum dominierenden e-Moll (Dezime $E-g$ im Akkordeon und $h$ als erster Ton der Singstimme) einen Gegenpol auf gis andeuten. Das fisis wird allerdings im temperierten System realisiert und auf eine enharmonische Schärfung wird verzichtet. ${ }^{29}$ Sie hätte eine irritierende Schwebung zum $g$ des Akkordeons ergeben und das $>$ Eigene $<$ dieses Ganges des lyrischen Ichs betont. Dadurch, dass bei Karrer die Singstimme mit fisis $^{1}$ und das Akkordeon mit $g$ um eine Oktave verschoben die gleiche Tonhöhe spielen, wird das Spezielle dieses Ganges zu etwas >Gedachtem<, eher auf dem Papier als in der klanglichen Realität Vorhandenem, was auch eine Aussage ist: Das lyrische Ich imaginiert zwar einen vermeintlich anderen Ton als das Akkordeon, in Wahrheit klingt er aber gleich.

Die Unterschiede zur zweiten Beiseit-Vertonung von Bruno Karrer, die seinen ersten Walser-Zyklus abschließt, sind zwar minimal, aber von entscheidender Bedeutung, und sie manifestieren sich alle schon in den ersten Takten (vgl. Abb. 58). Während im ersten Beiseit der einzige oktavierte Ton des Liedes mit $h^{1}$ erst ganz am Schluss beim zweiten »ich« erreicht wird, ist diese Oktavierung bei der zweiten Vertonung schon in den ersten vier Tönen der Singstimme gegeben; und $h^{1}$ wird in Version 2 klar zum Ich- und Schicksalston: »ich $\mathrm{ma}[\mathrm{che}] \ll, »[$ bin] ich« und »bei[seit] «.

Das zweite Beiseit zeigt sich auf diese Weise als das entschiedenere; der Gang ins >Beiseit< ist hier vollzogen. Nach dem ersten Beiseit herrscht noch Schockstarre »reglos bleiben bis zum Folgenden!« (Abb. 57, T. 164); das Beiseit

29 Zum Beispiel um 16 Cent, indem er in harmonisch gis-Moll von $e$ aus eine natürliche kleine Terz $(6 / 5=316$ Cent $)$ zugefügt hätte, was für fisis in Bezug auf $c(=$ Null $)$ die absolute Tonhöhe von 716 Cent ergeben würde, statt des gleichstufig temperierten $g$ respektive fisis von 700 Cent. Cent ist die heute übliche Maßeinheit für Intervalle: Eine Oktave hat 1200 Cent, ein äquidistanter Halbton 100 Cent. 

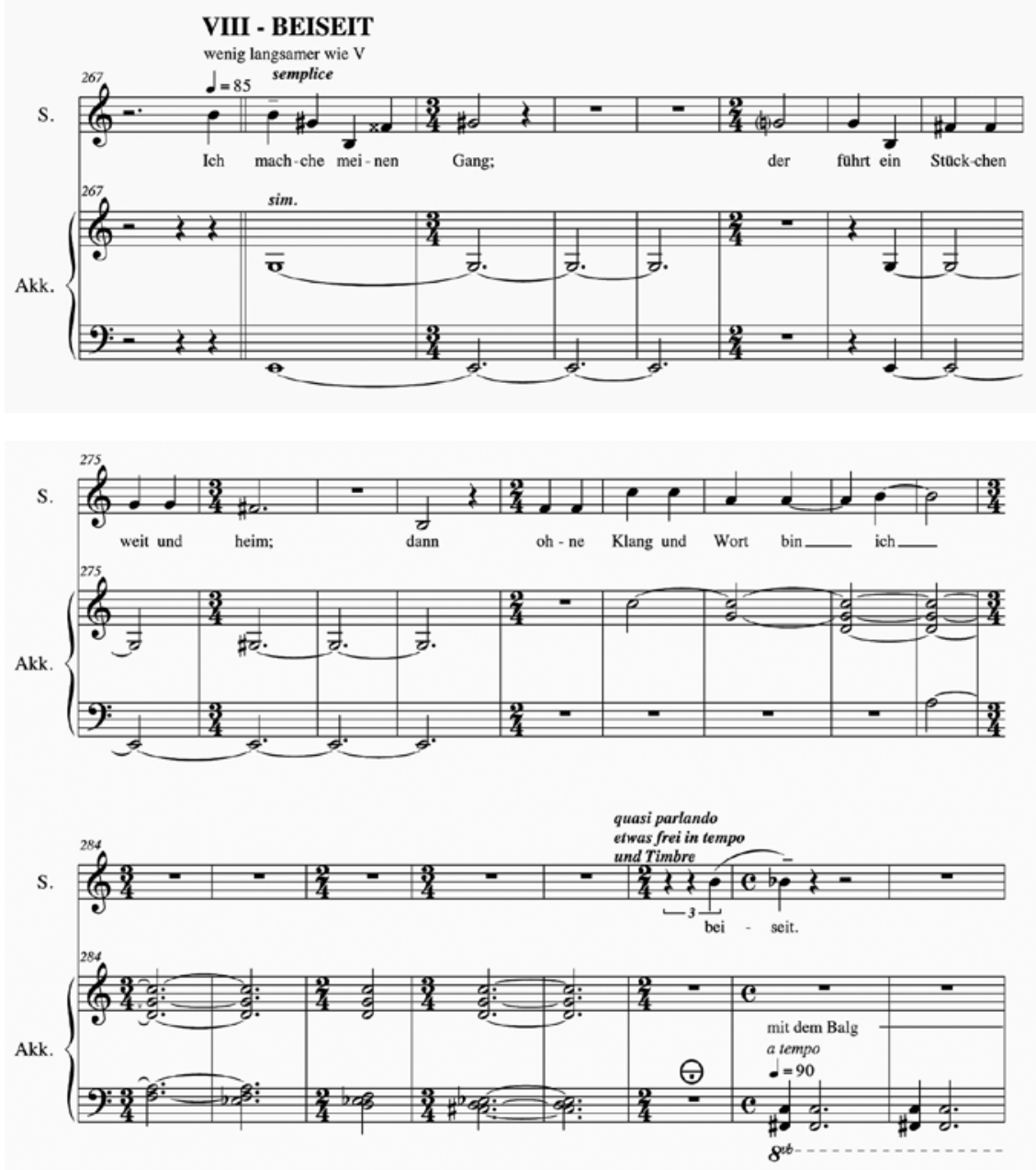

Abb. 58 Bruno Karrer: Beiseit II

der zweiten Version wird im Parlando und freier vorgetragen, fällt aber mit dem Tritonus im ächzenden Subkontrabass-Register des Akkordeons zusammen. Auch von der Tonverteilung sstimmt< das zweite Beiseit: Zwölf Töne fallen auf $h(7)$ und $g(5)$; die anderen zwölf Töne fallen auf die verbleibenden sechs Tonhöhen. Die in der Singstimme fehlenden chromatischen Töne cis, $d$, es und $e$ kommen alle in der Akkordeonpartie vor, die in der Anzahl und Gruppierung von fünf und dreimal sechs $(=23)$ Tönen die Strukturzahl des gesamten Zyklus in beiden Beiseit-Vertonungen aufrechterhält. Für die Vertonung des Wortes »beiseit« findet auch Bruno Karrer eine spezielle Lösung, erklingt hier doch 
das zuvor vermiedene $b$. Eigentlich ist das Lied mit sieben chromatischen Tonhöhen komponiert, die sich alle innerhalb der Quinte $f-c$ befinden. Das $b$ erweitert die Reihe auf acht Tonhöhen und durchbricht das System der sieben Töne; zugleich ist es aber auch der letzte fehlende chromatische Ton in dieser Quinte und vervollständigt diese somit. Nicht zuletzt steht das $b$ harmonisch im Tritonus-Verhältnis zum e-Moll des Liedanfangs. Das alles wird von Karrer unaufgeregt in die Figur eines chromatisch absteigenden Seufzers gefasst.

Erwähnt sei noch, dass Bruno Karrer 2009 als Paraphrase der Walser-Zyklen ein monumentales Klavierstück von 30 Minuten Dauer komponierte, das die Motive aufnimmt, erweitert, moduliert und in verschiedenste stilistische Zonen führt.

Die Fantasie ist ein Arrangement dieser drei Zyklen für Klavier solo, gekürzt und wo nötig ergänzt - ohne die Worte vielleicht umso sprechender? - Jedenfalls brauchte ich die Fantasie, um mich von Walser und vom »Walsern« wieder lösen zu können. ${ }^{30}$

\subsection{Daniel Fueter: fort und fort (2008)}

Zum Abschied von Karl Scheuber als Dirigent des Schwulen Männerchors Zürich (schmaz) komponierte Daniel Fueter eine Kantate mit Texten von Robert Walser, Werner Lutz und Thomas Hürlimann für Männerchor und für das Engadiner Volksmusikensemble Ils Fränzlis da Tschlin, ${ }^{31}$ damals noch in der alten Besetzung mit Kornett.

Karl Scheuber ( $\left.{ }^{*} 1943\right)$ zählt zu den führenden Schweizer Chordirigenten und ist eine prägende Figur des Zürcher Musiklebens. Aus einem durchaus demokratischen Verständnis heraus arbeitete er begeistert mit Laien und scheute sich nicht vor der Kärrnerarbeit, welche die Einstudierung gerade großer Chorwerke für einen Laienchor bedeutet.

Daniel Fueter war ein früher Förderer des 1990 gegründeten Schwulen Männerchores: Nur drei Wochen nach der Chorgründung kam der Schmaz bereits zu einem Engagement im Schauspielhaus. Für das Stück Der letzte Gast von Thomas Hürlimann brauchte Fueter einen qualitativ hochstehenden

30 Karrer: [Einführung zum Konzert vom 27.11.20o9 im Pfalzkeller St. Gallen], S. 2.

31 Für Ils Fränzlis da Tschlin haben auch andere Komponisten der zeitgenössischen Musik Werke komponiert. Während sich Martin Derungs mit Vistas chi's müdan [(An)-sichten, die sich verändern] und Urs Peter Schneider mit Sechs Etuden aus dem Zyklus »Meilensteine« für fünf Volksmusiker kaum auf die Idiomatik der Volksmusik einließen, geht Daniel Fueter in fort und fort klar von diesen Idiomen aus. 
Männerchor. Es waren nur drei kleine Lieder von einigen Minuten Dauer, doch dieser Einsatz verhalf dem Schmaz zu einem glänzenden Auftakt. ${ }^{32}$

Den kecken Namen »Schmaz « legte sich der Schwule Männerchor übrigens erst zu, als er 1991 am Schweizerischen Gesangsfest in Luzern nicht unter seinem eigentlichen Namen auftreten durfte. Das Wörtchen »schwul« störte die Verantwortlichen.

2011 zog sich Karl Scheuber nach zwanzig Jahren von der Leitung des Schmaz zurück. Er hatte in dieser Zeit den Chor nicht nur als seriösen Männerchor etablieren können, sondern das konservative Image des Männerchors grundlegend verändert. Daniel Fueters Kantate fort und fort reflektiert diese Entwicklung und ist mit dem Gebetchen von Werner Lutz auch eine witzige Hommage an Karl Scheuber:

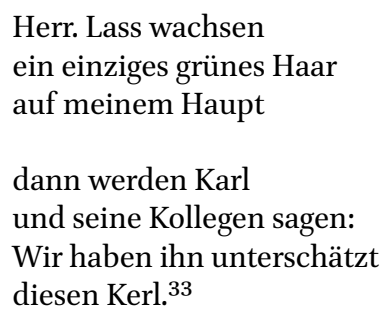

Vor diesem Hintergrund wird deutlich, weshalb die Beiseit-Vertonung von Daniel Fueter die unbeschwerteste und humorvollste der hier besprochenen Kompositionen ist. Der Chortradition verpflichtet ist auch die Wiederholung des Textes, der ein erstes Mal nur von den zweiten Tenören und den ersten Bässen, dann von allen Stimmen und schließlich als Reprise wieder nur von den Chorstimmen Tenor 2 und Bass 1 vorgetragen wird:

\begin{abstract}
Eine Art Volkston war gegeben. Den - dachte ich - mit der äusserlichen Einfachheit der Texte verbinden zu können. Die Vertonung kann nicht den Anspruch erheben, die grossen Dimensionen des Walser-Textes auszuloten. Abschied war das Thema, und während der letzte Text von Hürlimann den Lebensbogen beschreibt, habe ich den Walser auf das Bild des Lebenskreises reduziert: Fortgehen und heimkommen. Deshalb auch die Textwiederholung, was ich mir selbst zumeist verbitte. ${ }^{34}$
\end{abstract}

Wie schon bei seiner Filmmusik zu Walser (vgl. Kap. 8.3) spielt Fueter auch bei fort und fort geschickt mit rhythmischer Varietät: Nach einer vertrackten Einleitung im 5/8-Takt schafft er Differenzierung vor allem mit Taktwechseln und

32 Dworschak: Erfolgreicher Kampf gegen Vorurteile, S. 13.

33 Fueter: fort und fort, S. 13-23.

34 E-Mail von Daniel Fueter an Roman Brotbeck vom 28.o5.2020. 
genauer Platzierung des homophonen Chorgesangs in die metrische Struktur. Er wechselt zwischen 2/4- und 6/8-Takt und bringt damit ein feines und leicht irritierendes `Schütteln< in den Vortrag. Das zeigt sich schön am Ende des vierstimmigen Chorteils, im Übergang in die nur von den Streichern begleitete Wiederholung des zweistimmigen Teils. Fueter schließt ohne Unterbruch und Vorbereitung an; die pfiffige und mit Flatterzunge des Kornetts vorbereitete Kadenz wird nicht ausgekostet, bruchlos geht es mit den Taktwechseln weiter (vgl. Abb. 59). Es bleibt die Spannung zwischen der >Wir<-Form des Männerchors und der >Ich〈-Form des Beiseit-Gedichts. Daniel Fueter erklärt es so: »[N]atürlich war der schmaz damals immer noch >beiseit« und so weht auch das Thema Einsamkeit durch den Minizyklus. «35

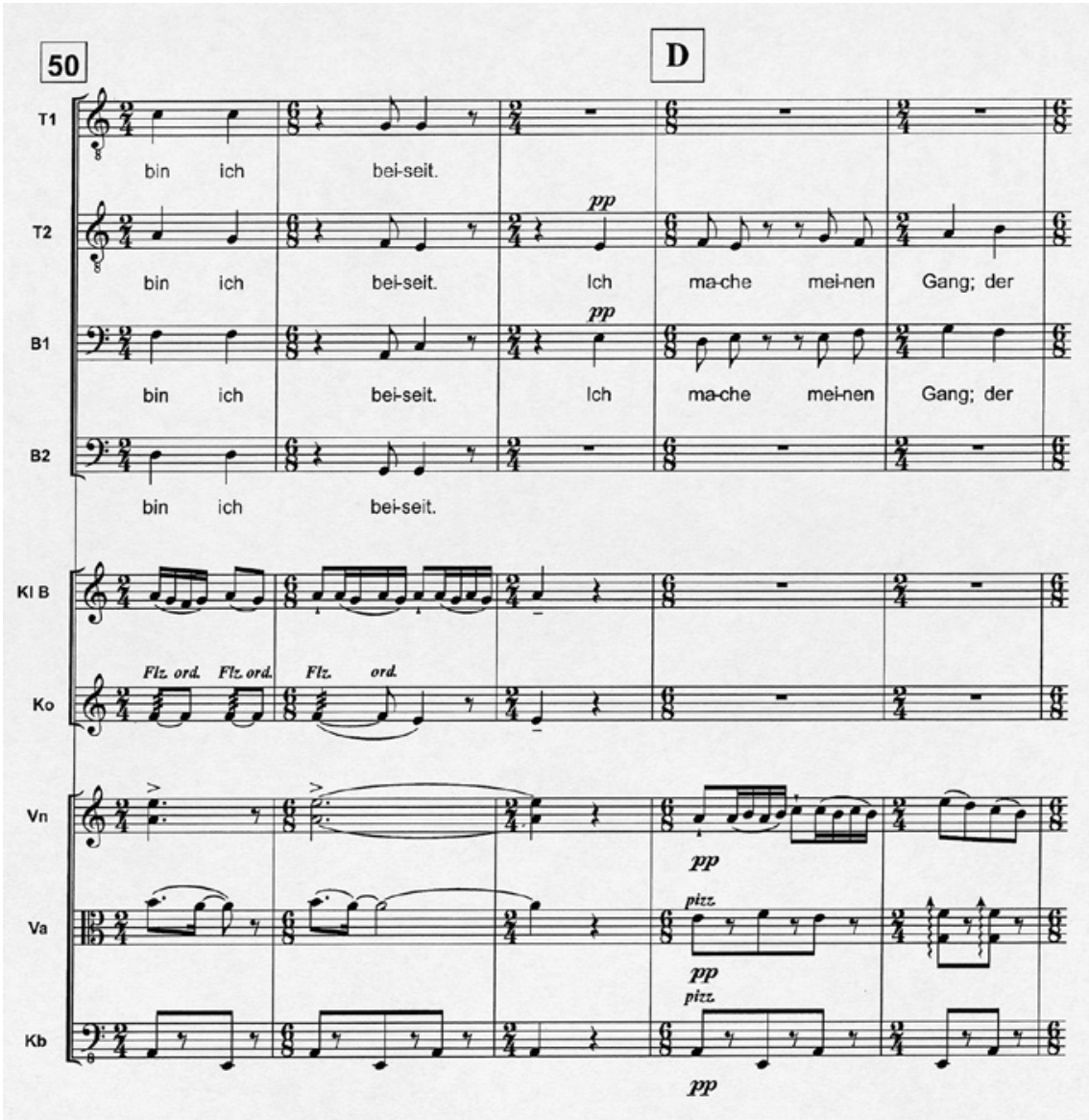

Abb. 59 Daniel Fueter: Beiseit aus fort und fort, S. 10 
10.13 Martin Wistinghausen: Spuren (2010/11) und drei Beiseit (2010; 2015/16)

Martin Wistinghausen ( $\left.{ }^{*} 1979\right)$ hat sich als Sänger und Komponist intensiv mit Robert Walser auseinandergesetzt: Als Sänger brachte er schon 2001 In meinen Ohren ... von Klaus Oldemeyer zur Uraufführung. Das war der Auslöser für die eigene Auseinandersetzung mit Walsers Gedicht:

»Beiseit« habe ich durch die Vertonung von Klaus Oldemeyer kennen gelernt, das Gedicht ging mir nicht mehr aus dem Kopf und Jahre nach der UA der Oldemeyer-Lieder habe ich es dann selbst bearbeitet. ${ }^{36}$

Martin Wistinghausen ist Sänger und Komponist, hat beide Fächer studiert - Gesang beim legendären Bassisten Kurt Moll und bei Rudolf Piernay, Komposition bei Ulrich Leyendecker sowie bei Adriana Hölszky am Salzburger Mozarteum. Wistinghausen hat mit seiner Bassstimme wesentlich zur >Vertiefung< der musikalischen Walser-Rezeption beigetragen, denn lange Zeit dominierten hohe Stimmlagen die Walser-Vertonungen - Tenöre, Frauenstimmen und Kontratenöre. 2012 sang er die Uraufführung von Schneien von Erich S. Hermann, einem Studienkollegen aus der Leyendecker-Klasse in Mannheim (vgl. Kap. 8.6.3).

2017 und 2018 gestaltete Wistinghausen gemeinsam mit Ulrich Eisenlohr, Professor für Liedbegleitung an der Kölner Musikhochschule, Konzerte, in denen Lieder aus Schuberts Winterreise mit Robert Walser-Vertonungen kombiniert wurden; ${ }^{37}$ dabei erklangen auch drei Uraufführungen: Von Erik Janson ( $\left.{ }^{*} 1967\right)$ zwei 2017 überarbeitete Jugendwerke, Wiegen (SW 13, 12) und Abendlied (SW 13, 42), von Norbert Laufer ( $\left.{ }^{*} 1960\right)$ Zwei Lieder für Bass und Klavier ${ }^{38}$ und von Claes Jasper Biehl ( $\left.{ }^{*} 1979\right)$ eine weitere Beiseit-Vertonung (vgl. Kap. 10.15).

36 E-Mail von Martin Wistinghausen an Roman Brotbeck vom 20.10.2016.

37 Konzerte am 07.10.2017 in der Neanderkirche Düsseldorf sowie am 21.01.2018 in der Kulturkirche Pax Christi in Krefeld-Oppum mit Walser-Vertonungen von Claes Biehl (UA), Erich S. Hermann, Norbert Laufer (UA), Erik Janson (UA) und Martin Wistinghausen, kombiniert mit Liedern aus Franz Schuberts Winterreise D 911 (Nummer 1, 2, 3, 4, 7, 11, 18, 22, 20). Bass: Martin Wistinghausen; Klavier: Ulrich Eisenlohr. In Krefeld erklang nur eines von Erik Jansons Jugendliedern, dafür von Klaus Oldemeyer das Lied Wiegen.

38 Auf meine Sinne (SW 13, 45) ist im Klavier harmonisch und in der Singstimme melodisch von Nonen geprägt; Stille (SW 13, 17f.) zeichnet sich durch einen chiastischen Vertonungsansatz aus, indem die Wörter »still«, »Stille« und »Trost« im Fortissimo in hoher Lage gesungen und von satten Klavierakkorden begleitet werden. In den anderen Partien des Liedes begleitet das Klavier zweistimmig; die rechte Klavierhand verdoppelt die Melodie der Gesangsstimme in unterschiedlichen Oktavlagen, was einen irritierenden Effekt ergibt, zumal die linke Hand meist in Gegenbewegung dazu verläuft. 
Martin Wistinghausen hat Beiseit in vier Besetzungsvarianten vertont: zum einen als selbstständige und mit Beiseit betitelte Kompositionen für Bass und Instrumentalensemble, für Bass und Klavier sowie für Frauenstimme und Klavier, zum anderen integriert in den Liederzyklus Spuren für Bass und Violoncello. Die musikalische Aussage ist in allen Varianten ähnlich.

Der lakonische Charakter und das »sprachliche Verstummen « haben mich besonders angesprochen. In allen meinen Versionen zieht sich die Musik ja am Ende völlig zurück: zunächst geht die Singstimme ins Sprechen über (»ohne Klang«), schließlich dann ins Flüstern - Silbe für Silbe (»und (ohne) Wort«). Auch das Begleitinstrument / die Begleitinstrumente führt / führen am Ende nur noch tonlose Aktionen aus. ${ }^{39}$

Wistingshausens Beiseit-Versionen lassen sich auf zwei Grundtypen zurückführen, die im Zyklus Spuren als Beiseit (I) und Beiseit (II) den Zyklus umrahmen. Auf diesen Zyklus für Bass und Violoncello konzentrieren sich deshalb die folgenden Ausführungen.

Neben Walser enthält Spuren Vertonungen von Ingeborg Bachmann, Ernst Jandl, Peter Hille und Paul Celan. Es ist eine Auswahl, die der Collage deutscher Literatur in Alexander Goehrs Verschwindendes Wort (vgl. Kap. 10.14) durchaus nahe ist. Die Vertonungen werden bei Wistinghausen allerdings nicht aneinandergereiht, sondern als Mehrfachvertonungen von Walser und Bachmann eng aufeinander bezogen. Der Text von Ingeborg Bachmann wird viermal unterschiedlich vertont und verbindet wie ein dunkles Rondo den zehnteiligen Zyklus.

\author{
Unter einem fremden Himmel \\ Schatten Rosen \\ Schatten \\ auf einer fremden Erde \\ zwischen Rosen und Schatten \\ in einem fremden Wasser \\ mein Schatten 40
}

Die Form des Zyklus ist spiegelsymmetrisch um die Achse Jandl/Hille angeordnet. Walser/Bachmann bzw. Bachmann/Walser bilden den Rahmen.

Robert Walser: Beiseit (I)

Ingeborg Bachmann: Schatten Rosen Schatten [1956] (I)

Ernst Jandl: vor der grossen stille $[1975]^{41}$

\footnotetext{
39 E-Mail von Martin Wistinghausen an Roman Brotbeck vom 20.10.2016.

40 Bachmann: Sämtliche Gedichte, S. 143.

41 Jandl: Gesammelte Werke. Zweiter Band. Gedichte 2, S. 25 o.
} 


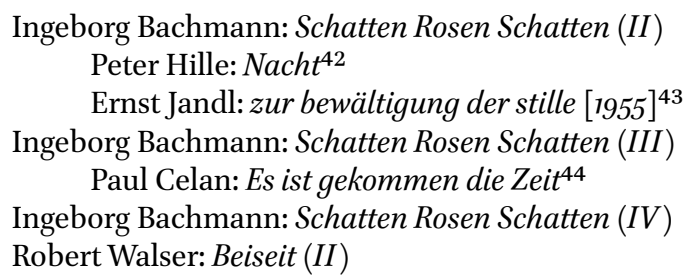

Wistinghausen lässt das erste Beiseit in der Mitte abbrechen und in Bachmanns Gedicht übergehen: »Ich mache meinen Gang, der führt ein Stückchen weit« - »Unter einem fremden Himmel Schatten«. In reziproker Weise führt Bachmanns Text am Schluss des Zyklus in Walsers Beiseit (II) zurück: »in einem fremden Wasser mein Schatten « - »Ich mache meinen Gang «. Die Texte ergeben nicht nur durch dieses Ineinanderfließen ein dichtes Gewebe: Bachmanns Gedicht stammt aus Walsers Sterbejahr 1956. Darin verarbeitet sie die Trennung von Paul Celan, ${ }^{45}$ der im Zyklus mit einem Gedicht aus Fadensonnen (1968) vertreten ist, das Celan am 13. Mai 1967 in der Psychiatrischen Universitätsklinik Sainte-Anne geschrieben hatte. ${ }^{46}$ Ernst Jandl wiederum schafft den Bezug zum Sprachvirtuosen und fanatischen Reimer, quasi zum >Komponisten< Walser. Das erste Gedicht von Jandl ist 1955 entstanden, als Walser noch lebte. Und das kurze Gedicht von Peter Hille (1854-1904) verweist auf ein Alter Ego Walsers, das jene Gänge und Tiefen des Lebens auslotete, die sich der vorsichtigere Walser eigentlich doch lieber in seinem Zimmer ausdachte.

Die beiden Anfänge der Beiseit-Vertonungen in Spuren unterscheiden sich stark. Das eröffnende Beiseit (I) beginnt mit insistierenden Tonrepetitionen des Cellos (vgl. Abb. 6o) auf der leeren G-Saite; von der tieferen C-Saite aus wird zuerst vierteltönig, später immer ausschweifender glissandiert. Wie bei der Vertonung von Oldemeyer wiederholt Wistinghausen »mache meinen Gang « mehrfach, aber nicht als Echo und ohne Melodie, sondern wie eine Sprechstörung auf dem Ton $g$; wie unter Zwang werden die Wörter »Ich« (dreimal), »mache (sechsmal), »meinen« (neunmal) und »Gang « (elfmal) wiederholt. Beim zweiten Vers wird diese >sprechbereite Katatonie (vgl. Einleitung) noch insStotternde gesteigert:»derführt ein Stückchen weit-Stückchen-Stückchen weit - Stü, Stü, Stü, Stückchen weit - Stückchen weit - chen weit - weit « ${ }^{47}$ Das Ganze wird begleitet vom wild in alle Richtungen glissandierenden Violoncello.

42 Hille: Ich bin, also ist Schönheit, S. 3 .

43 Jandl: Gesammelte Werke. Erster Band. Gedichte 1, S. 619.

44 Celan: Die Gedichte, S. 259.

45 Vgl. May/Goßen/Lehmann: Celan-Handbuch, S. $226 f$.

46 Vgl. Celan: Die Gedichte, S. 955.

47 Wistinghausen:Spuren, S. 2. 


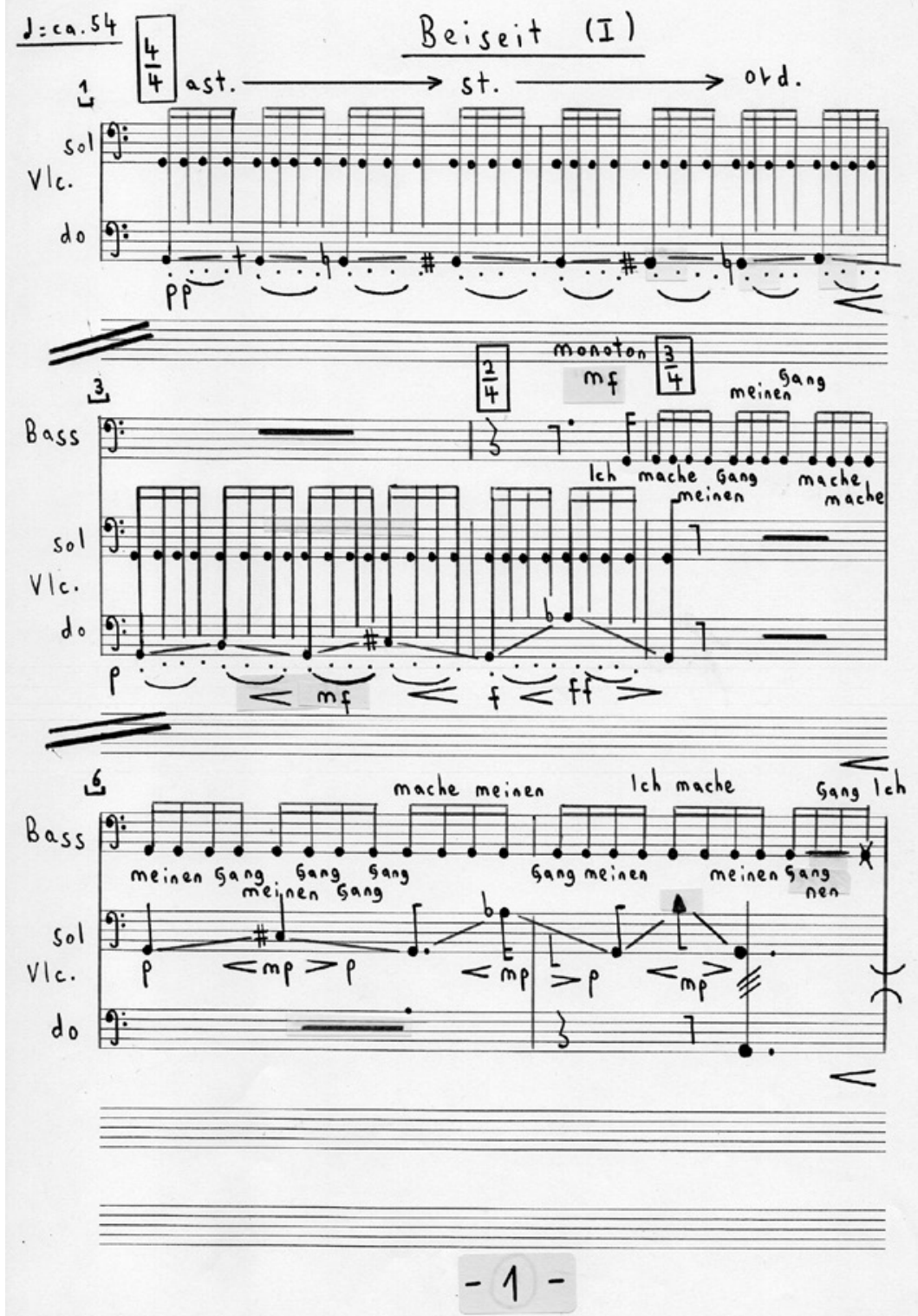

Abb. 6o Martin Wistinghausen: Beiseit (I) aus Spuren, S. 1 


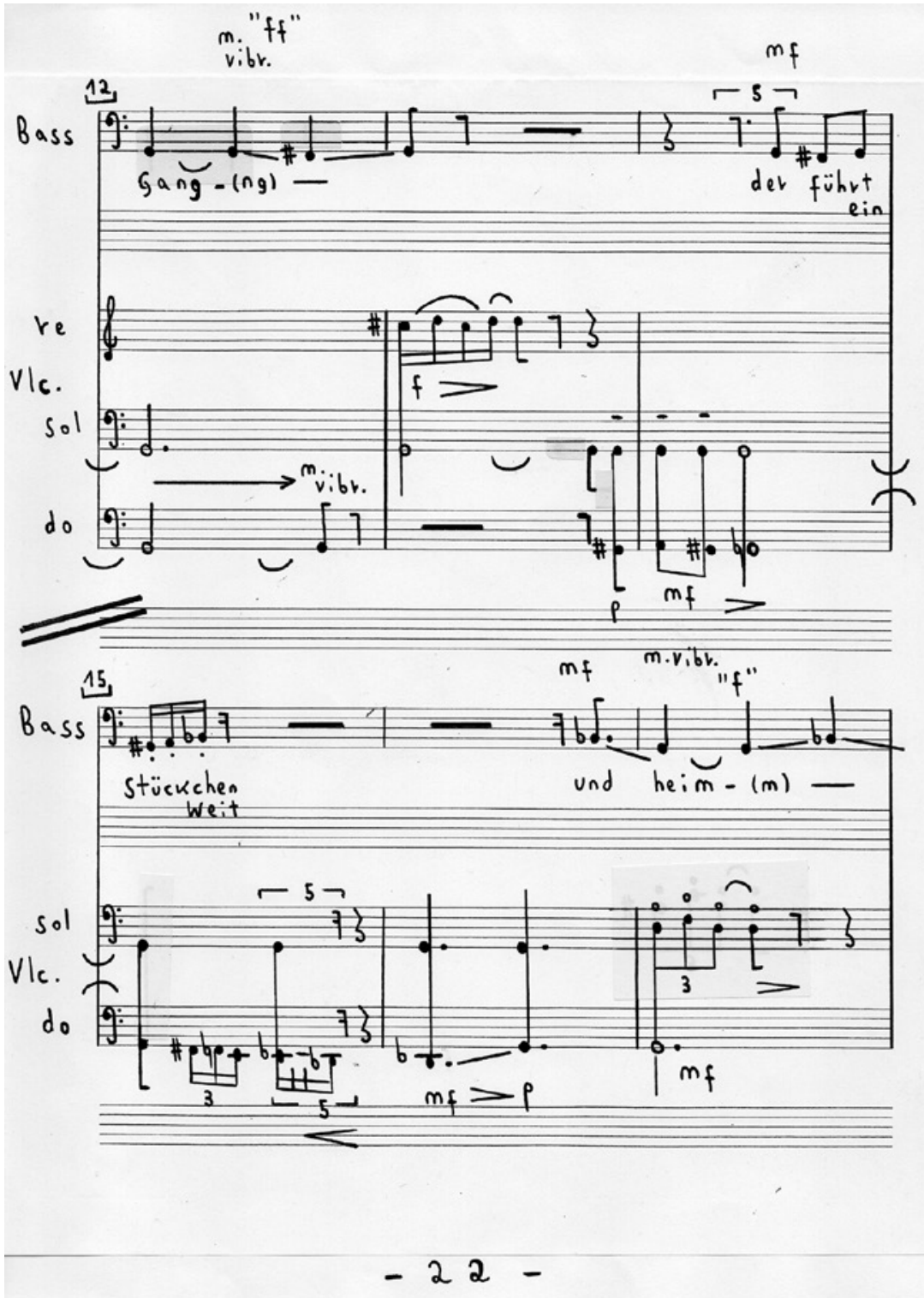

Abb. $61 \quad$ Martin Wistinghausen: Beiseit (II) aus Spuren, S. 22 
Beiseit (II) (vgl. Abb. 61) geht von einer ähnlichen Disposition aus und ist doch in der Wirkung gänzlich anders. Das Cello übernimmt das Tonmaterial des Beginns von Beiseit (I), ist allerdings ruhiger gesetzt. In der Gesangsstimme gibt es noch Spuren des `Sprechkrampfs< von Beiseit (I), zum Beispiel in den überhasteten Sechzehnteln von »mache meinen« und »Stückchen weit«, sonst aber werden die Wörter »Gang-(ng)« und vor allem »heim- $(\mathrm{m})$ « auch in den nasalen Konsonanten lange ausgesungen. Die Singstimme entfernt sich nur minimal - ein Stückchen weit - vom $g$, führt aber nach dem dreimaligen »heim « wieder auf das $g$ zurück. Dieses dreimal wiederholte »heim « wirkt wie ein Ausklingen und Abschiednehmen vor dem gesprochenen und vom Cello nur noch perkussiv begleiteten Schluss.

Von den beiden Beiseit-Vertonungen in Spuren hat Wistinghausen die späteren Varianten des Werks abgeleitet. Abgesehen vom fehlenden Schluss bei Beiseit (I) unterscheiden sich die Versionen durch die Anfänge: In der Version für Bass und Instrumental-Ensemble wird der Anfang von Beiseit (II) verwendet, während die Versionen für Bass bzw. Frauenstimme und Klavier von Beiseit (I) ausgehen. Die Version für Ensemble bekommt etwas Beschwörendes und Ritualhaftes, das an japanisches Nō-Theater erinnert; die anderen Versionen sind bedrängender, weil von den überhasteten $>$ Sprechstörungen< übergangslos in die Sprachlosigkeit geführt wird.

\subsection{Alexander Goehr: Verschwindendes Wort (2015)}

Im Alter von drei Monaten verließ Alexander Goehr ( $\left.{ }^{*} 1932\right)$ mit seinen Eltern Deutschland in Richtung England. Nach Franz von Papens >Preußenschlag` vom 2o. Juli 1932 mit der Entmachtung der preußischen Koalitionsregierung unter der Leitung des Sozialdemokraten Otto Braun konnte sich in Berlin die antisemitische Repression schon vor der nationalsozialistischen Machtübernahme ausbreiten. So wurde Alexanders Vater Walter Goehr (1903-196o), Schönberg-Schüler und Dirigent beim Berliner Rundfunk, wegen seiner jüdischen Herkunft entlassen; er emigrierte mit seiner Familie nach England, nachdem er in Berlin eine vielversprechende Karriere begonnen hatte und wohl auch mit den ersten Walser-Vertonern James Simon (vgl. Kap. 1) und Wladimir Vogel (vgl. Kap. 3) in Kontakt stand. ${ }^{48}$ In England wurde er zu einem der führenden Dirigenten, der sich nicht nur für zeitgenössische Musik,

48 Bei James Simon gibt es im nur fragmentarisch erhaltenen Nachlass keinen Nachweis eines Kontaktes; in Wladimir Vogels Nachlass gibt es eine Fotoserie aus den Jahren 19461948, in denen Walter Goehr mehrfach mit Vogel abgebildet ist - ein deutlicher Hinweis 
sondern auch für Alte Musik und insbesondere Claudio Monteverdi einsetzte. Nach 1945 pflegte Walter Goehr regen Kontakt zur Schola Cantorum Basiliensis und deren ersten Lehrern August Wenzinger (Violoncello) und Max Meili (Tenor). Mit dem Tonhalle-Orchester Zürich spielte er Monteverdis letzte Oper L'incoronazione di Poppea auf Schallplatte ein und führte das Werk 1955 in Zürich auch konzertant auf.9 Am 24. April 1959 leitete Walter Goehr die Uraufführung von Hanns Eislers Deutscher Sinfonie mit der DDR-Staatskapelle an der deutschen Staatsoper Berlin - ein hochpolitischer Akt. Alexander Goehr setzte sich nach dem Tod seines Vaters dafür ein, dass Eislers Deutsche Sinfonie auch in England aufgeführt wurde. ${ }^{50}$ Leben und Schaffen von Alexander Goehr wurden stark durch die Erfahrungen seines Vaters geprägt, was sich an der Komposition Verschwindendes Wort besonders zeigt.

Alexander Goehr wuchs in einem musikalisch und intellektuell offenen Elternhaus auf, geprägt vom aufgeklärten Judentum und vom Widerstand gegen das >Dritte Reich $<$. Er ist mit der englischen Musikgeschichte eng verbunden, gehörte zusammen mit Peter Maxwell Davies, Harrison Birtwistle und John Ogdon zur New Music Manchester Group, und doch ist die jüdische Kultur und die Emigrationserfahrung seiner Eltern in seinem Komponieren bis heute präsent und taucht in unterschiedlichen Werken auf, was sich auch in vielen deutschsprachigen Werken zeigt: 1964 vertonte Goehr Gedichte von Kindern im Konzentrationslager Theresienstadt (In Theresienstadt, ohne Opuszahl), 1967 Gedichte seines Freundes Erich Fried (Warngedichte op. 22) und 1979 begann die Auseinandersetzung mit Franz Kafka (Das Gesetz der Quadrille op. 40). Themen der Antike und des Alten Testaments gewinnen zunehmend an Bedeutung; 2012 beschäftigte sich Goehr auch kritisch mit Israels Siedlungspolitik und der Vertreibung der palästinensischen Bevölkerung (To These Dark Steps. The Fathers are Watching op. 90).

Die wichtigsten Auseinandersetzungen mit seiner deutschen Herkunft sind TurmMusik op. 85 (2010) und die daraus hervorgegangene Komposition Verschwindendes Wort (2013-2015). Das Thema des Turmbaus zu Babel

darauf, dass sich die beiden schon vor 1933 kannten. Musikabteilung der Zentralbibliothek Zürich, Mus NL 116, H 8.

49 Vgl. Schuh: Monteverdis letzte Oper. Dass Walter Goehr auch in der Neuausgabe der Enzyklopädie Die Musik in Geschichte und Gegenwart (MGG) kein eigener Artikel gewidmet ist, erstaunt zwar nicht, denn der Ausschluss von Emigranten, den die alte MGG schon fast systematisch betrieb (vgl. Brotbeck: Verdrängung und Abwehr), wurde in der Neufassung wacker fortgeführt (vgl. Brotbeck: Zur Neufassung der $M G G$ ), aber skandalös bleibt es trotzdem. Zu seinem Vater hat Alexander Goehr ein aufschlussreiches Interview gegeben, vgl. Royal College of Music: Interview with Alexander Goehr.

50 Vgl. Schebera: Hanns Eislers »Deutsche Symphonie« und ders.: Hanns Eisler, Walter Goehr and Alexander Goehr. 
bearbeitet Alexander Goehr in deutscher Sprache, so als ließe sich die Hybris des Türmebauens nach den Erfahrungen des 20. Jahrhunderts nur in der deutschen Sprache angemessen behandeln. Er verwendet darin Texte von Jakob Böhme, Friedrich Dürrenmatt, Franz Kafka und der Bibel. Ursprünglich hatte er noch mehr Texte vorgesehen, »but setting them was postponed, as the whole conception was too long «. ${ }^{1}$ So komponierte er 2013 mit den in der TurmMusik nicht verwendeten Texten Verschwindendes Wort, ursprünglich für Mezzosopran, Tenor und Klavier. 2015 instrumentierte er die Komposition für kleines Ensemble.

Der Zyklus ist ein Beispiel für Alexander Goehrs aufgelichteten Spätstil, der auch die Auseinandersetzung mit der venezianischen Oper zeigt, die ihm schon von seinem Vater in die Wiege gelegt wurde. So werden die Instrumente (Flöte, Englischhorn, Klarinette/Bassklarinette, Horn, Klavier, zwei Violinen und Viola) in Verschwindendes Wort nicht in der Koloristik seines Lehrers Olivier Messiaen behandelt, die in Goehrs Frühwerk omnipräsent ist, sondern wie im Barock als Register, das mit einer bestimmten Instrumentalfarbe eine ganze Arie prägt.

Das zeigt ein Überblick der Besetzungen zu dem zwölfteiligen Zyklus, der aus fünf Instrumentalstücken (Preludes), drei Duetten und je drei Sololiedern für Mezzosopran respektive Tenor besteht.

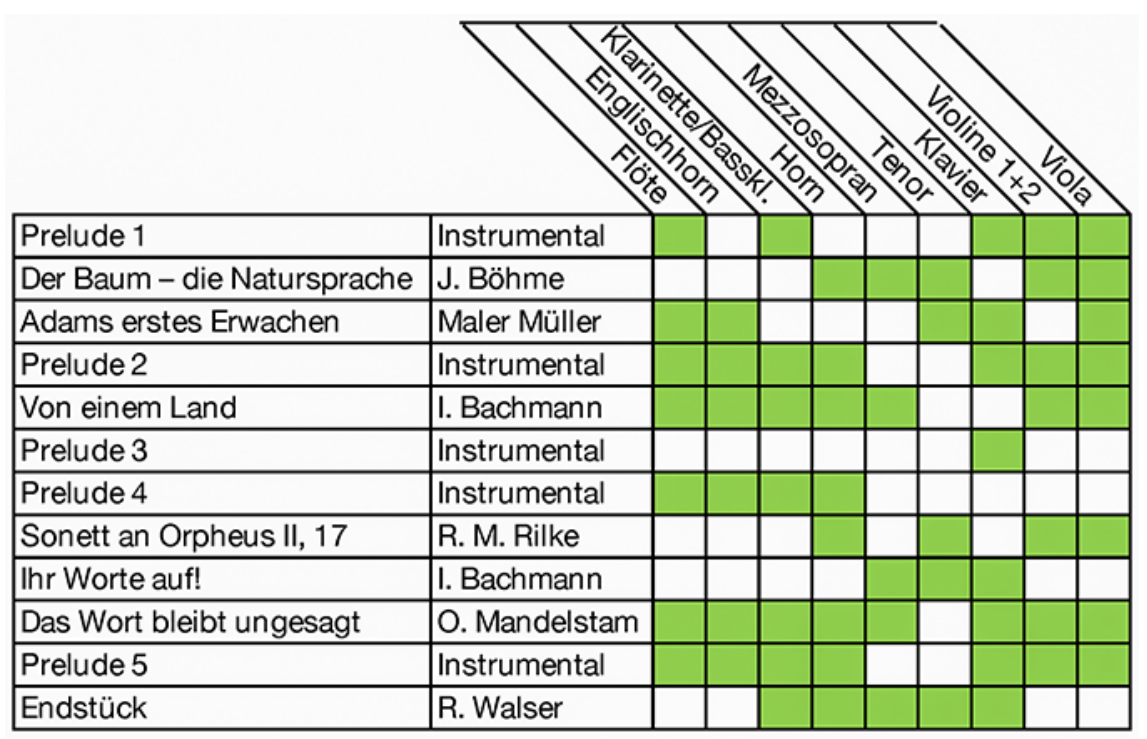

Abb. 62 Überblick der Besetzungen in Goehr: Verschwindendes Wort

$5^{1} \quad$ Goehr: Verschwindendes Wort, [Vorwort, S. 3]. 
Auch innerhalb der einzelnen Teile nach Texten von Böhme bis Walser wird das Komponieren mit Instrumentalregistern beibehalten; so besteht der Mittelteil des zweiten Preludes aus einem langen Klaviersolo, und der fünfte Teil Von einem Land wird zuerst nur von den Bläsern, später nur von den Streichern und erst zum Schluss von allen Instrumenten außer dem Klavier begleitet. ${ }^{52}$

Die literarischen Kontexte, in die Alexander Goehr als englischer Komponist mit deutscher Herkunft Robert Walser stellt, sind spannend, weil der klassische Kanon von Goethe, Hölderlin und Eichendorff etc. umgangen wird: Zuerst der frühe Mystiker und Philosoph Jakob Böhme (1575-1624), verfolgt wegen Häresie, dann der Sturm-und-Drang-Dichter, deutschrömische Maler und Kupferstecher Johannes Friedrich Müller (1749-1825) alias >Maler Müller` oder >Teufelsmüller`, schließlich die Walser-Zeitgenossen Rainer Maria Rilke (1875-1926) und Ossip Mandelstam (1891-1938), bei dem Goehr immer auch den deutschen Übersetzer Paul Celan (1920-1970) erwähnt, den mit Ingeborg Bachmann (1926-1973), deren Texte im Zyklus den breitesten Raum einnehmen, eine wechselhafte Beziehung verband. ${ }^{53}$

Walser ist an den Schluss gesetzt und mit dem Titel Endstück versehen (vgl. Abb. 62). Überraschenderweise wählt Goehr gerade beim Ich-Gedicht Beiseit die Form des Duetts. Da drei der sieben Texte (Böhme, Rilke und Bachmann 1) $>$ ich-los< sind, wirkt dies noch auffälliger.

Schaut man allerdings auf den Schluss des Stücks mit dem im Einklang von Tenor und Sopran gesungenen $g^{1}$ kommt man nicht darum herum, an eines der berühmtesten Liebesduette der Musikgeschichte zu denken: Pur ti miro, das >Endstück von Monteverdis L'incoronazione di Poppea, das auch im Einklang auf $g$ endet und das Alexander Goehr durch die Schallplattenaufnahme seines Vaters früh kennengelernt hat. Tatsächlich entdeckt man viele musikalische Figuren der Barockoper: Zu Beginn des Duetts mit dem zweimaligen »Ich mache meinen Gang« das Initium des Soprans und den im Umfang erweiterten und leicht verzierten Respons des Tenors, beide von großen Terzen dominiert. Dann singen sie gemeinsam weiter: Zuerst bewegen sich die Stimmen bei »der führt ein Stückchen weit« bis zur Undezime auseinander, dann folgt die Retraktion und die Intervalle zwischen den Stimmen werden immer enger (in den eckigen Klammern sind die Anzahl Halbtöne angezeigt): »und « [10]»heim« [9], »dann« $[8] »$ oh-[7]ne« [6]»Klang« [4]. All das erklingt im beschwingten 6/8-Takt, was diese Beiseit-Vertonung zu einer

$5^{2} \quad$ Einzelne Teile von Schwindendes Wort sind Hommagen an Goehrs damals kürzlich verstorbene amerikanische Komponistenkollegen Milton Babbitt (†2011), Elliott Carter (†2012) und Gunther Schuller (†2015). 


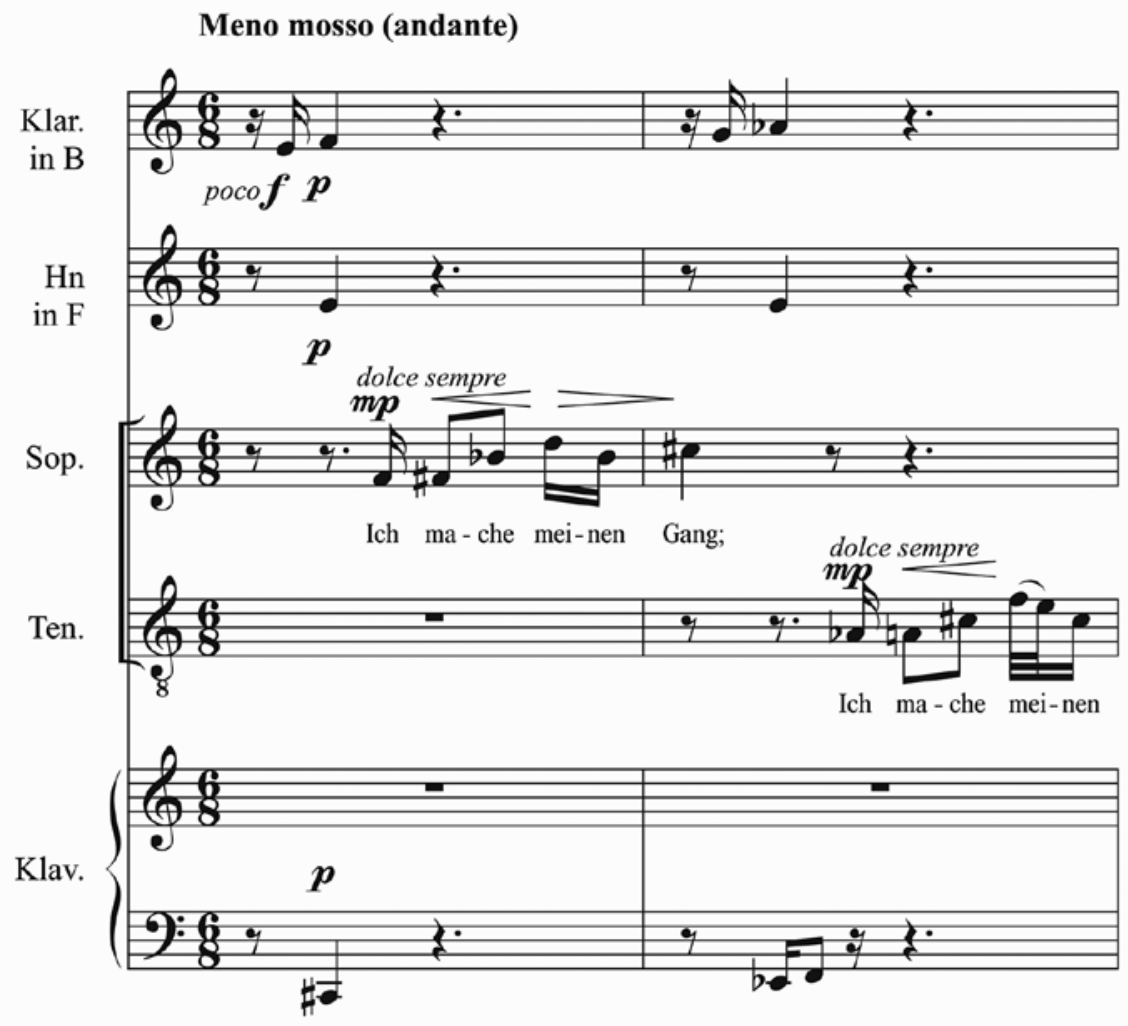

Abb. 63 Alexander Goehr: Beiseit aus Verschwindendes Wort, S. 58 

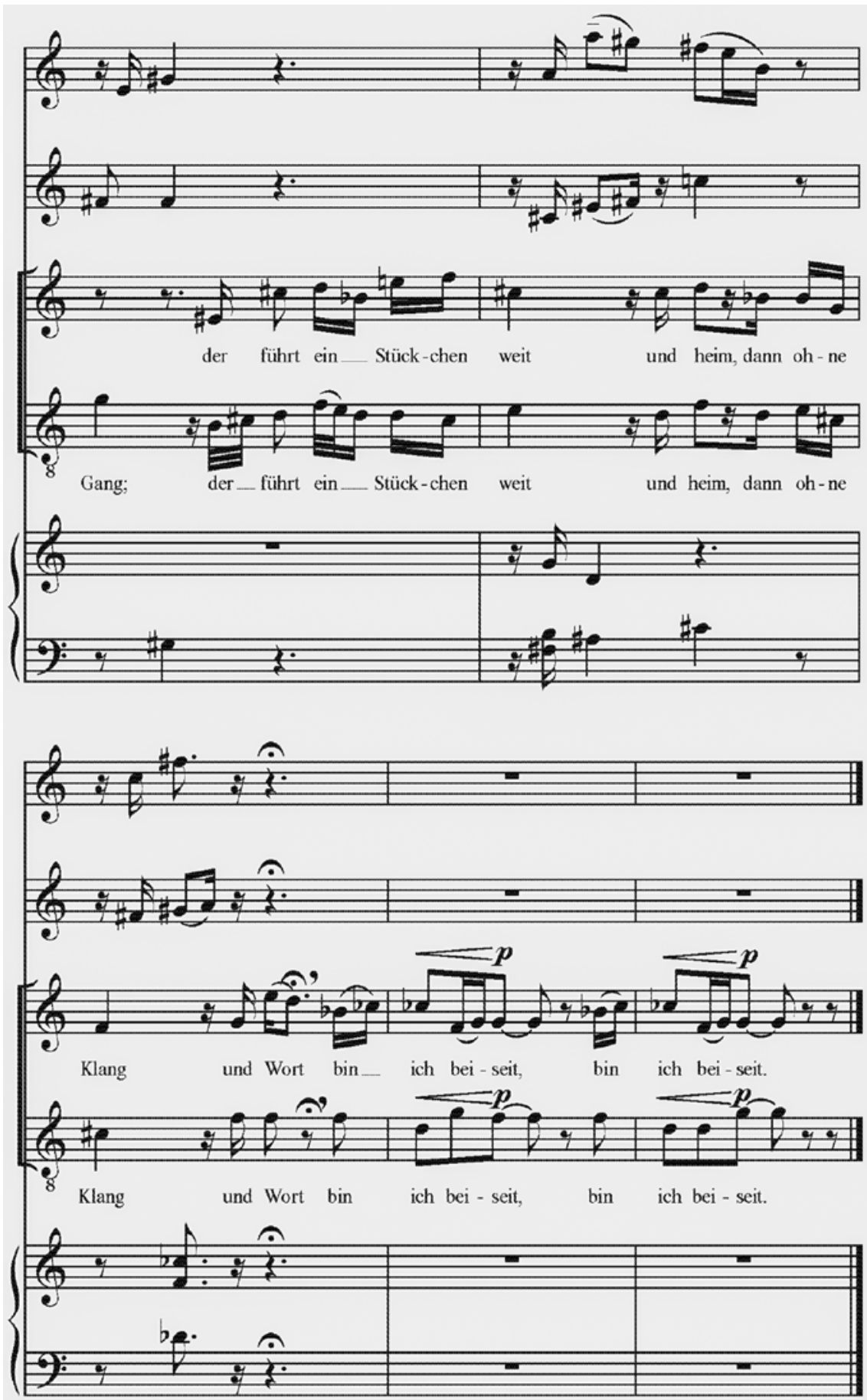
leichten und fast >befreiten< macht. In seiner Einführung zum Werk erwähnt Goehr explizit »the inscription on the tomb of Robert Walser «. ${ }^{44}$ Grabsteine sind Rufe an die Lebenden: Bei einem Komponisten wie Alexander Goehr, der sich musikalisch auch mit der griechischen Antike auseinandersetzt, kommt einem unwillkürlich der berühmteste musikalische Grabstein der Musikgeschichte in den Sinn, das Seikilos-Epitaph aus der Spätantike. Der tote Seikilos ruft die Vorbeiwandernden auf, nicht zu lange zu trauern, es bleibe nur eine kurze Frist zu leben und das Ende bringe die Zeit von selbst. ${ }^{55}$ Über den griechischen Buchstaben der runden Säule ist in altgriechischer Notation eine Melodie - meist ebenfalls im 6/8-Takt transkribiert - in den Stein geschlagen. Das Beiseit-Gedicht als Paraphrase des Seikilos-Liedes - das bringt Robert Walser in weite (musik-)historische Kontexte.

Schon fast ironisch wirkt bei Takt 5 im Endstück der fragmentierte Dominantnonakkord (mit übermäßiger None) des-f-(as)-ces-e des Klaviers, was harmonisch auf ges/fis verweist und wechseldominantisch auf $g$ bezogen werden könnte. Die letzten Wörter »bin ich beiseit« werden nur mit wenigen Tönen dargestellt. Der Tenor verfügt über drei Töne $(d, f, g)$, der Sopran über vier $(b, c e s, f, g)$; weil $f$ und $g$ in beiden Stimmen vorkommen, ergibt dies insgesamt fünf Töne. Fast alle Melodien sind Kombinationen und Umkehrvarianten des Pur ti miro-Motivs mit aufsteigender Sekundbewegung und Quartfall. Beide Stimmen singen nun in engster Lage, das erste »beiseit« endet noch auf einer Dissonanz; erst beim zweiten »beiseit«, das vom Sopran unverändert wiederholt wird, kommt es dank einer minimalen Umstellung der Töne im Tenor zum einzigen Einklang des Stücks - dem letzten Ton. Der BeiseitSchluss als Einklang und Symbol für eine Welt >ohne Klang und Wort oder mit Goehrs Werktitel für >verschwindendes Wort<. Der Einklang auch als das Ende der Ambivalenz?

Die Nähe zum Schluss von L'incoronazione di Poppea öffnet Abgründe, denn das Schlussduett Pur ti miro wird von Verbrechern angestimmt: von Nero und Poppea. Auf dem Weg ins Abseits ihres Liebesfests haben sie alles Störende aus dem Weg geräumt. Vertreter des Regietheaters haben in den vergangenen Jahrzehnten ganze Badewannen mit roter Farbe gefüllt, um auf diesen unmoralischen, ja >falschen< Schluss hinzuweisen, aber Monteverdis Musik bleibt davon unberührt; ${ }^{56}$ ihre Schönheit wäscht die Liebenden schon nach wenigen Sekunden von aller Schuld rein.

54 Goehr: Verschwindendes Wort, [Vorwort, S. 3].

55 Pöhlmann/West: Documents of ancient Greek music, S. gof.

$5^{6}$ Zur vieldiskutierten Frage, ob Monteverdi das Duett selbst geschrieben hat, vgl. Krummacher: »Pur ti miro«-Monteverdi zugeschrieben? 


\subsection{Claes Jasper Biehl: Beiseit (2017)}

In Zusammenhang mit dem Schubert-Walser-Projekt ${ }^{57}$ von Martin Wistinghausen ist 2017 eine weitere Beiseit-Vertonung entstanden, die nochmals neue Aspekte zeigt. Claes Jasper Biehl (*1979) hat sich bei den durchaus unterschiedlichen Kompositionslehrern York Höller und Clarence Barlow (auch Klarenz Barlow) ausbilden lassen; der eine ist interessiert an Grundgestalten, aus denen er wie Formeln die Musik entstehen lassen kann, der andere an Computermusik und ihren metamorphosierenden Prinzipien. Ein besonderes Interesse hat Biehl an Mikrotönen, über die er 2011 am Royal College of Music London auch promovierte.

Wie in Heinz Holligers Beiseit stellt auch Claes Jasper Biehl die Gesangsstimme in einen leeren Raum zwischen extremen Randlagen:

Ein Aspekt, der für das Stück sehr wichtig war, ist die deutliche Registertrennung innerhalb des Klavierparts (linke Hand in der tiefsten, rechte Hand in der höchsten Lage). Das Verharren in den Extrembereichen bei gleichzeitigem Aussparen der Mittellagen eröffnet einen geradezu übergroßen Raum, in den das Subjekt hineinstößt und >seinen Gang macht $<.58$

Biehls Beiseit beginnt mit einem Faustschlag auf den einzigen Klavierton, auf dem das ohne Kollateralschläge auf benachbarte Tasten möglich ist, dem tiefsten B des Klaviers, das als einzelne schwarze Taste isoliert ist, weil das Klavier über das tiefe As nicht mehr verfügt (vgl. Abb. 64). Dazu erklingt ein >Quartenakkord < mit zwei Tritoni ( $a s-d-g-c i s-f i s)$, ähnlich dem mystischen Akkord von Aleksandr Skrjabin, der in enger und dissonant geschärfter Lage gesetzt ist.

Der Faustschlag zu Beginn soll, abgesehen von seinem abstrakten Impulscharakter, eine Art Gegenwärtigkeit erzeugen, ein plötzliches Hier und Jetzt, auch als Ausdruck des Präsens in Walsers Gedicht. ${ }^{59}$

Dieses Präsens entwickelt sich zögerlich, denn es beginnt mit einem faustisch sinnierenden Sänger-Ich, das über seinen bisherigen Gang desillusioniert nachdenkt: zuerst mit dem tonlosen Repetieren des Frikativlautes $f$ (T. 1f.) - in den Spielanweisungen steht dazu »Frösteln« -, dann mit dem wegen der Pianissimo-Dynamik entfernt wirkenden Glockenklang (T. 3)

57 Konzert vom 07.10.2017 in der Neanderkirche in Düsseldorf; siehe Ausführungen zu Beiseit von Martin Wistinghausen in diesem Kapitel.

$5^{8}$ E-Mail von Claes Jasper Biehl an Roman Brotbeck vom 29.09.2020.

59 E-Mail von Claes Jasper Biehl an Roman Brotbeck vom 23.o9.2020. 


\section{Beiseit}

für Bass und Klavier

(2017)

Musik: Claes J. Biehl Text: Robert Walser
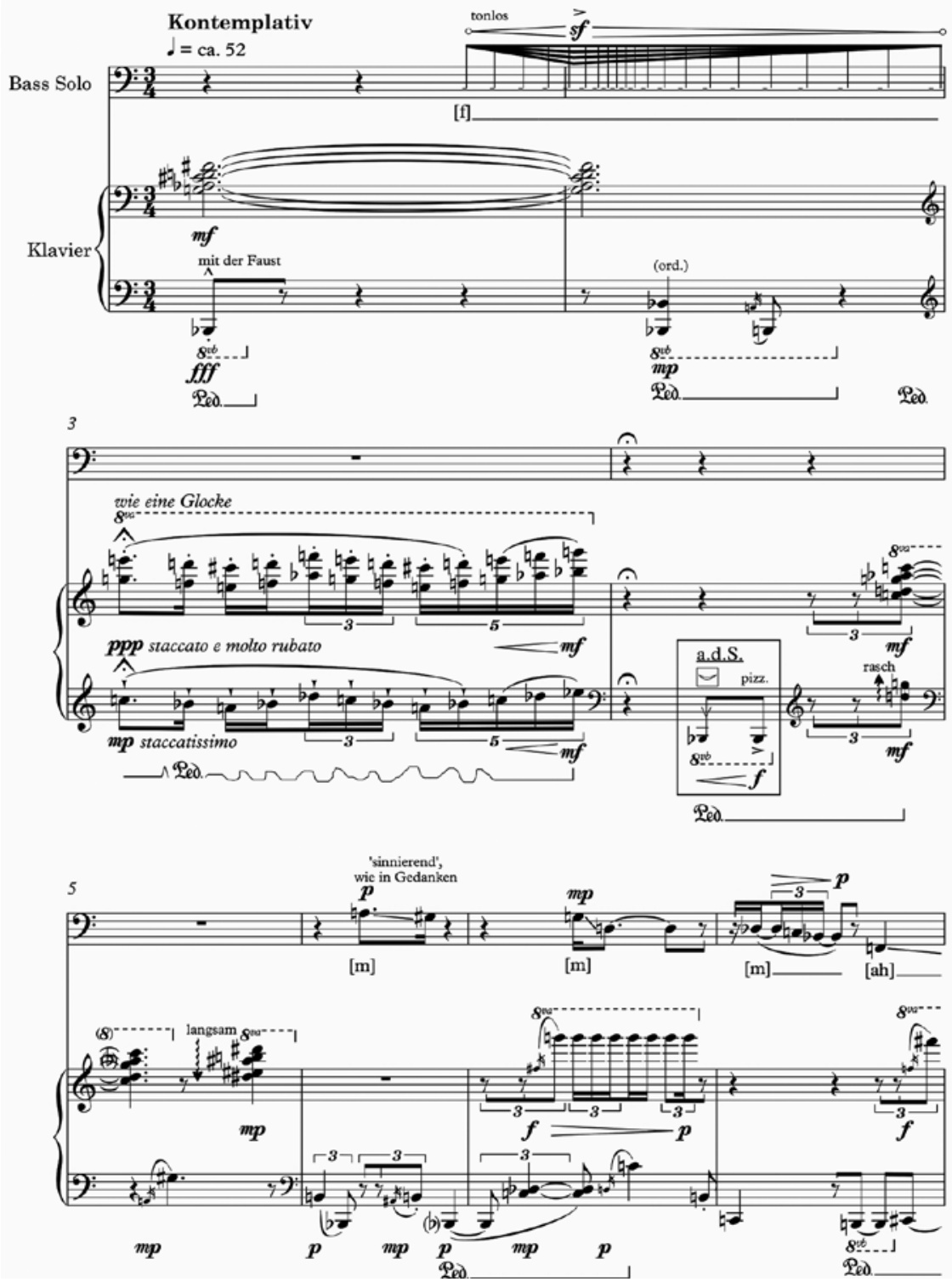

Abb. 64 Claes Jasper Biehl: Beiseit, S. 1 
in hoher Klavierlage, schließlich mit dem gesummten »m« (T. 6f.) - »wie in Gedanken« - und dem Glissando auf »ah« (T. 9) - laut Spielanweisung »bis zum tiefstmöglichen Ton«.

Kälte und Kargheit dominieren dabei das Klanggeschehen, gelegentlich unterbrochen von Erinnerungsfetzen. Bei Letzteren handelt es sich nicht um konkrete Zitate, sondern eher um Assoziationen an Bekanntes, am deutlichsten wahrnehmbar vielleicht anhand der biharmonischen Vierklänge in Takt 10.60

Nach solchem Vor-Gang wird das eigentliche Beiseit-Gedicht tatsächlich zum letzten, »immer zögerlich, stockend « (T. 11) geführten Gang, den der Sänger zum Schluss alleine geht: »bin ich beiseit« wird ohne Klavierbegleitung »zunehmend gehaucht«, aber durchaus auch befreit gesungen.

Claes Jasper Biehl hatte in Erwägung gezogen, Claude Debussys Des pas sur la neige $^{61} \mathrm{zu}$ zitieren - wie Christophe Schiess in Hibernation (vgl. Kap. 11.21) »diese Idee dann aber wieder verworfen, auch um ein solch kurzes Werk nicht noch mit einer zusätzlichen Ebene zu überfrachten. «62 Dieser Hinweis zeigt, wie Robert Walser bei unterschiedlichen Komponisten ähnliche Assoziationen auslöst. Die mannigfachen Lösungen, die aus solchen Assoziationen entstehen, machen das Faszinierende der musikalischen Walser-Rezeption aus.

\subsection{Thomas David Müller: Beiseit (2020)}

Es ist einer glücklichen Fügung zu verdanken, dass diese jüngste BeiseitVertonung hier überhaupt besprochen werden kann. Bei einem E-MailWechsel zu Drei Lieder von Thomas David Müller (vgl. Kap. 11.15.6) schickte mir der Komponist diese Vertonung, die hier erstveröffentlicht wird, $\mathrm{zu}$ - mit folgendem Kommentar: »Wo ich inzwischen gelandet bin mit Walser komponieren: Beiliegend das (unvermeidliche) Beiseit.« Es ist für eine Amateur-Sängerin geschrieben:

Und weil es mich seit 40 Jahren ärgert, dass fast alle meine Versuche für Amateure in der Realisierung misslungen sind, will ich es nochmals wissen. Das Resultat ist wie es ist: etwas didaktisch leider.

6o Ebd.

61 Vgl. sechstes Prélude in Debussy: Préludes. ier livre.

62 E-Mail von Claes Jasper Biehl an Roman Brotbeck vom 23.o9.2020. 
R. Walsw: BEISEIT

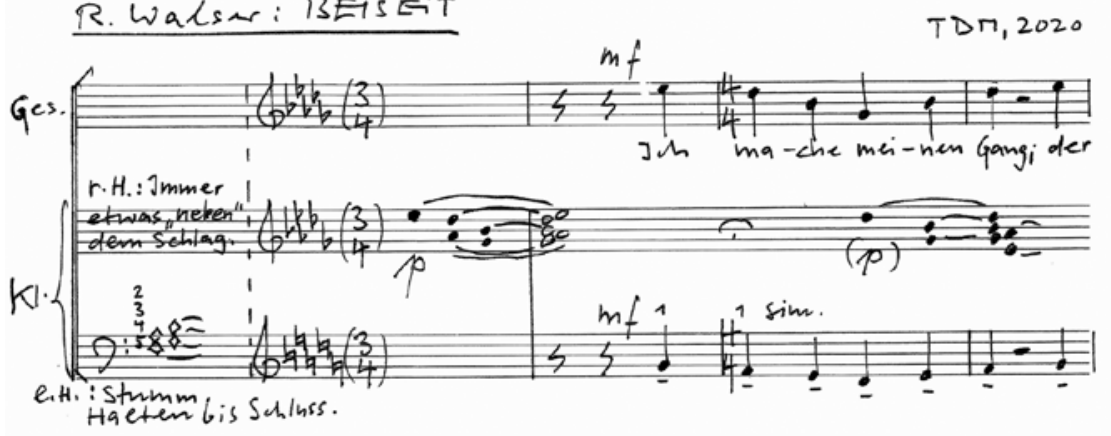

Hactem bis Schinss.
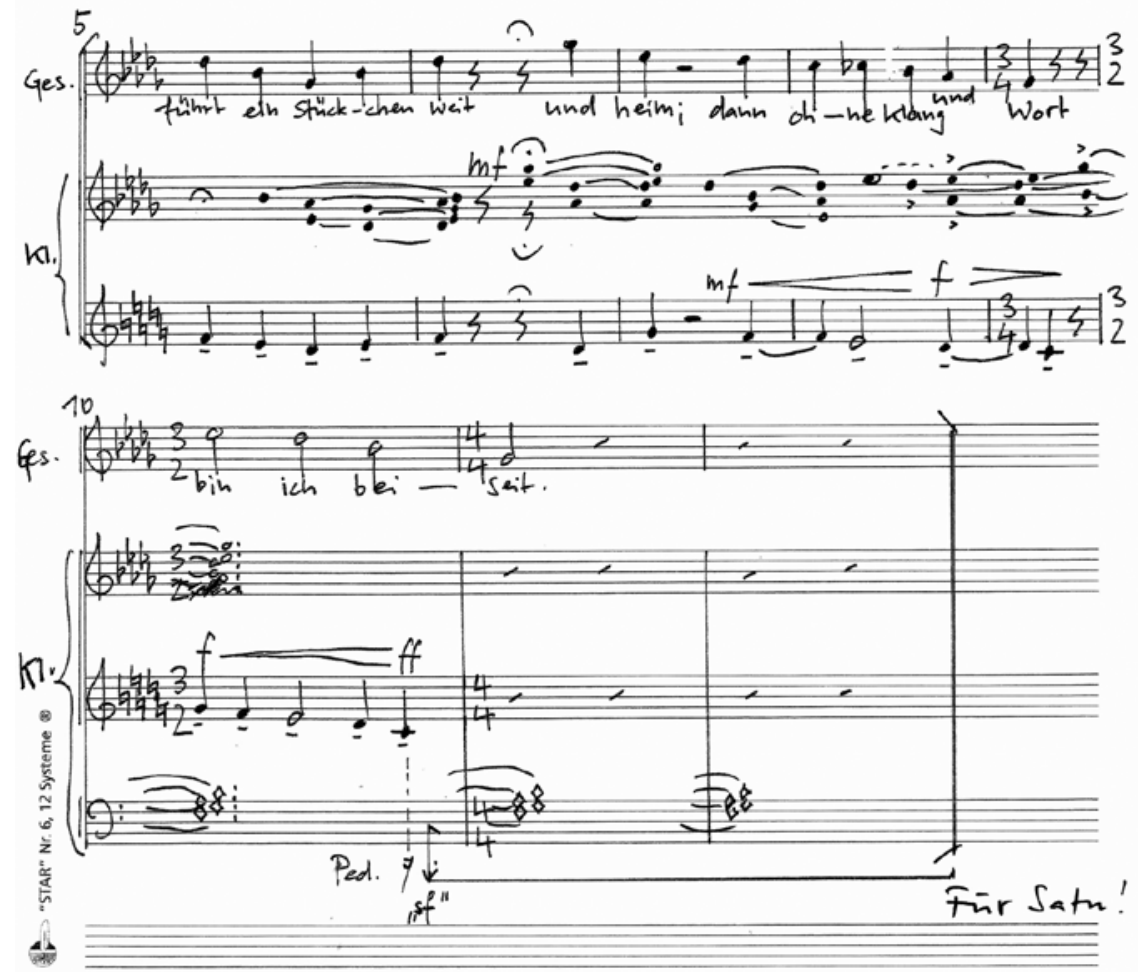

Abb. 65 Thomas David Müller: Beiseit 
Unter der lapidaren Anlage des Liedes (vgl. Abb. 65) stecken ähnliche Verspannungen wie in den Drei Liedern, die Müller für das Zürcher Walser-Projekt geschrieben hatte. Das zeigt sich schon bei der linken Hand des Klavierparts. Auf den ersten Blick erinnert das an eine erste Klavierstunde, wie sie auch Walser erlebt haben könnte, ${ }^{63}$ als man Fünftonstücke wie Alle meine Entlein mit den fünf Fingern einer Hand spielen lernte und streng darauf achten musste, dass alle Fingerchen immer die Tasten berühren. Bei Müller ist dies nun beinahe ins Schmerzhaft-Verspannte gedreht, denn die linke Hand ist hier an die Tasten >gefesselt $\longleftarrow$ Vier Finger müssen während des ganzen Liedes einen Cluster auf den stummen weißen Tasten $f-g$ - $a$ - $h$ drücken; deshalb verbleibt nur noch der Daumen, um die Melodie zu spielen, und für eine normale Hand ist das $g^{1}$ nur mit einer leichten Überspannung zwischen Zeigefinger und Daumen zu erreichen. Es wäre ein Leichtes gewesen, diese Tasten mit einem Gewicht stumm zu drücken und die Hand zu >befreien<. Aber Müller will, dass hier der Daumen von Taste zu Taste springen muss - ein Verstoß gegen alle pianistischen Fingersatzregeln. Das gibt dem Gang auf den weißen Tasten etwas merkwürdig Angestrengtes. In der rechten Hand entfaltet sich in diesem polytonalen Lied eine Gegenwelt: pentatonische Liegeklänge ausschließlich auf den schwarzen Tasten. ${ }^{64}$ Diese haben keine klare Richtung und sollen neben dem Takt angeschlagen werden, was ihre Ziellosigkeit noch erhöht. Allerdings verschieben sich die pentatonischen Liegeklänge während der ersten beiden Verse unbemerkt nach unten und greifen in die Spiellage der linken Hand bzw. des linken Daumens, der sich bei »Stückchen weit« neben der rechten Hand durchschlängeln muss. In dieser engen Lage reiben sich die beiden Systeme in scharfen Dissonanzen aneinander. Auch die Singstimme bewegt sich im pentatonischen Raum der schwarzen Tasten und kann sich daran auch orientieren; rhythmisch und melodisch läuft sie aber parallel zur linken Hand.

Die ersten beiden Verse werden mit auf- und absteigenden Bewegungen identisch realisiert. Mit je vier Tönen in der linken Hand und in der Singstimme schafft Müller ein einprägsames, auf und ab pendelndes Modell, das es ihm erlaubt, im zweiten Teil des Liedes mit verschiedenen Abweichungen von diesem Modell das Gedicht übergreifend zu interpretieren. Bei »und heim « wird das Pendeln gestoppt. Auf »und « singt die Stimme den höchsten Ton ges $^{2}$;

63 Vgl. die Bemerkungen zu Robert Walsers Klavierstunden in Kapitel 11.21 bei Hibernation von Christophe Schiess.

64 Es erinnert an die polytonalen Klavierstücke Nr. 7o Doppelgriffe gegen eine Melodie und Nr. 105 Spiel (mit zwei Fünftonskalen) aus dem dritten und vierten Band von Béla Bartóks Mikrokosmos. 
damit wird diese auffällige Elision im Gedicht deutlich hervorgehoben. Bei »heim《 springt die Bewegung in die Sexte $g^{1}-e s^{2}$ zurück, mit der das Lied auf »ich« beginnt und die auf »bin« in Takt 10 nochmals erscheint. Diese Sexte immer mit dem verspannten >Grenzton $<g^{1}$ der linken Hand - wird also mit dem lyrischen Ich und der Heimkehr verknüpft. Nach dieser >Heimkehr das Modell in zwei unterschiedliche absteigende Gänge geführt. Zu »ohne Klang « verlässt die Singstimme die Pentatonik und verengt sich zu einem chromatischen Abstieg. Das Klavier folgt ab Takt 6 von den Tonhöhen her dem Anfangsmodell und wird nun auf fünf Töne erweitert; zudem verlangsamt sich das Schreiten auf halbe Noten. Durch diese Verschiebungen werden Intervalle möglich, die in der polytonalen Grunddisposition eigentlich ausgeschlossen sind: auf »ohne « entsteht eine Parallele von zwei Quinten $\left(f^{1}-c^{2}\right.$ und $e^{1}-$ ces/ $h^{2}$ ), der gleich zweimal ein Tritonus auf »und Klang« folgt. Auch hier wird das die Elision bestimmende »und « hervorgehoben: im Klavier mit dem ersten Forte, in der Singstimme mit dem einzigen as ihrer Partie.

Gegen Ende verlässt auch die Singstimme das Schreiten in Viertelnoten, motivisch kehrt sie an den Anfang zurück. Das Klavier gestaltet dazu den einzigen Fortissimo-Schluss der Beiseit-Vertonungen, der mit einem Knall des Pedals firmiert wird. Dieser aktiviert die Äolsharfen-ähnlichen Obertöne der stumm gedrückten Saiten, deren Effekt für viele wohl erst hier bewusst wahrgenommen wird. Nachdem die Singstimme auf »bei-« zur linken Klavierhand mit der einzigen Septime des Stücks dissoniert, tritt sie mit der letzten Silbe »-seit« allein in diesen mystischen Obertonraum ein. Die linke Hand hat übrigens mit dem Fortissimo- $c^{1}$ jene entspannte und natürliche< Lage erreicht, die am Anfang jeder Klavierstunde steht.

Mit dem Schlüssel-C als tiefstem angeschlagenem Ton und unter der Vorgabe, eine Musik für Amateure zu schreiben, hat Thomas David Müller ein subtiles Beiseit geschaffen, bei dem jedes Element zum Nachsinnen einlädt. 